\title{
$=\therefore$
}

NASA Contractor Report 187061

\section{Conceptual Design of a Self-Deployable, High Performance Parabolic Concentrator for Advanced Solar-Dynamic Power Systems}

Hans J. Dehne

Acurex Corporation

Mountain View, California

May 1991

Prepared for

Lewis Research Center

Under Contract No. NAS3-25341

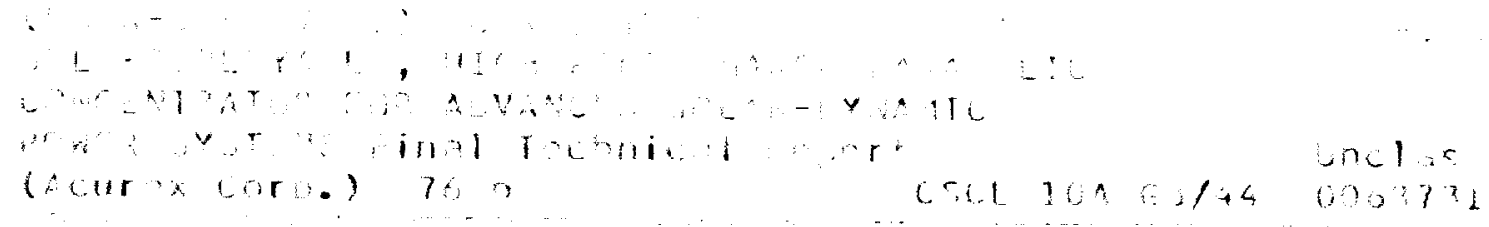




\section{ABSTRACT}

NASA plans for future missions in space include the use of advanced solar dynamic power systems as sources of electricity. This type of system has been successfully used to produce electricity for terrestrial applications, but never for space applications. The first such system is being considered for use on the Space Station. It is presently in the development phases and this contract was part of this effort.

Because of short development schedules for the Space Station, the solar dynamic power system design is of necessity conservative. That is, the development will be as low risk and high reliability as possible. This conservative approach, however, rules out consideration of a number of innovative component concepts with a potential for higher efficiency and lower weight that also have a high risk associated with their development. This is especially true for the solar concentrator. In parallel with the Space Station efforts, NASA has initiated programs to develop advanced solar dynamic power systems and components for space applications beyond 2000 .

NASA's long range concentrator research and development program is aimed at identifying the most promising concentrator concept for the various sizes and developing the technology so that these concentrators can be confidently designed and built to meet all the requirements.

The concentrator conceptual design work performed under this contract is described here. The design study was centered around two main efforts:

- Conceptual design of a self-deploying, high-performance parabolic concentrator

- Materials selection for a lightweight, shape-stable concentrator

The proposed deployment concept utilizes rigid gore-shaped reflective panels. The assembled concentrator takes an annular shape with a void in the center. In the packaged transportation configuration, the panels are stacked vertically, similar to a deck of playing cards, in a compact dispenser cartridge. Upon deployment of the concentrator, the dispenser remains part of the assembly as the interface between the concentrator, the receiver/engine support structure, and the space station or satellite. The deployable concentrator concept is applicable to a range of solar dynamic power systems of $25 \mathrm{~kW}_{\mathrm{e}}$ to in excess of $75 \mathrm{~kW}_{\mathrm{e}}$. The specification goal was for a size range of $10 \mathrm{~kW}_{\mathrm{e}}$ to $100 \mathrm{~kW}_{\mathrm{e}}$. The concept allows for a family of power system sizes all using the same packaging and deployment technique. Smaller or larger sizes could also be accommodated but would require significant resizing of the dispenser and mechanisms. The receiver/engine and its support structure are part of the deployment package.

A review was also conducted of previously proposed concentrating collectors. The "sunflower" previously designed by TRW offers a very attractive design, but is limited in the size that can be accommodated on the Space Shuttle.

The primary structural material selected for the concentrator is a Poly-ethyl-ethyl-ketone/carbon fiber (PEEK/carbon fiber) composite also refered to as APC-2 or Vitrex by the manufacturer. This composite has a nearly neutral coefficient of thermal expansion which leads to shape stable characteristics under thermal gradient conditions. This material is suitable for lightweight structures while avoiding moisture absorption and microcracking inherent in some other composite materials.

Substantial efforts were undertaken to produce a highly specular surface on the composite. Most of them failed to produce the results hoped for. It appears that micromovements of the base material cause substantial loss of specularity during thermal cycling. Although the overall coefficient of thermal expansion of the composite laminate is near zero, the coefficient for the PEEK matrix is not, nor is it for the carbon fibers. As a result, thermally induced stresses due to micromovement of the fibers and matrix in relation to each other cause the surface to become nonspecular. 
The best results were obtained with flow-coats or spin coatings of $\mathbf{2 0}$ to $\mathbf{4 0}$ micron thickness. Program resources did not allow for the full evaluation of coating variables or testing for environmental integrity in a simulated space environment. 
Abstract $\ldots \ldots \ldots \ldots \ldots \ldots \ldots \ldots \ldots \ldots \ldots \ldots \ldots \ldots \ldots \ldots \ldots \ldots \ldots \ldots \ldots \ldots$

SECTION 1 SUMMARY $\ldots \ldots \ldots \ldots \ldots \ldots \ldots \ldots \ldots \ldots \ldots \ldots \ldots \ldots \ldots \ldots$

SECTION 2 INTRODUCTION $\ldots \ldots \ldots \ldots \ldots \ldots \ldots \ldots \ldots \ldots \ldots \ldots \ldots \ldots \ldots \ldots \ldots$

SECTION 3 CONCEPTUAL DESIGN $\ldots \ldots \ldots \ldots \ldots \ldots \ldots \ldots \ldots \ldots \ldots \ldots \ldots \ldots$

3.1 PRELIMINARY SPECIFICATIONS $\ldots \ldots \ldots \ldots \ldots \ldots \ldots \ldots \ldots \ldots$

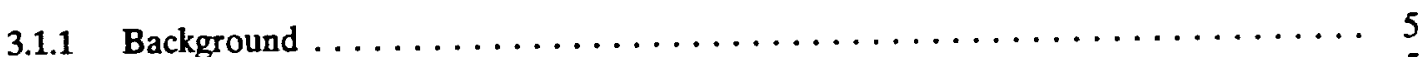

3.1.2 General Requirements $\ldots \ldots \ldots \ldots \ldots \ldots \ldots \ldots \ldots \ldots \ldots \ldots \ldots \ldots$

3.2 SYSTEM SIZING FOR $25 \mathrm{~kW}(\mathrm{NET}) \ldots \ldots \ldots \ldots \ldots \ldots \ldots \ldots \ldots$

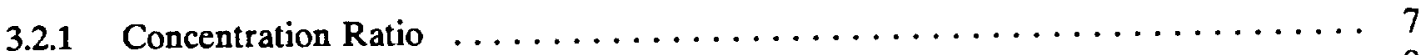

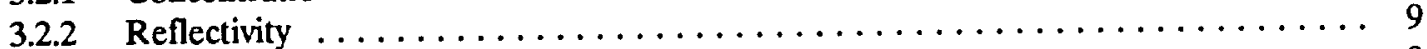

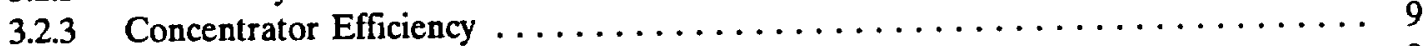

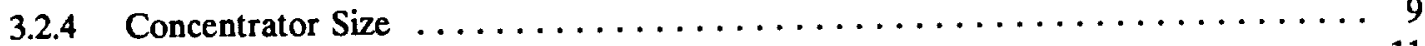

3.2.5 Power System Summary $\ldots \ldots \ldots \ldots \ldots \ldots \ldots \ldots \ldots \ldots \ldots \ldots \ldots \ldots \ldots \ldots \ldots$

3.3 DEVELOPMENT OF THE CONCEPTUAL DESIGN $\ldots \ldots \ldots \ldots \ldots \ldots \ldots$

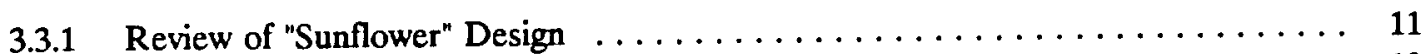

3.3.2 Acurex Concentrator Conceptual Design $\ldots \ldots \ldots \ldots \ldots \ldots \ldots \ldots \ldots \ldots$

SECTION 4 MATERIALS SELECTION AND REFLECTOR DEVELOPMENT WORK . . . . . . 23

4.1 SELECTION OF BASE MATERIAL $\ldots \ldots \ldots \ldots \ldots \ldots \ldots \ldots \ldots \ldots \ldots$

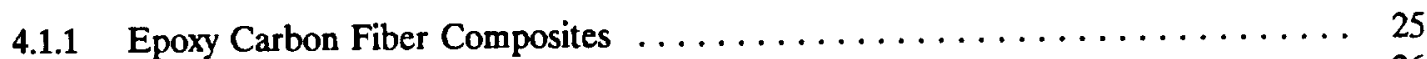

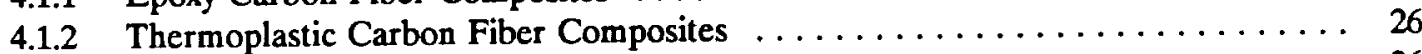

4.1.3 Selection of Base Material Configuration $\ldots \ldots \ldots \ldots \ldots \ldots \ldots \ldots \ldots \ldots$

4.2 SURFACE LEVELING AND REFLECTIVE COATING .......... 28

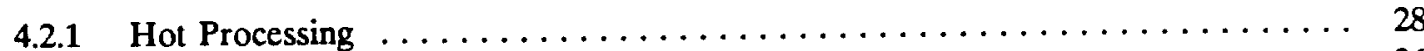

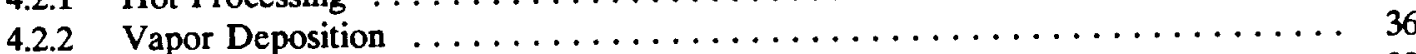

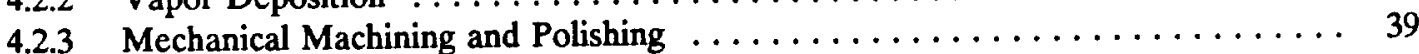

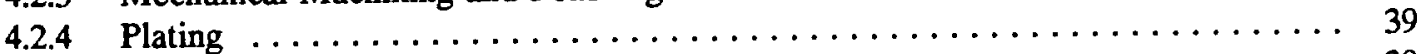

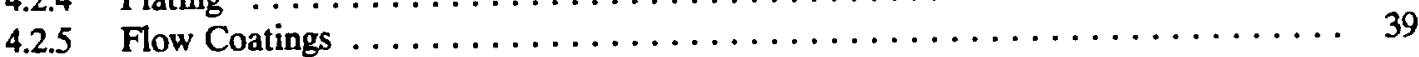

4.3 REFLECTOR COATING $\ldots \ldots \ldots \ldots \ldots \ldots \ldots \ldots \ldots \ldots \ldots \ldots \ldots \ldots \ldots$

SECTION 5 CONCLUSION $\ldots \ldots \ldots \ldots \ldots \ldots \ldots \ldots \ldots \ldots \ldots \ldots \ldots \ldots$

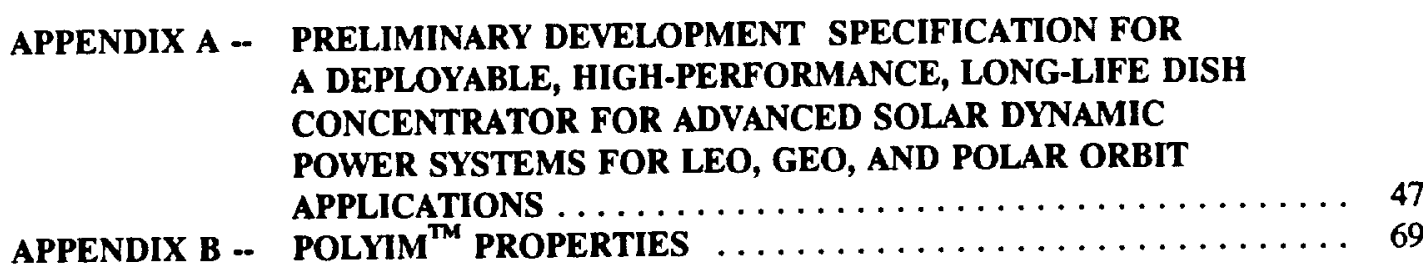




\section{LIST OF ILLUSTRATIONS}

Figure $1 \quad$ Effect of concentration ratio on intercept factor $\ldots \ldots \ldots \ldots \ldots \ldots \ldots \ldots \ldots$

Figure $2 \quad$ Power system energy conversion chart $\ldots \ldots \ldots \ldots \ldots \ldots \ldots \ldots \ldots \ldots \ldots \ldots \ldots \ldots$

Figure $3 \quad$ Deployed Space Solar Dynamic Power System Concentrator $\ldots \ldots \ldots \ldots \ldots \ldots \ldots \ldots$

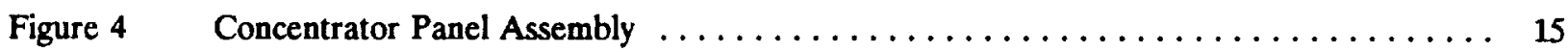

Figure $5 \quad$ Concentrator Panel Assembly - Exploded View $\ldots \ldots \ldots \ldots \ldots \ldots \ldots$

Figure $6 \quad$ An Individual Reflective Panel for the Innovative Concentrator (IC) $\ldots \ldots \ldots \ldots$

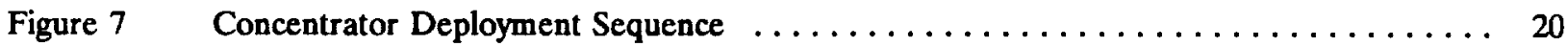

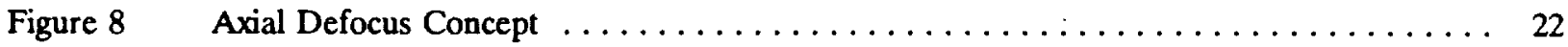

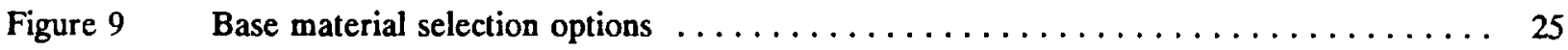

Figure $10 \quad$ Surface leveling alternatives and reflector coatings $\ldots \ldots \ldots \ldots \ldots \ldots \ldots \ldots$

Figure 11 Surface of PEEK/carbon fiber composite showing the orientation and density of

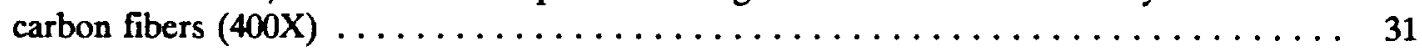

Figure 12 Aluminum surface after lamination to a PEEK/carbon fiber sample $(400 \mathrm{X}) \ldots \ldots$

Figure 13 Section of a composite sample showing the aluminum layer, carbon fibers, PEEK, and second layer of carbon fibers $(400 \mathrm{X}) \ldots \ldots \ldots \ldots \ldots \ldots \ldots \ldots \ldots \ldots \ldots$

Figure 14 Cross-section of sample showing voids near the surface. Other samples showed similar voids between plies. This appears not be unusual $(200 \mathrm{X}) \ldots \ldots \ldots \ldots \ldots \ldots 33$

Figure 15 Surface Profile Measurement of $\mathrm{SiO}_{2}$ Coated Peek Samples $\ldots \ldots \ldots \ldots \ldots \ldots$ 


\section{SECTION 1 \\ SUMMARY}

This technical report documents the concentrator conceptual design work performed under the NASA-funded project "Conceptual Design of a Deployable, High-Performance Long-Life Dish Concentrator for Advanced Solar Dynamic Power Systems" (DPSC), Contract NAS 3-25341.

The objective of this project was to develop an automatically deployable high performance solar concentrator that could be scaled to provide an output of 10 to $100 \mathrm{~kW}_{\mathrm{e}}$ of electrical power at an overall system efficiency of 30 percent or better with a service life of 15 years in LEO, GEO and/or polar orbit.

On this project a scalable conceptual design for a concentrator of nominal $25 \mathrm{~kW}_{\mathrm{e}}$ electrical power output was developed incorporating many innovative features addressing the special requirements of the space environment. The development was limited to the concentrator only and did not address the power conversion or heat rejection system. The concentrator designed consists of a paraboloidal ring with an outside diameter of $13.4 \mathrm{~m}$ and an inside diameter of $6.1 \mathrm{~m}$. The semi-rigid pie-shaped panels of the DPSC are stored in a dispenser frame during launch from which they are automatically deployed by various mechanisms without extra-vehicular-assistance (EVA). Safety was given particular attention in providing for special defocus and focus procedures to place the sun-spot into the receiver cavity.

Major emphasis was placed on the development of a viable reflector surface on the PEEK/carbon fiber composite material for use in space. The very low weight goals directed the program toward the use of these materials. Many methods were tried to planarize the surface of the composite to allow for the deposition of a highly specular reflective surface that would be resistant to the environment in space. The project was unsuccessful in reaching this goal although a promising method requiring further research was identified. The findings during the project provide some evidence that it may not be possible to fabricate a highly specular surface on a non-homogeneous surface that is subjected to a thermocyclic environment. 



\section{SECTION 2 \\ INTRODUCTION}

This technical report documents the concentrator conceptual design work performed under the NASA-funded project "Conceptual Design of a Deployable, High-Performance Long-Life Dish Concentrator for Advanced Solar Dynamic Power Systems" (DPSC), Contract NAS 3-25341.

NASA plans for future missions in space may include the use of advanced solar dynamic power systems as sources of electricity. This type of system has been successfully used to produce electricity for terrestrial applications, but never for space applications. The first such system is being considered for use on the Space Station. It is presently in the development phases.

A conservative design approach will be used for the solar dynamic power system design for the Space Station. That is, the development will be as low risk and high reliability as possible. This conservative approach, however, rules out consideration of a number of innovative component concepts with a potential for higher efficiency and lower weight that also have a high risk associated with their development. This is especially true for the solar concentrator. In parallel with the Space Station efforts, NASA has initiated a technology program to develop advanced solar dynamic power system components for space applications beyond 2000.

NASA's long range concentrator research and technology development program is aimed at identifying the most promising concentrator concept for the various sizes and developing the needed technology so that these concentrators can be confidently designed and fabricated to meet all the requirements.

The conceptual design of the concentrator is discussed in Section 3, whereas material selection and development work is presented in Section 4. 



\section{SECTION 3 \\ CONCEPTUAL DESIGN}

The conceptual design of the concentrator was carried out in several tasks. Specifications were in part provided by NASA and those requirements were extended to include more comprehensive details in a development specification. The tasks carried out were:

- Preparation of a comprehensive Preliminary Development Specification

- Sizing of a concentrator for a $25 \mathrm{~kW}$ (net) electrical power system

- Development of a conceptual design of a concentrator system based on PEEK/carbon fiber composite materials as the base material

- Determination of a suitable manufacturing technique for the various system components

- Development of an automatic deployment method of the concentrator system

- Determination that a highly specular surface could be produced on the selected base material

- Identification of risk factors to the successful design, fabrication, deployment, and reliability of the concentrator

The above tasks were addressed within the program scope to a greater or smaller detail.

\subsection{PRELIMINARY SPECIFICATIONS}

\subsubsection{Background}

The goal of the program was to develop a conceptual design for a concentrator that had wide application, could be scaled for various sizes without major basic design modifications, had a high solar-to-electric conversion efficiency, and offered a long operational life.

To ensure that available resources were effectively deployed, high risk areas such as the materials from which the concentrator would be built were researched first to permit definition of appropriate designs and methodologies.

NASA-Lewis would provide the various receiver/engine parameters, such as weight, geometric dimensions, aperture size, and configuration, as well as space station or satellite attachment configurations and load limits.

The conceptual design was to consist of drawings, sketches, and narrative descriptions for the concentrator package/dispenser, concentrator, receiver/engine support system, reflective panels, and the deployment methodology. The program was only partially funded and a decision was made to concentrate the program effort on critical materials questions to determine the feasibility of utilizing the identified base structure materials as the substrate for a space concentrator mirror.

\subsubsection{General Requirements}

The requirements for the advanced solar dynamic power systems concentrator (DPSC) was categorized into:

- Environmental and

- Power system requirements

Environmental requirements deal with the terrestrial, launch, and orbital conditions the dynamic power system concentrator (DPSC) will be exposed to, that are imposed on the design. 
The environmental requirements defined were:

- Launch requirements

- Configuration

- Static loads

- Dynamic loads

- Thermal environmental loads

- Electrical environmental loads

- Deployment requirements

- Orbiter release requirements

- Articulation requirements

- Deployment requirements

- Orbital operation requirements

- System requirements for orbital operation

- Static loads

- Dynamic loads

- Thermal environment

- Electrical environment

- Atmospheric environment

- Atomic oxygen (Low earth orbit, LEO)

- Ultraviolet radiation

- Thermal cycling

- Electron and proton radiation

- Micromedia and space debris

- Solar constant

The power system requirements for the DPSC were largely defined by NASA as follows:

(1) The deployable, high-performance, long-life dish concentrator for advanced solar dynamic power systems shall be designed to satisfy all requirements for the manufacture, assembly, deployment, and service and meet key goals and requirements of size, efficiency weight, and performance. Specifically:

- Concentration ratio: minimum -2000 , goal -5000

- Concentrator efficiency: minimum -90 percent, goal -95 percent

- Maximum efficiency degradation at end of life -10 percent

- Specific weight: maximum $-1.5 \mathrm{Kg} / \mathrm{m}^{2}, \mathrm{goal}-<1.0 \mathrm{Kg} / \mathrm{m}^{2}$

- Operational life: 15 years in LEO, GEO, and/or polar orbit

- Launch vehicle: space transportation system

- Automatic on-orbit deployment (without EVA, Extra-Vehicular-Activity)

- Size range: 10 to $100 \mathrm{~kW}_{e}$ at an overall system efficiency of 30 percent

- Survivability

- Terrestrial environment: during fabrication, ground checkout, assembly, transportation, and handling

- Launch environment: pressure and temperature changes as well as acoustical and vibrational loads

- Orbital conditions: post deployment, vacuum, thermal cycling, and vibration load

(2) The baseline design shall be for a $25 \mathrm{~kW}$, power system and be symmetric about the axis. Providing a solar to electric system efficiency of 30 percent, the concentrator must be sized to allow for 60 minutes of sun exposure and 30 minutes of shading in a 90 -minute orbit. The DPSC shall be designed to be placed in orbit by the space shuttle. It is envisioned that the concentrator including all components, i.e., panels, structure, power module, and power module support, will be packaged in a dispenser, cartridge, or other packaging device. During the conceptual design, no specific requirements will be imposed other than interface requirements to permit the exploration of several concepts including the "sunflower" concept developed by NASA-Lewis in the 1960 s. 
A detailed study was conducted to determine the requirements of the concentrator and assign specific measurable quantities to each requirement. These requirements were documented in a "Preliminary Development Specification for a Deployable, High-Performance, Long-Life Dish Concentrator for Advanced Solar Dynamic Power Systems for LEO, GEO, and Polar Orbit Applications" attached in Appendix A.

From the design specification it was possible to determine the basic requirements of concentrator size based on concentration ratio, reflectivity, and concentrator efficiency. The selected values for these variables were based on the substantial experience Acurex has in concentrator design. Although it was well known that atomic oxygen attacks silver reflectors, the design was based on silver coatings in hopes that a protective layer could be found. An aluminum reflector could always serve as a backup if silver was not feasible. A silver coating was desirable because the reflectivity of silver is higher than that of aluminum resulting in a smaller concentrator for the same electric power output level. If the concentrator size is smaller, the stabilizing power requirements in space could be reduced resulting in less fuel use. As a result total weight to be placed into orbit would be lower resulting in lower operating costs for the power system. This is also the reason why parabolic concentrators may be more attractive than photovoltaic solar power systems, since photovoltaic system are larger and require proportionately more fuel for stabilization in space. Pointing accuracy for photovoltaic systems is not as critical, however.

\section{$3.2 \quad$ SYSTEM SIZING FOR $25 \mathrm{~kW}$ (NET)}

\subsubsection{Concentration Ratio}

The concentration ratio of the solar collector is defined as the ratio of the concentrator projected area to the receiver aperture area. This term approximates the average solar flux across the receiver aperture. The peak flux may be an order of magnitude higher than the average. The higher the concentration ratio, the more precise the optics must be, and this results in higher heat flux on the receiver surfaces. Higher concentration ratios translate into smaller receiver apertures which decrease radiation heat losses from the aperture. Selection of a concentration ratio for a solar dynamic power system is an involved trade study and optimization, including concentrator, receiver, engine, and radiator parameters. The intent of the concentrator development is to allow for the highest concentration ratio that can be reasonably achieved. The established design requirement for the concentration ratio is a minimum of 2000 and a goal of 5000 dimensionless. For terrestrial concentrators, a number have higher concentration ratios than 2000 , but none that we are familiar with, can function efficiently at 5000 .

For example, a concentrator with a concentration ratio of 3000 can be detailed. The following example starts with an assessment of the concentrator optical error budgets. Optical errors which spread the focal spot consist of reflector specularity, tracking errors, sun size effect, and reflector slope errors. Each of these effects can be treated as a separate Gaussian distribution and combined in a root-mean-square manner to produce a total flux distribution in the aperture plane. The appropriate equation is:

$$
\delta^{2}=\sigma_{w}^{2}+\sigma_{p}^{2}+\sigma_{\sin }^{2}+\left(2 \sigma_{\text {sope }}\right)^{2}
$$

where:

$$
\begin{aligned}
\delta & =\text { convoluted error } \\
\sigma_{w} & =\text { standard deviation of the specularity spread of the optical surface } \\
\sigma_{p} & =\text { standard deviation of the pointing error of the concentrator } \\
\sigma_{\text {sun }} & =\text { standard deviation of the angular spread of the incoming direct sunlight } \\
\sigma_{\text {slope }} & =\text { standard deviation of the slope errors of the concentrator }
\end{aligned}
$$

The specularity of the reflective surface is estimated as $1.2 \mathrm{mrad}$. Typical reflector materials range from $0.2 \mathrm{mrad}$ for second-surface glass to $1.2 \mathrm{mrad}$ for metalized polymer films. Results of specularity measurements on experimental front-surface reflectors are similar to the metalized films. 
The tracking error budget for typical terrestrial concentrators is $0.1^{\circ}$, which converts to $1.7 \mathrm{mrad}$. It is expected that similar tracking accuracy can be achieved in the space application.

Angular spread of the incoming direct sunlight is caused by the finite size of the sun. In terrestrial applications, the angular spread increases with decreasing insolation level. This decrease is caused by scattering due to clouds, moisture, and dust in the atmosphere. For peak terrestrial conditions, $\sigma_{\text {mun }}=2.3 \mathrm{mrad}$. This value is probably a reasonable representation of the conditions in low earth orbit (LEO).

Reflector slope error has several contributors, including reflective panel manufacturing tolerances, thermal gradient induced deflections, panel alignment, and support structure tolerances. Individual contributors can be budgeted as follows:

$$
\begin{aligned}
\sigma_{\text {mlg }} & =2 \mathrm{mrad} \\
\sigma_{\text {thermal }} & =0 \mathrm{mrad} \\
\sigma_{\text {aligh }} & =1 \mathrm{mrad} \\
\sigma_{\text {aruature }} & =1 \mathrm{mrad}
\end{aligned}
$$

When these contributors to the slope error are combined in a root-mean-square manner, the resulting reflector slope error is $2.45 \mathrm{mrad}$.

The panel manufacturing error of $2 \mathrm{mrad}$ dictates high quality surface accuracy. The best panels we know of in the terrestrial program achieved $1 \mathrm{mrad}$ surface accuracy for segments $8 \mathrm{ft}$ long $\times 3 \mathrm{ft}$ at the widest end. Since panels for the solar dynamic concentrator are of this general size, the 2 mrad budget probably represents the best accuracy to be expected.

The slope error contribution of thermally-induced deflections is expected to be negligible because the reflective panel and structure will be fabricated from composites with very low thermal expansion coefficients. Values for structural accuracy and panel alignment are budgetary and will depend on detailed designs and manufacturing techniques.

Combining all the separate distributions into a single flux distribution yields the convolved error of the reflector:

$$
\delta=\sqrt{1.2^{2}+1.7^{2}+2.3^{2}+[2(2.45)]^{2}}=5.80 \mathrm{mrad}
$$

The flux distribution in the focal plane can be approximated by use of the Aparisi equation if the rim angle of the parabolic is known:

$$
\sigma_{f}^{2}=\delta^{2} / \sin ^{2} \theta
$$

where:

$\sigma_{1}=$ standard deviation of the flux distribution in the focal plane

$\theta=$ rim angle of the concentrator

A $53^{\circ}$ rim angle corresponds to a focal ratio of 0.5 . This rim angle should be the optimum for yielding the smallest image size on the focal plane for the high-quality concentrators of interest here.

If a receiver aperture is centered in the flux distribution at the focal plane, the resultant fraction of energy through the aperture (intercept factor) is expressed by:

$$
\varphi=1=e\left(-\frac{1}{2 C \sigma_{f}^{2}}\right)
$$


where:

$$
\mathrm{C}=\text { concentrator ratio of the collector }
$$

This equation may be solved for a concentration ratio of 3000 using the slope errors defined previously. The equation yields an intercept factor of 0.96 and means that 96 percent of the reflected energy from the concentrator enters the receiver and 4 percent illuminates the receiver aperture lip or misses entirely. For the defined slope error values, the effect of concentration ratio on intercept factor is illustrated in Figure 1.

\subsubsection{Reflectivity}

The total hemispherical reflectivity target is set at 0.95 . We feel that this target can be achieved using a silver front-surface reflector approach, by depositing various thin-film layers directly onto the composite substrate of the reflector panel. The total reflectivity of the silver film approaches 0.98 . Protective coating on the silver drops the reflectivity to 0.96 . The 0.95 target value allows for some small amount of soiling of the front-surface reflector.

\subsubsection{Concentrator Efficiency}

The concentrator efficiency is defined by the equation:

$$
\eta=\rho G \phi
$$

where:

$\eta=$ Concentrator efficiency based on the projected area of the collector.

$\rho=$ Total hemispherical reflectivity. A value of 0.95 for new, front-surface silver reflectors is the goal.

$G=$ Blocking and shading correction which includes the effects of receiver shadow, receiver support structure shadow and blocking of reflected rays, and nonreflective areas between facets of the concentrator. A value of 0.99 should be achievable for the ring configuration. (The Acurex Innovative Concentrator has $\mathrm{G}=0.97$.)

$\phi=$ Intercept factor for the receiver aperture. Use a value of 0.96 as previously discussed.

For the parameters defined, the concentrator long-term efficiency is $\boldsymbol{\eta}=0.90$.

\subsection{Concentrator Size}

The size of the concentrator required to power a $25 \mathrm{~kW}$, output engine/generator can be estimated by assigning efficiencies to the various system components. The overall power system efficiency is the product of all the component efficiencies. The efficiency expectations were developed by Acurex from experience gained in terrestrial concentrator programs. These values are listed in Table 1.

The sizing criteria for the concentrator is that it be large enough to collect sufficient solar energy to operate the power system continuously at $25 \mathrm{~kW}_{e}$. In LEO, the orbit time is approximately 90 minutes with 60 minutes of sun and the remainder shade. Therefore, the concentrator must collect enough energy in 60 minutes to operate the engine/generator for 90 minutes. During the shaded 30 minutes, the engine/generator is powered out of thermal storage with an attendant storage efficiency of approximately 0.70 . This criteria then dictates that $143 \mathrm{~kW}-\mathrm{hr}$ of insolation must be intercepted in 60 minutes in order to fuel the power system. Knowing the insolation in LEO allows sizing of the concentrator:

$$
A=\frac{q}{I}
$$

where:

$$
\begin{aligned}
& A=\text { Gross concentrator area, } \mathrm{m}^{2} \\
& \mathrm{q}=\text { Energy impinging on concentrator }=143 \mathrm{~kW} \\
& \mathrm{I}=\text { Insolation }=1.353 \mathrm{~kW} / \mathrm{m}^{2}
\end{aligned}
$$




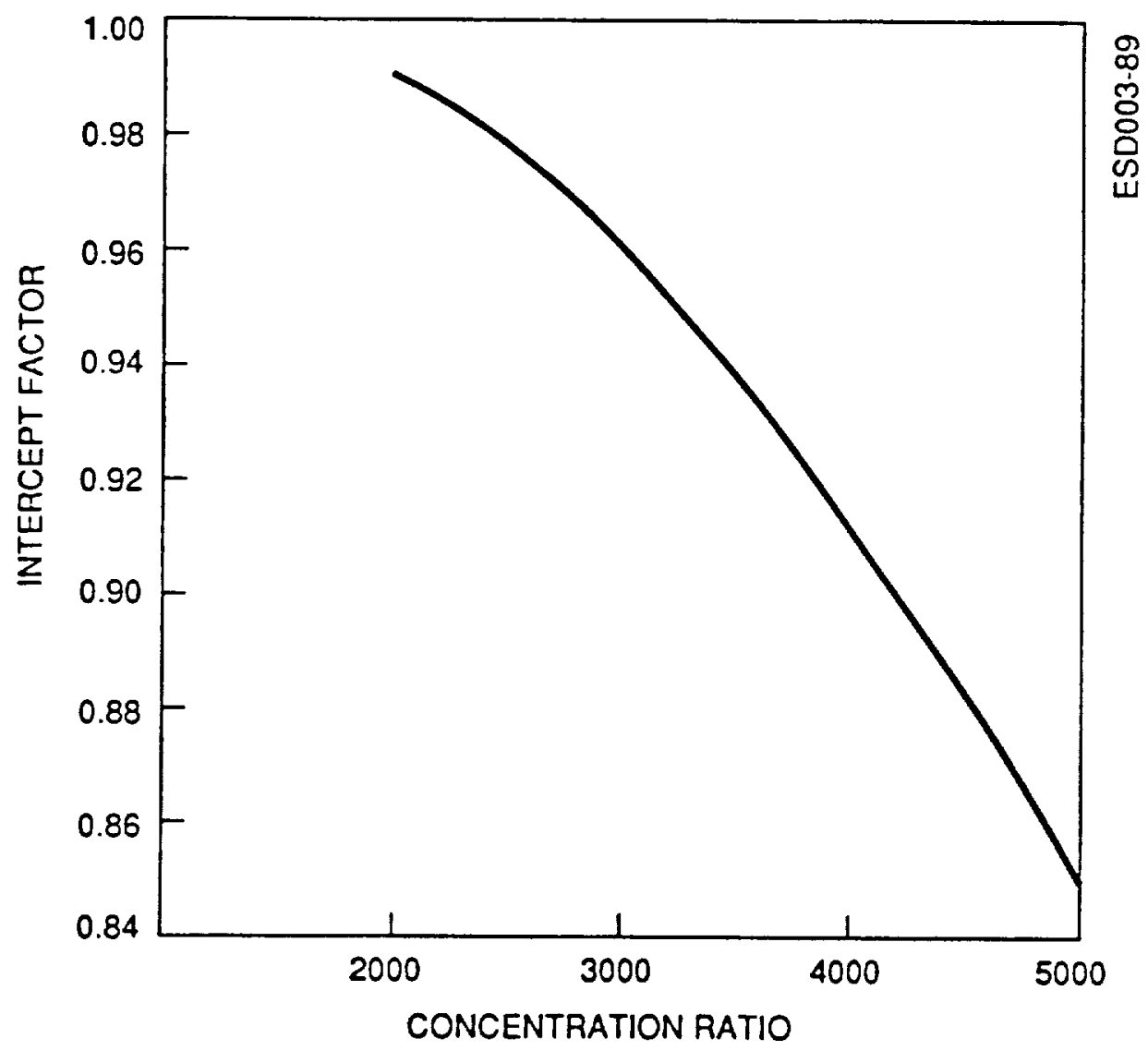

Figure 1. Effect of concentration ratio on intercept factor

Table 1. Component efficiencies

\begin{tabular}{|l|c|c|}
\hline \multicolumn{1}{|c|}{ Component } & $\begin{array}{c}\text { Emiency Without } \\
\text { Thermal Storage }\end{array}$ & $\begin{array}{c}\text { Emiciency Using" } \\
\text { Thermal Storage }\end{array}$ \\
\hline Concentrator & 0.90 & 0.90 \\
Receiver & 0.80 & 0.80 \\
Engine (incl. supp. & 0.43 & 0.43 \\
systems) & 0.96 & 0.96 \\
Generator & - & 0.70 \\
Thermal storage & 0.30 & 0.21 \\
Overall power system & & \\
\hline
\end{tabular}

'Operational mode during sun portion of orbit.

Operational mode during shade portion of orbit. 
Therefore, the required active area of the concentrator is $106 \mathrm{~m}^{2}$.

If the concentrator is defined as a ring or annulus with an inside diameter of $6.1 \mathrm{~m}(20 \mathrm{ft})$, the outside diameter given the required area is approximately $13.41 \mathrm{~m}(44 \mathrm{ft})$.

\subsubsection{Power System Summary}

The solar dynamic power system performance is summarized in the "waterfall" type chart of Figure 2. The chart starts on the left side with the incident solar flux and specifies each energy loss throughout the energy conversion process to the $25 \mathrm{~kW}_{\mathrm{e}}$ output of the electrical generator. The chart is based on a 90 -minute orbit with 60 minutes of sun and a continuous power system output of $25 \mathrm{~kW}_{\mathbf{e}}$.

\section{DEVELOPMENT OF THE CONCEPTUAL DESIGN}

As part of the development effort, Acurex reviewed prior design efforts to determine if these designs had applicability toward new developments. In particular, Acurex reviewed the "Sunflower" design.

\subsubsection{Review of "Sunflower" Design}

Acurex reviewed the designs of previous studies and in particular the design of the "Sunflower" designed in the 1960s under Contract No. NAS 5-462 by TRW, Inc., Cleveland, Ohio, to determine if those principles should be applied to the new development efforts. The work performed under this contract was reported in NASA Contractor Report NAS CR-46.

Acurex concluded that the "Sunflower" design had many good features and may have potential for application where the net power to be delivered is no larger than $20 \mathrm{~kW}$. This power level can be achieved by the incorporation into the "Sunflower" design of the latest reflector technology, along with a minimum thermal-to-electric conversion efficiency of 35 to 40 percent. The "Sunflower" parabolic concentrator was originally designed to deliver a net electric power output of $3 \mathrm{~kW}_{\mathrm{e}}$. The concentration ratio of this concentrator was approximately 720 and the solar constant used to calculate these results was 1353 watts $/ \mathrm{m}^{2}$. Total agreement on the correct solar constant appropriate for this calculation has not been reached and this value is provided for reference.

Under the contract completed by TRW, a full-size mechanically functional concentrator of $9.81 \mathrm{~m}(32.2 \mathrm{ft})$ in diameter was designed and constructed, composed of 30 deployable segments for the purpose of structural integrity testing. Several full-size segments were fabricated, coated with the reflective coating, and evaluated. The preprototype collector was successfully deployed in a simulated zero gravity environment, and also subjected to expected launch and orbital vibration and acceleration loads for structural integrity verification. No major problems were observed. A full solar performance test facility had also been designed and built for ultimate full system testing.

The "Sunflower" concentrator had an outside diameter of $9.81 \mathrm{~m}(32.2 \mathrm{ft})$, an inside diameter of $2.8 \mathrm{~m}(9.2 \mathrm{ft})$, a focal length of $5.18 \mathrm{~m}(17 \mathrm{ft})$, and an aperture area of $71.4 \mathrm{~m}^{2}\left(747 \mathrm{ft}^{2}\right)$. This size suggests that depending on the orbital sun/shading ratio and an overall system conversion efficiency of 30 percent, a $20 \mathrm{~kW}$, system is feasible. Other system constraints, such as packaging volume or configuration, are likely to be limiting criteria for application. As in most applications, only a total system approach evaluating all aspects of the power system will determine whether a particular system has greater merit. The total system will include the heat rejection system, the power conversion system, the receiver, the concentrator, the tracking system and the transport system.

A few items were recommended by the TRW team for incorporation into the design. It was suggested that segment or panel locks be incorporated to insure complete and secure deployment. Work in this area was not completed under the contract.

The "Sunflower" concentrator offers simplicity and reliability of deployment for smaller power level requirements and offers an alternative for consideration. Many of the techniques developed under the contract are applicable to larger concentrators, particularly the fabrication of the optical coating as will be discussed in Section 4. Optical coatings may be composed of different materials, but the general techniques have potential. 

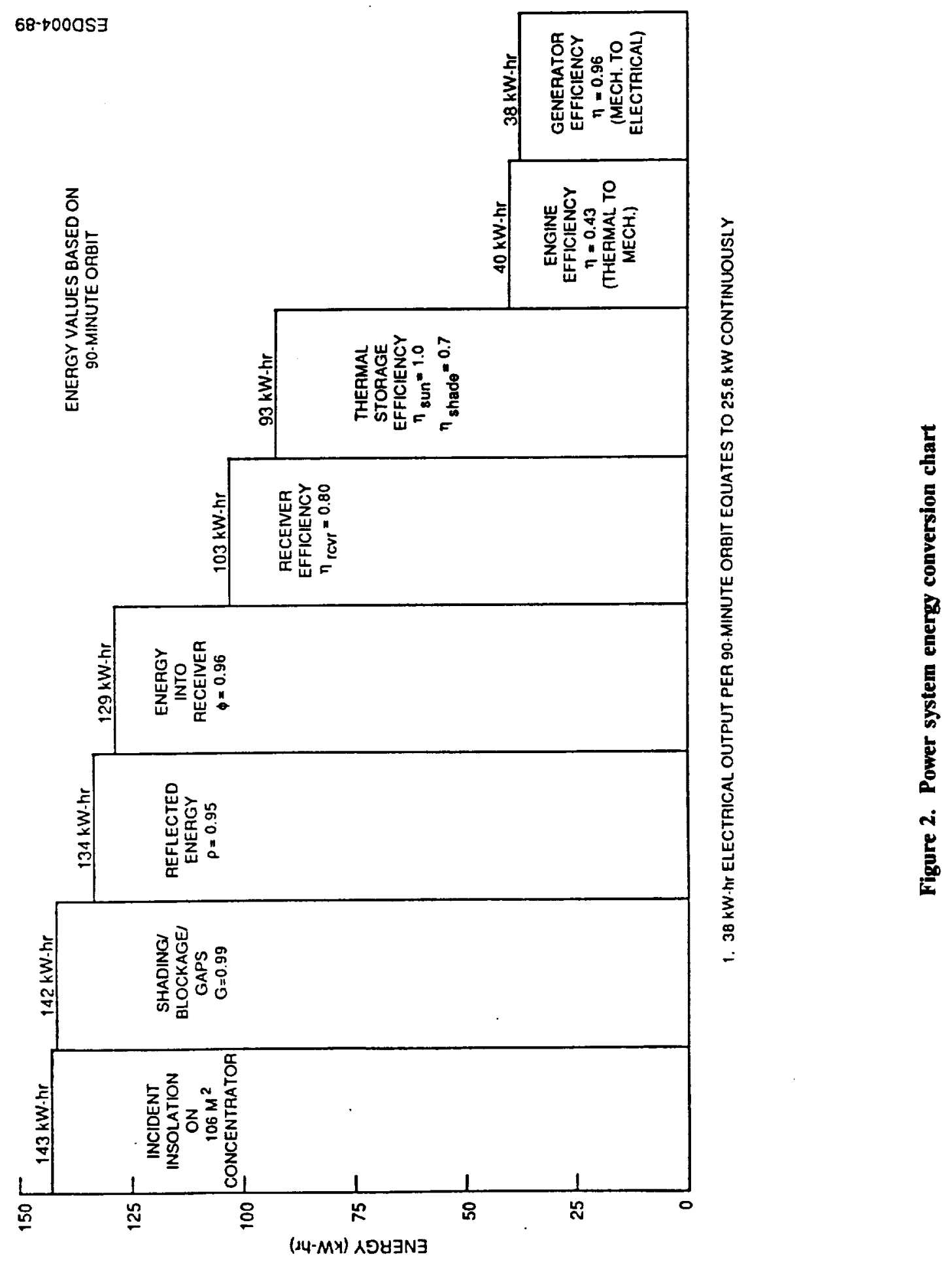


\section{3 .2}

Acurex Concentrator Conceptual Design -.

Figures 3, 4, and 5 show the conceptual design of the deployed space solar concentrator, concentrator panel assembly, and concentrator panel assembly - exploded view, respectively.

\section{Deployed Space Solar Concentrator}

The basic idea incorporated in the shape of the concentrator is the deletion of the center. Most concentrators developed to date have pie-shaped-sections that are joined at the edge. These sections become very long as the concentrator becomes larger, making the package difficult or impossible to transport. A ring type concentrator allows for all panels to be of the same length regardless of ring size, allowing for standardization in the packaging approach.

The concept covers a family of power system sizes in a shipping configuration with the same footprint in the transporting vehicle. For example, the concentrator shipping configuration for power systems from $25 \mathrm{~kW}_{\mathrm{e}}$ up to $75 \mathrm{~kW}$, would have a footprint of approximately $1.5 \mathrm{~m}(5 \mathrm{ft})$ by $4.6 \mathrm{~m}(15 \mathrm{ft})$. The smaller systems require fewer pie-shaped-sections and would have a height of approximately $1.5 \mathrm{~m}(5 \mathrm{ft})$ while the larger systems stack higher doubling the height to approximately $3.0 \mathrm{~m}(10 \mathrm{ft})$. The annular concentrator concept accommodates the larger size concentrators by holding the reflective panel length constant, increasing the number of panels, and increasing the external diameter and the void diameter in the center of the concentrator. This allows standardization of design and deployment of a family of power systems covering a power size range of 3:1.

As can be seen in Figure 3, the receiver, engine and radiator, and its support structure are also part of the deployment package. A support beam is folded onto the dispenser during launch holding the receiver, engine and radiator in place. The dispenser serves as the gimbal attachment to the space station, allowing for the appropriate movement of the concentrator relative to the space station. The concentrator will be directionally "stationary," i.e., always pointing toward the sun, whereas the space station may be facing the earth. This calls for complex motions between the two major systems.

\section{Concentrator Panel Assembly}

The reflective panel concept was derived from the Acurex Innovative Point Focus Solar Concentrator project for the Department of Energy. The Innovative Concentrator (IC) is a 15m diameter dish concentrator that utilizes gore-shaped panels constructed of two-part sheet metal. Each panel shown in Figure 6. consist of a back panel frame and a front panel reflector. The back panel frame provides the needed support and stiffness. It had been stamped from sheetmetal to form strong and rigid hat section ribs. The back panel frame by itself is nonrigid until the front reflective panel has been attached. When the front and back panel are bonded together over a precision mandrel they become a structural element with great stiffness due to the box sections that are formed. The mandrel induced parabolic curvature is accurately maintained by internal shear forces in the panel laminate structure. For the space application, this same design concept is adopted as can be seen in Figure 5. A frame is proposed to be constructed from "hat-section" composite materials to which reflective panel elements are attached with adhesives or by other means as appropriate for the materials used. Deployment mechanisms and guide rails are attached to the panels and the "dispenser cartridge."

A complete reflector panel consists of a frame to which five smaller contoured reflecting panels are mounted either by fasteners or adhesive. The frame supports the reflector panels and provides for stiffness of the structure and a structural element to which deployment mechanisms and spring actuators can be securely attached. The frame also provides for "gliding" surfaces to prevent scratching of the reflective surfaces. Positioning pins and locks are incorporated into the frame that secure each panel to the next and form the structure of the dish. The actuators consist of small, passive, spring-driven motors that retract cables that pull the reflective panels into their respective deployed positions and lock them in place. The scheme developed insures positive guidance of each panel to the desired position. The function of the method was tested and demonstrated with a simple model. These tests demonstrated that deployment is independent of orientation or gravity forces and would therefore also function in space. There are many details that have to be designed once a final material selection has been made. It was not possible to develop a final panel design without a final material specification. The final material specification hinged upon the feasibility of producing a highly specular reflective coating on the preliminarily selected PEEK/carbon fiber material. Although it was hoped that this material would be selected, designing a complete panel based on this material selection was premature and would have resulted in the expenditure of 


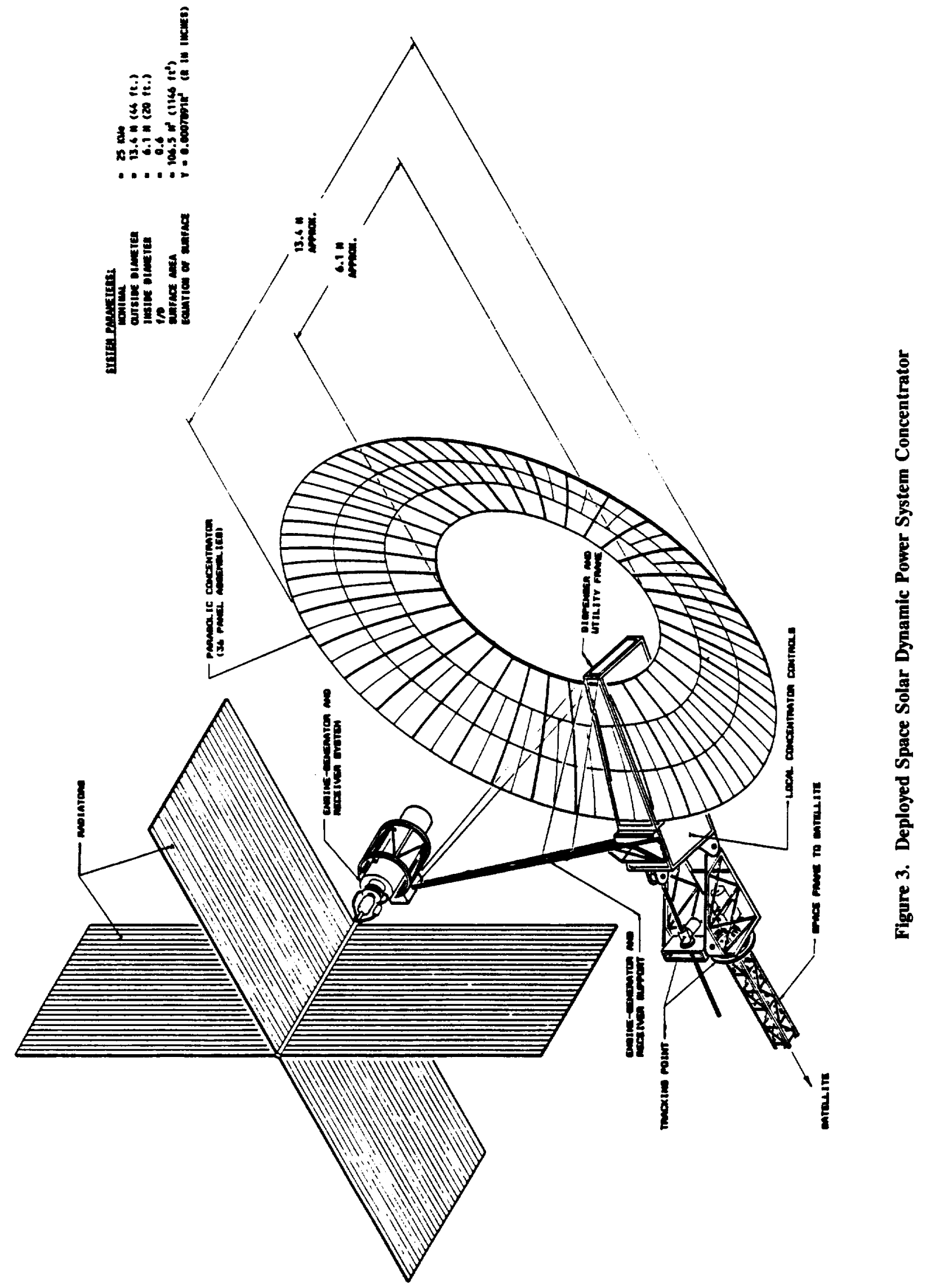




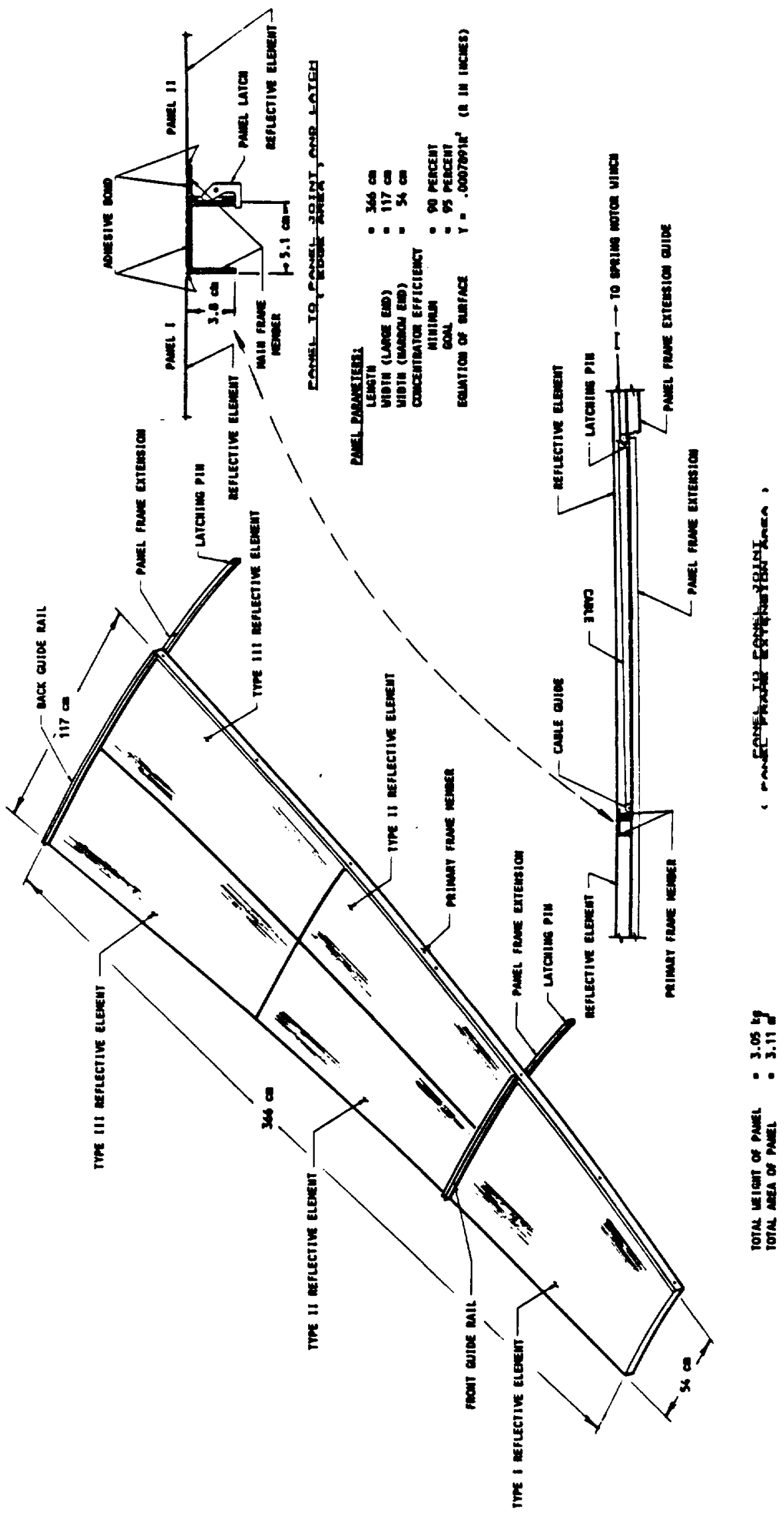

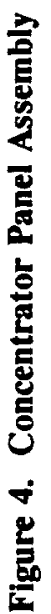

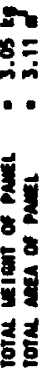




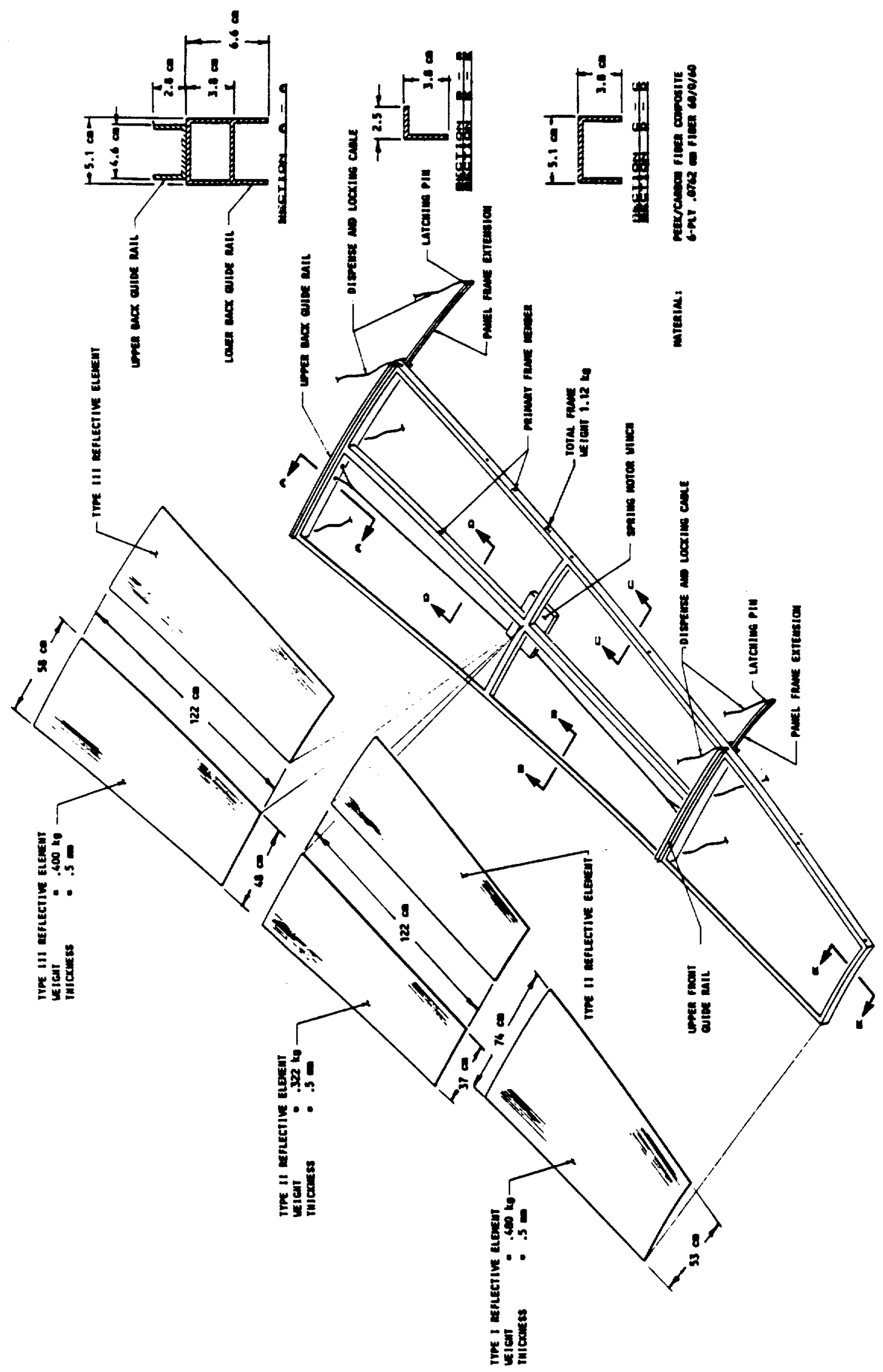

है 


\section{ORIGINAL PAGE}

BLACK AND WHITE PHOTOGRAPH
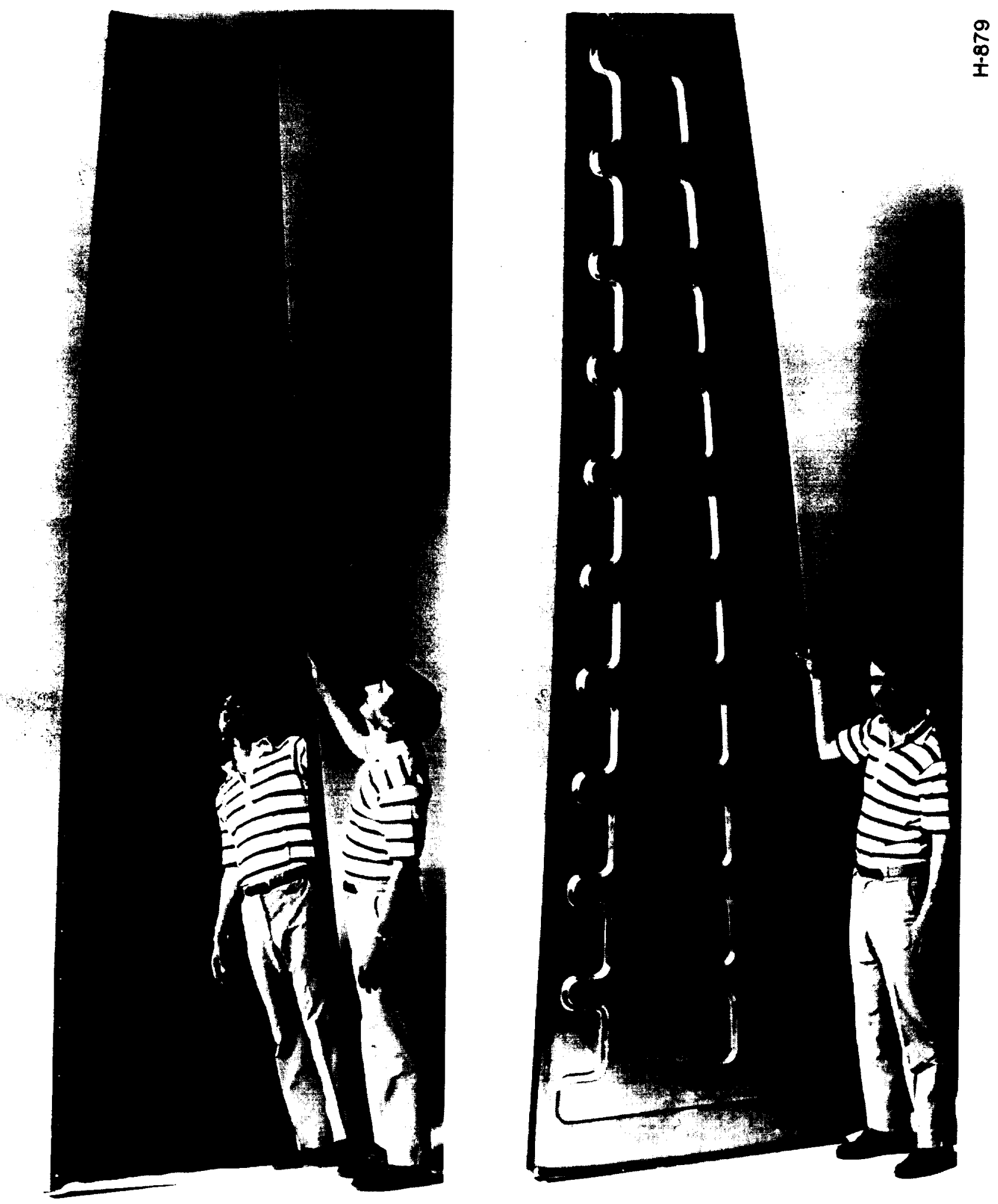

\section{Innovative Concentrator Reflective Panel}

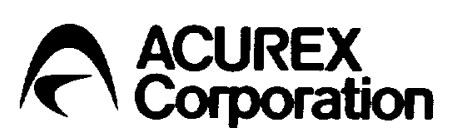

Figure 6. An Individual Reflective Panel for the Innovative Concentrator (IC) 

vast resources. The detail design effort including computer analysis of strength and stiffness requirements was not planned until the suitability of the material had been ascertained. Programmatic scope and funding reductions precluded the completion of these originally planned activities. Accurate detailed cross-section dimensions and weights could therefore not be determined. Estimates of the concentrator reflective panel weight per $\mathrm{m}^{2}$ were made. These estimates confirmed that the $1 \mathrm{~kg} / \mathrm{m}^{2}$ could be achieved.

\section{Concentrator Deployment}

Figure 3 shows the deployed space solar dynamic power system concentrator. The concentrator system consists of the space frame to concentrator gimbal joint, the dispenser and utility frame, the parabolic concentrator panel assembly, the engine-generator and receiver support, the engine-generator and receiver system and the heat rejection radiators. In addition, local concentrator controls are located in the dispenser and utility frame. The concentrator shown in the figure depicts the size necessary for a $25 \mathrm{~kW}_{\mathrm{e}}$ system. Detailed information regarding the engine was not available and could only be estimated based on Acurex in-house knowledge of the development status of many of these systems and what the likely size and weight of such a system may be. This development program was only directed at the concentrator itself. In order to develop a total deployment scheme some consideration had to be given to these components, however, to provide for space in a launch vehicle and to evaluate the total packaging feasibility.

The automatic deployment sequence of the concentrator is shown schematically in Figure 7. All the reflective panels for a complete concentrator are packaged in the dispenser cartridge that also serves as the transportation container shown in View A, Figure 7. The reflective panels are stacked in the dispenser and are held firmly in place during launch. Support rails on the front surface of each reflector separate the panels and prevent damage to the delicate front reflective surface. The edges of the panels are locked by the deployment mechanisms prior to deployment. In preparation for the deployment sequence, the dispenser cartridge is attached to the tracking joint of the space station or satellite, and an electrical power connection is made. Most deployment mechanisms are planned to be powered by passive springs except for a few triggers and latches. This minimizes the power and control requirements. The concept followed is for sequence control by latching mechanisms that only permit continued deployment at completion of the prior sequence step.

The deployment sequence is initiated by electronic signal or equivalent. The first deployment sequence step is the extension of the top panel in the stack out of the dispenser. The panel moves out of the dispenser in fan fashion along guide rails that maintain the relative position of the panel with the dispenser. The mechanism extends the top panel in the stack out edgewise until the panel edge reaches a predetermined position. The panel is locked to the next panels' edge with detent locks at that point. The second panel is now moved out of the dispenser with the first panel attached and so on until all panels have been extended out of the dispenser (see View B in Figure 7). Tag lines attached to the first panel are now retrieved, guiding the first panel lock pins into the last panel lock bushings closing the concentrator ring. The concentrator now forms a rigid structure due to its three dimensional shape. The last panel is securely fastened to the dispenser cartridge as the structural interface between the concentrator and the tracking joint attached to the space station or satellite. The support structure for the receiver, engine and radiators is deployed next (View C and D, Figure 7). The support structure is also attached to the dispenser cartridge, thereby avoiding the transmission of structural loads into and through the concentrator which might cause deflections causing distortion of its optical characteristics.

The receiver, engine and radiators are deployed after the concentrator has been latched by unfolding of the support beam. Stabilizing cables are used to prevent rotation of the support beam during concentrator maneuvers. Care must be taken to place the concentrator pointing away from the sun during deployment to prevent damage to various components due to stray concentrated light.

An issue of great importance that has received relatively little attention in the design of point focus concentrators is the great hazard components are exposed to when the concentrated sun spot is focussed on components other than the receiver. Receiver face plate tests have shown that only very high temperature materials with low coefficients of thermal expansion can withstand the high heat fluxes. Terrestrial point focus collectors are for this reason designed for high slew rates for "sun acquisition". The same methodology in space would be very difficult to implement since large reaction forces are necessary and it is unrealistic to expect that the dish could be brought to a fixed position without oscillation in fractions of a second. The heat flux of this concentrator would require exactly this, however. The concentrated sun spot represents a serious safety hazard to equipment as well as personnel that must be managed during any deployment scheme for a 


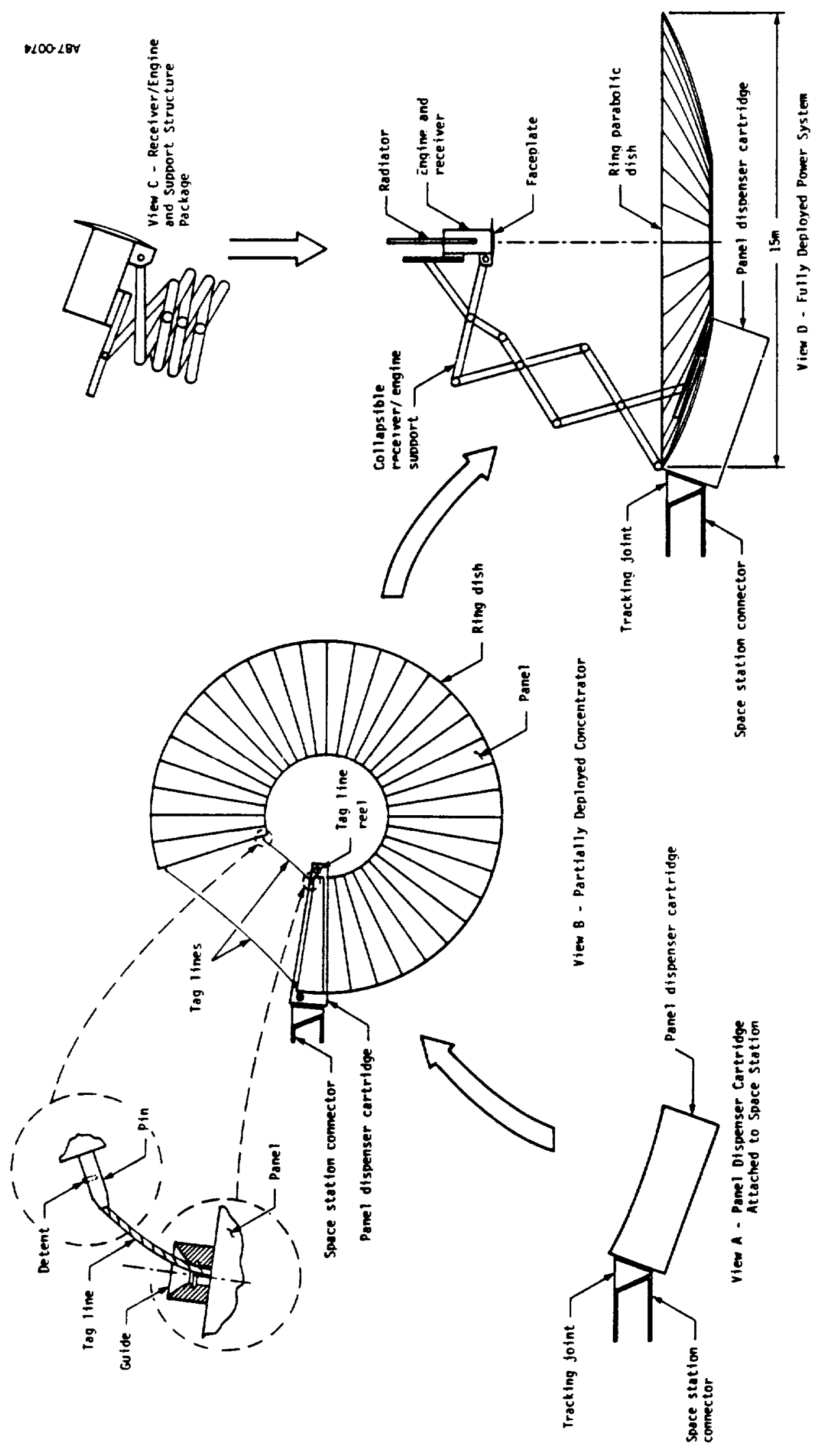

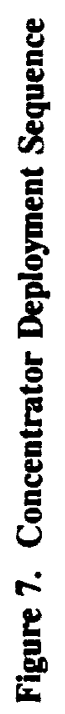


parabolic concentrating collector in space. In addition, automatic deployment of the concentrator has very high priority to relieve the astronauts of dangerous EVA activity and also reduce the cost of deployment sequences.

The concentrator receiver, engine and radiator are designed to be defocused by moving these systems along the axis of the concentrator (see Figure 8), causing the sun image to become diffuse and preventing highly concentrated sunlight to damage the face plate of the receiver. The ring configuration of the concentrator allows for the receiver, engine and radiators to be "parked" along the axis without sun exposure, a feature not available on terrestrial concentrators, due to size and structural limitations on earth. Moving the receiver along the axis further insures the stability of the space concentrator during sun acquisition. The concentrator can be aligned with the sun prior to moving the receiver into the "receive heat flux" position. The concentrator is free of torque maneuvers and can be rapidly moved without the potential for twist. The concentrator and receiver/engine and radiators move in opposing directions counteracting each other. This addresses the difficult question of moving a large space structure a fixed amount very rapidly and immediately bringing it to a stop. Axis acquisition relieves the reaction force requirement since the concentrator and receiver, engine and radiator systems can oppose each other.

Room is provided in the dispenser frame adjacent to the panels for tracking and power module controls. Attaching the controls directly to the dish will significantly reduce the amount of cabling and wiring connecting the concentrator and space station. Cabling connections to the space station from the concentrator must be routed through the gimbal joint and they may be exposed to significant flexing over time. This cable is therefore a potential failure part of the concentrator. If the number of conductors can be reduced the likelihood of failure can be reduced proportionately. A power cable and a redundant twisted wire pair control cable may be all that is necessary with this configuration.

Manufacturing techniques, as well as designs, are dependent on the selected material used to fabricate the components. The conceptual design could not effectively be carried further without the material selection having been made. 


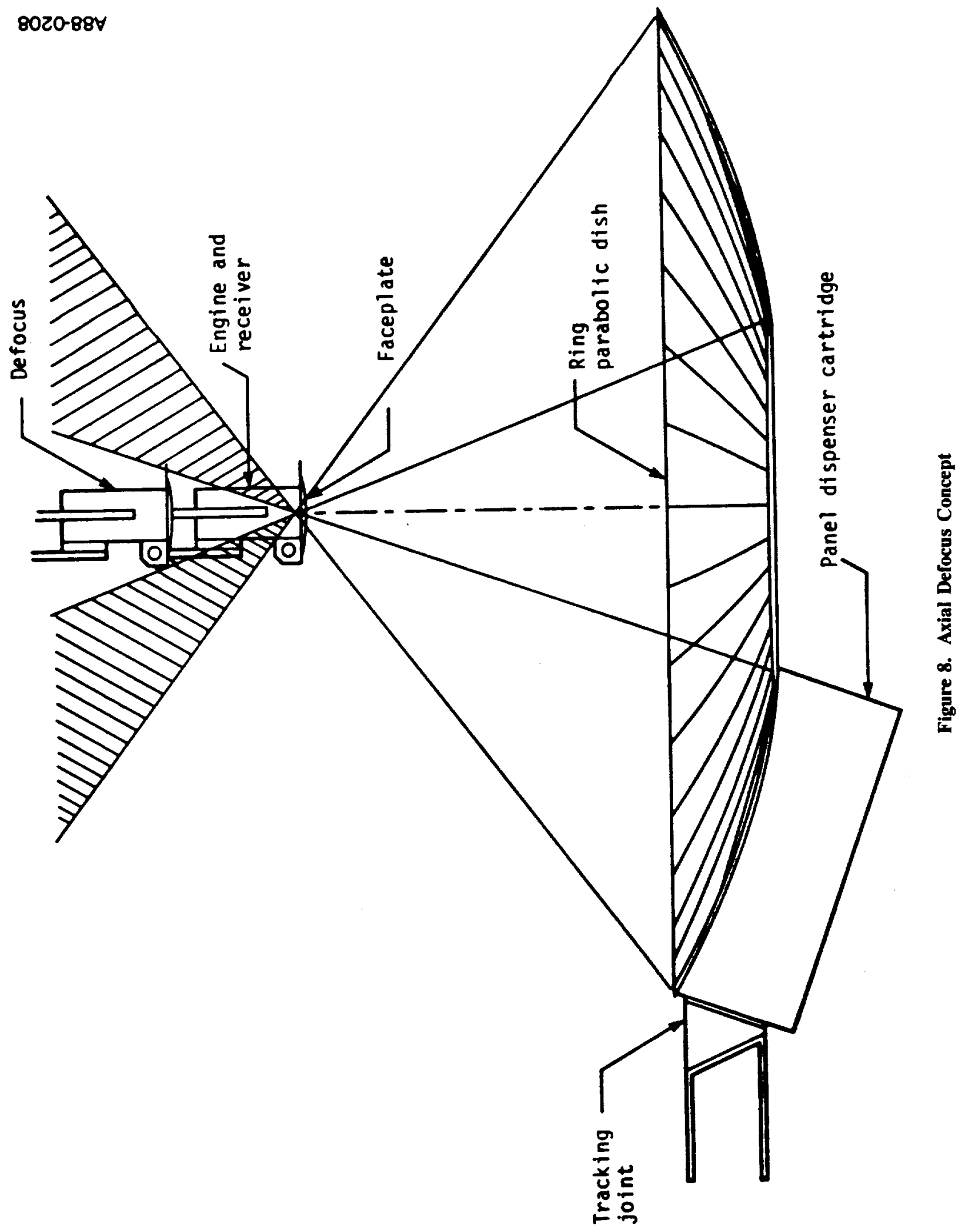




\section{SECTION 4 \\ MATERIAIS SELECTION AND REFLECTOR DEVELOPMENT WORK}

The material selection for the concentrator is of key importance due to the highly corrosive environment and the thermal cycling the concentrator is exposed to during the sun/shade cycle in LEO.

Acurex conducted a detailed literature search to determine the problems and solutions presented by various researchers and organizations. Of particular interest were the reports detailing the effects of thermal cycling on composite materials for space structures. Epoxy composites, when subjected to thermal cycling, experience microcracking of varying severity.

A detailed review of the presently available epoxy/carbon fiber composite materials for use as base materials found that many questions could be raised as to their suitability for the proposed environment. The big attraction of these materials is their great stiffness and strength in relation to weight. Since the most likely "figure of merit" of a system will likely be based on $\$ / \mathrm{kWH}$ delivered in space the specific stiffness of the material and the strength to weight ratio are very important parameters.

The concentration ratio required to achieve the efficiencies desired will require very accurate concentrators and the material properties are of utmost importance. It is unlikely that the "inflatable" collectors will be able to achieve the goals set by these specifications.

The most important problems in LEO orbit are atomic oxygen attack, radiation, and other less severe hazards such as micrometeorites and space debris.

The findings of the literature review prompted a search for a more ideal material than epoxy carbon fiber composites. A list of criteria was established to allow for rating the material. The primary service criteria were the following:

- Maximum efficiency degradation at end of life: 10 percent

- Minimum concentrator efficiency: 90 percent, goal 95 percent

- Thermal cycling due to sun/shade cycle: $\pm 112^{\circ} \mathrm{C}\left( \pm 200^{\circ} \mathrm{F}\right)$

These major criteria, which must be satisfied by the concentrator before satisfactory performance in space can be assured, translated into more direct design criteria for the materials:

- The material must be light and strong to reduce the costs of placement

- The material must be thermally stable to ensure that distortions due to thermal gradients are small in order to maintain the focal quality of the concentrator as it moves back and forth from sun exposure to shade and it must not develop micro cracks

- The specular reflectance of the finished material must be high and environmentally durable to ensure the life and performance of the system

- The materials should be relatively low in cost and easily manufactured into the design shapes needed

- Fastening and assembly techniques should be simple and reliable

- The material must not absorb moisture which may contribute to dimensional instability of the material.

The task of producing a durable lightweight space mirror can further be divided into several tasks: 
- Selection of the base material to satisfy global requirements

- Production of a specular mirror surface on the base material

- Protection of the mirror surface from the environment

Production of a durable light weight space mirror was identified in the literature as one of the most crucial tasks in the design of a parabolic high-performance concentrator for space applications.

\subsection{SELECTION OF BASE MATERIAL}

The selection of the base material for the concentrator is of immense importance and may well be the most important decision contributing to the success of the concentrating collector. Point focus solar concentrators with very high optical qualities (high reflectivity and high concentration ratios), performance and life require that the properties of the material be largely unaffected by thermal cycling, thermal gradients and environmental attack.

The concentrator will be exposed to many thermal cycles as the satellite moves from sun exposure into the shade of earth while in orbit. Strong thermal gradients are experienced by the system components that may result in distortions of the structural shape of the concentrator causing large-scale optical distortions of the concentrated sun image in the focal plane. These distortions could be sufficiently large to partially defocus the image. The larger image of the sun spot (fire ball) may "spill over" onto the receiver face plate. The very large heat flux on this surface would then cause damage and destruction of the face plate and later the power conversion system. The seriousness of this potential problem can not be over emphasized. In the event of face plate heating the capability to defocus the concentrator and move the power conversion system into a safe location must be provided. Concentrator wobble would also call for this capability.

Thermal transients induced by the sun/shade cycle must not significantly influence the structural/optical shape and must also leave the optical surface unchanged. Micro changes of the surface may influence the optical quality, particularly reflectivity, that would significantly effect the amount of energy that could be collected by the power conversion system. Changes in the optical quality may also have a significant impact on the amount of energy that is absorbed by the concentrator reflective panels and may introduce larger thermal gradients than would result with constant optical properties. Finally, internal material stresses are minimized if the thermal transients are small. Materials that have high conductivity would help in equilibrating temperature differences.

It must be possible to attach a highly specular surface or coating to the base material to produce the required space mirror. Environmental considerations are of great importance. Atomic oxygen attack in LEO is of particular concern. Silver mirror coatings require significant protection from atomic oxygen. To provide this protection will be very difficult, since micrometeorite or space debris impacts may damage any protective coatings exposing the silver. Efforts on this program were directed to identify a base material that would meet the challenging requirements for a space concentrator. Carbon fiber composites have many characteristics that were deemed beneficial to this program and this was the reason for their early selection.

Carbon fiber composites can be designed to have specific characteristics that are very beneficial in the design of components. The materials can be tailored. If strength in a particular direction of a part is needed, the fibers can be oriented to provide the needed strength at minimum weight. The material can also be tailored with the appropriate resin to have a coefficient of thermal expansion near zero which would lead to structural/optical stability of the concentrator. These features made carbon fiber composites ideal candidates for space applications. Carbon fiber composites are subject to erosion and atomic oxygen attack in space, but it was felt that these difficulties could be overcome by design. Aluminum and particularly aluminum oxides are very resistent to attack in the space environment. Cladding of composite materials with aluminum is an option that could be explored. Aluminum as the structural components of a space concentrator appears undesirable, because aluminum has a very high coefficient of thermal expansion. Aluminum reflectors are resistant to atomic oxygen attack, but lack structural shape stability in the cyclic thermal environment in LEO. Composite materials also have a favorable strength to weight ratio and showed much greater promise in being able to meet the weight goals of this development program. To meet the weight requirements of the collector, it would be necessary to evaluate how many layers a composite would be necessary to meet the stability and accuracy requirements for this application. Figure 9 shows two options of carbon fiber materials and the various ply-configurations that were considered. 


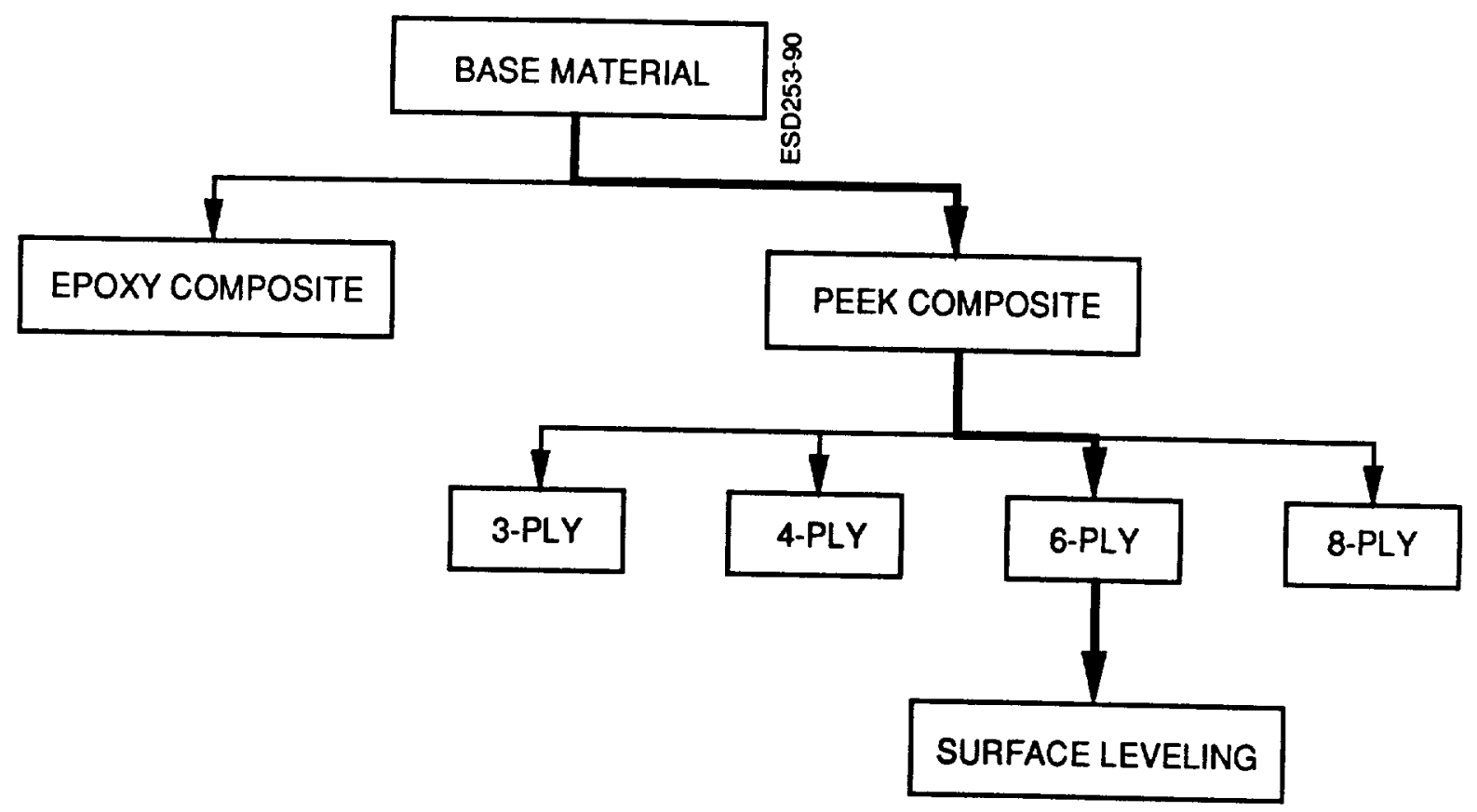

Figure 9. Base material selection options

\subsubsection{Epoxy Carbon Fiber Composites}

The epoxy/carbon fiber composite materials are hygroscopic and absorb moisture readily in the terrestrial environment. Typical absorption is 2 percent by weight. With the absorption of moisture, volume changes occur which have the tendency to distort the materials. These distortions have been observed on sample mirrors that have been manufactured by others. However, the manufacture of large space structures in a completely dry environment would be very cumbersome. If other materials are available which do not have these characteristics, they would certainly be preferable. Predicting the performance of a mirror distorted by moisture intrusion would be very difficult. In space, the materials would certainly dry out in time and performance might change.

The epoxy/carbon fiber composite materials also exhibit microcracking when exposed to thermal cycling, due to their brittle microstructure. The cracks usually start at the surface and may progress through the entire structure. These cracks would expose any mirror surface to the environment and, even if structurally not detrimental (which has not been shown), would most likely result in significant edge corrosion. It also appears that the number of microcracks increases with thermal cycling, and no "saturation" level has been observed thus far in experiments conducted. Tests reviewed had cycled these materials up to 500 times, whereas the space concentrator should be designed for 100,000 cycles. It was initially believed that microcracking would stabilize at some maximum level and that the carbon fibers would not be affected directly. Depending on the bond strength between the matrix and the carbon fiber, cracks have been observed to pass through the fibers. This could have very serious consequences in the long term.

The problems with epoxy/carbon fiber composite materials have not gone unnoticed, and substantial efforts are underway to explore alternative materials for applications in space by industry. Materials that show promise are thermoplastic/carbon fiber composites, and in particular, PEEK composites. Silverman and Jones of TRW Space \& Technology Group reported the following at the 33rd International SAMPE Symposium, March 7 through 10, 1988:

"Expected performance improvements over current graphite/epoxy composites include negligible moisture absorption, improved microcrack resistance, greater damage tolerance, significantly improved thermal stability, postformability, reuse of scrap, improved repairability, and indefinite prepreg shelf life." 
Epoxy/carbon fiber composite materials manufacturing techniques have matured to some degree. These materials are "laid up" on madrels or forms and allowed to cure. Baking of the parts is usually required to cross-link the epoxy. The cost of tooling does not have to be high. The large ovens required are often the highest cost items.

\subsubsection{Thermoplastic Carbon Fiber Composites}

The advantages listed in the literature of thermoplastic carbon fiber composites particularly PEEK (polyethylethylketone) led to further investigation of these materials.

Thermoplastic composite materials are fairly new and reports of performance have only recently been published. The thermoplastic materials have not been used in the past, primarily because of differences in the way parts are manufactured compared to epoxy carbon fiber materials, and the difficulty in obtaining good adhesion between the carbon fibers and the PEEK matrix.

Thermoplastic composite materials are chemically stable at room temperature and have indefinite shelf-life. The unidirectional ply-materials are laminated by the application of heat and pressure in a press tailored to the need of the material. This process is referred to as consolidation. Consolidation of the ply-material can result in the final part form, or in a sheet that will be subjected to further forming. Forming can be accomplished in a cold press into which the preheated composite materials are placed. Speed of operation is critical to insure the proper forming and cooling cycle. The severity of the forming to be performed also determines whether this operation should occur during the initial consolidation phase or during a final "sizing" operation. To gain the full strength of the composite, fibers should not be crimped, implying that only small forming operations should be performed once consolidation has occurred.

PEEK is a hot-melt adhesive with a relatively high service temperature. When the material is heated for processing, it must be isolated from the press platen to prevent adhesion. This is done with aluminum sheets, treated with a release agent, that are laid on both sides of the laminate. The aluminum sheets, typically 0.004 to 0.007 inches thick, can subsequently be peeled off. The adhesive will not stick to "cold" surfaces and this feature allows for post forming after the composite has been consolidated. It was also hoped that a very smooth surface could be obtained which could be used as a base for a reflective surface. Tests were conducted to determine the quality of surface obtainable.

Tests on thermoplastic materials performed by others and reported in the literature have shown that the adhesion between the carbon fibers and the thermoplastic matrix was poor. This was due to two factors. First, the carbon fiber surface did not form a good bond with the thermoplastic material; and, second, the distribution of the thermoplastic material around the fibers was not uniform. These problems have been addressed by the suppliers in different ways and the final solution has probably not been implemented as yet. Two companies offer independent solutions to each problem, but a combined solution has not been offered. ICI Fiberite offers a PEEK/carbon fiber material where the carbon fibers have been treated with a proprietary process to enhance adhesion. This material has exhibited good structural strength in tests, with no failures along the carbon fiber surface. Distribution of the PEEK material in the yarn is by "commingling," a term applied when strands of fibers of PEEK and carbon are combining in the yarn. The Heltra Division of Courtaulds Fibres Ld. of Coventry, England, offers yarn produced by the Heltra process. This process combines PEEK and carbon fibers in the proper proportion in the yarn by mixing the individual fibers and allocating where they are to be placed within the yarn, insuring that PEEK will wet all carbon fiber surfaces. The ideal material combines these two processes, ensuring maximum uniformity in the matrix and, therefore, predictability of performance. In the absence of this combined solution, ICI Fiberite offers the best alternative at the present. Currently, these materials are offered in 0.005 -ply thickness from which consolidated sheet is made. Some work has been done with thinner materials $(0.003$-inch), but this work is in the experimental stages.

Because PEEK/carbon fiber composites offered greater environmental stability compared to epoxy/carbon fiber composites, Acurex recommended the use of PEEK/carbon fiber composites as the base material for the reflective panels.

\subsection{Selection of Base Material Configuration}

The PEEK/carbon fiber base material is available in standard form in 40-cm (16-inch) by 40-cm (16-inch), 1-mm (0.040-in) thick, 8-ply quasi-isotropic sheets in 45 -degree lay-up. Each ply is $.13 \mathrm{~mm}$ thick. Some experimental work has been done with $80-\mathrm{gr} / \mathrm{sqm}$ material, but the industry seems to standardize around the $.13-\mathrm{mm}(.005$-in) material. 
Larger sheets are all custom made and the lay-up is specified by the customer, i.e., \pm 60 or other. The larger sheets are typically not as smooth and they are destined for further processing. They have been produced by vacuum bagging rather than by pressing between two hot platens as the smaller sheets are.

To minimize the weight of the panels, it was desired to determine the stiffness and flatness of various lay-ups of peek/carbon fiber composites. Laminates of 3-, 4, and 6-ply laminates were investigated.

The 3-ply configuration exhibited a definite waviness even though the material is theoretically balanced. The 4-ply configuration was warped and the 6-ply configuration was reasonably flat. The key to understanding the observed phenomena is that the material should be flat on a theoretical basis when all plies are truly identical, but this is not the case in practice. When the prepreg material is prepared, the PEEK is most likely not completely and evenly distributed on the front and back of the carbon fibers, causing small discrepancies from the ideal location that result in slight dislocations in the consolidated sheet. If the prepeg orientation is $90 / 0 / 0 / 90$, the individual carbon fibers cannot act upon another and any small location error within the lay-up will not be counteracted as in a 0/-60/+60/+60/-60/0 6-ply lay-up. The flatness of a consolidated sheet will improve with the number of layers of prepeg if the lay-up is balanced. A 6-ply lay-up is the minimum that should be considered for the reflective panel. The final configuration anticipates the use of 0.003 in. prepeg material to reduce the weight of the panels.

There was also a noticeable difference in the stiffness of the panels in the $\mathbf{x}$ and $\mathbf{y}$ direction. This should be expected from basic stress considerations; however, the actual samples demonstrated the differences dramatically. The detailed design of the concentrator must take full advantage of these characteristics. The design of the concentrator and individual components in conjunction with a comprehensive finite element stress analysis will show where high and low strength and stiffness materials are required. The materials can then be custom tailored to meet the specific needs in those areas providing for the lowest possible concentrator weight. In design with conventional materials this is not possible. To provide greater strength or stiffness it was necessary to increase the cross-section or to change the section modulus. This methodology usually had the effect of significantly increasing the weight of structures. Composite materials offer the opportunity to minimize weight by custom tailoring of the material properties. The design is by its nature iterative in that changes in the material composition must be verified by the structural model and further modification may be necessary before the design meets all functional and design requirements.

Of particular interest was a laminate that consisted of six layers of extra fine APC-2 plus a very thin aluminum sheet on each side for environmental protection. A mirror surface would be deposited on the front side of the package by vapor deposition. The total package thickness would be $.50 \mathrm{~mm}\left\{0.020\right.$ inches $\left(6 \times 0.003^{\prime \prime} \mathrm{PEEK} /\right.$ carbon fibers $+2 \mathrm{x}$ $0.001^{\prime \prime}$ aluminum thickness) $\}$. Weight of this panel would be $618 \mathrm{~g} / \mathrm{sqm}$. This weight would allow for some structural elements and still meet the overall program goal. Presently available material of 0.005 -in plies would amount to $1,030 \mathrm{~g} / \mathrm{sqm}$, also satisfying the program goal.

The manufacturing techniques considered for the panels were discussed in section 4.1.2. The techniques will require some relatively costly tooling such as dies and forming tools that have heating and cooling capabilities. High accuracy requirements of the concentrator also contributes to higher costs. Tooling also tends to become more expensive as the size of components increases. This increase in cost is not proportional to size, but rather increases at much higher than proportional rates for larger parts. To minimize this cost, individual panel sizes were designed that limited the panels to a maximum of $3 \times 4 \mathrm{ft}$. These panels would be mounted on frames that would be $4 \mathrm{ft}$ wide and approximately $12 \mathrm{ft}$ long.

Review of forming techniques of the material indicate that accurate forms can be produced with this material. The material is first formed by hot consolidation into the desired shape. A second hot pressing operation in a final "sizing" die is then used to impart the final accurate shape required. The primary difficulty will be in the prediction of thermal distortion due to differential movement of the forming tool and the composite. The errors can be corrected, however, by form iteration. Form iteration is a very expensive method to correct for part imperfections after the form tools have been produced. To date, however, no reliable form prediction algorithm has been developed for the automotive industry that would free this industry from this method to shape automobile parts on the first try. "Springback" and plastic flow in forming dies are extremely complex manufacturing operations that have so far eluded complete prediction. Considering the vast amounts spent on automotive parts forms every year and the fact that this very competitive industry is still using this tried and true, but expensive method, leads us to believe that for this low production effort, this method would also be the best approach. 
Based on the results of these initial investigations a 6-ply PEEK/carbon fiber composite material was chosen for the reflective panels.

The next investigation centered on producing a smooth surface on the base material to provide a base for a highly specular mirror.

\subsection{SURFACE LEVELING AND REFLECTIVE COATING}

Leveling the surface of the panels was known to be a difficult task on composite materials, however, the magnitude of the difficulty was not recognized until much later in the program. It is not certain that a solution can be found that will satisfy the needs for space solar concentrators. From previous work, it was known that front-surface silver reflectors are severely attacked in space by atomic oxygen and reliable protective layers would be required to protect the coating. Micropits in reflecting layers such as silver and aluminum are a fact of life. Atomic oxygen asher tests have shown that these layers are undercut when the substrate is susceptible to atomic oxygen attack. Small pinholes are the initiation sites of corrosion that attack the silver film from the back, growing to unacceptably large areas. Silver was the first choice for its high reflectivity. Additional environmental tests would have to confirm whether a silver coating could be adequately protected from corrosion in the space environment. The second choice is aluminum. It has much higher environmental resistance but offers a lower reflectivity. Any high-quality reflector would require a very smooth surface with a surface roughness not exceeding .5 micron peak to peak. An aluminum sample having a specular reflectivity of 92 percent when measured with a profilometer with a .4 micron radius stylus support this finding. A smoother surface will improve the reflectivity and particularly the specular, angular sensitivity. Figure 10 shows the various surface leveling alternatives and reflector coatings that were tried on this program with varying degrees of success or failure. The surface treatment to smooth the surface applied can be categorized into:

- Hot processing

- Vapor deposition

- Mechanical machining or polishing

- Plating

- Flow coating

Under each major category, variations of the process could be applied.

The following sections describe experiments and results obtained in attempting to level the surface of PEEK/carbon fiber composite samples and apply a reflective coating.

\subsubsection{Hot Processing}

Hot processing of the thermoplastic composite relies on mechanical compression of the sample above the solidus temperature to squeeze hot matrix material to the surface where it is smoothed against a polished surface. A number of different techniques described below were attempted, all of which failed to achieve the desired results. One concept, the "aluminum sandwich," was particularly interesting.

\section{Aluminum Sandwich}

It was learned in the course of the study of alternatives that PEEK/carbon fiber composites are also attacked by the space environment. Atomic oxygen will attack the material and weight losses have been recorded. A composite material that is covered on both sides with a thin aluminum foil would be protected from the environment to a large degree. Furthermore, techniques for leveling an aluminum surface are better understood than applying a leveling coat to a composite material. In this experiment an attempt was made to heat the composite material between two thin aluminum foils and allow the parts to adhere to each other. The front aluminum surface was to serve as the base for the reflective surface and the backside aluminum sheet was to provide protection against atomic oxygen attack. 


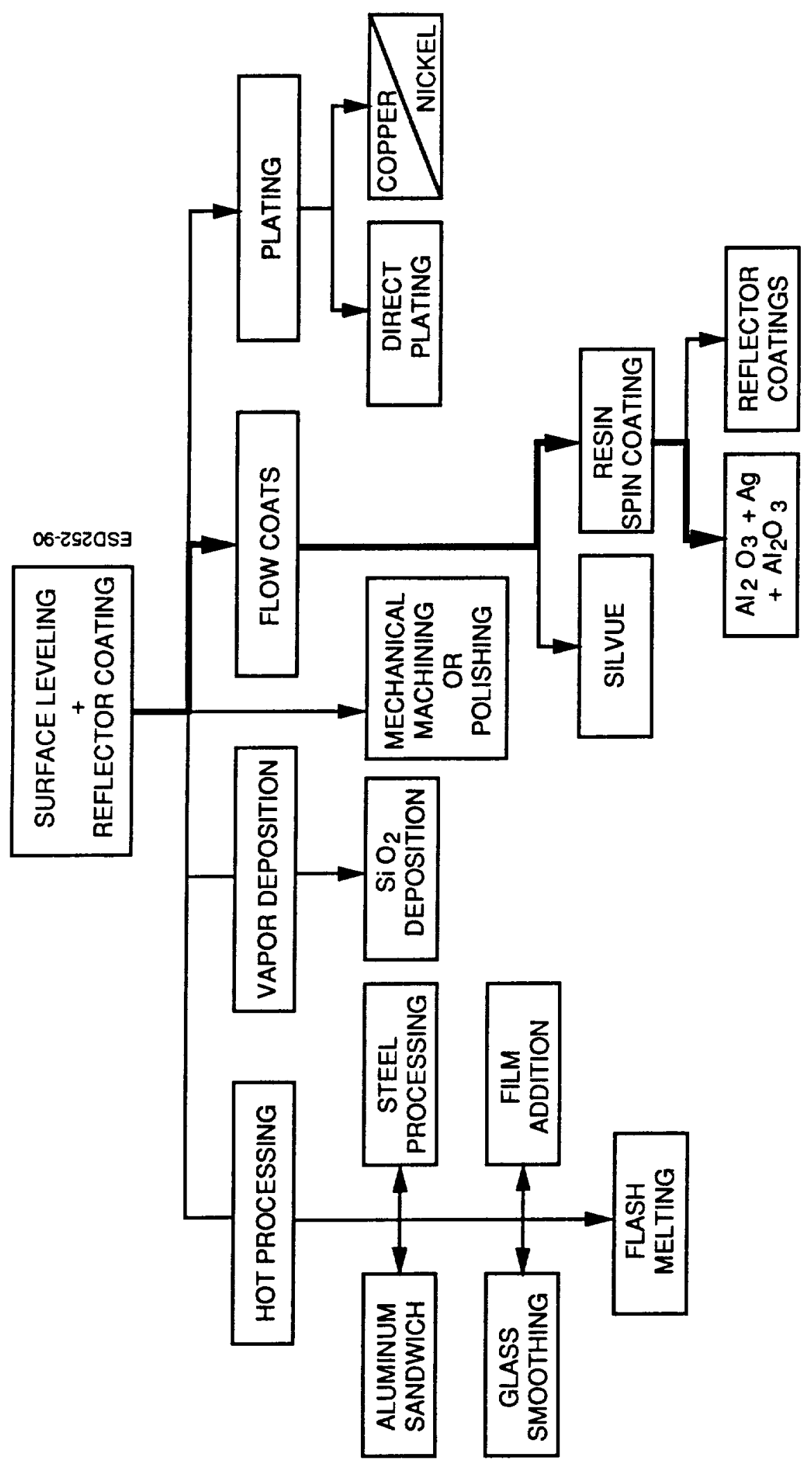

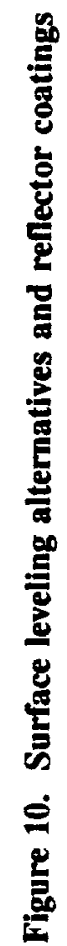


The samples were examined in the oven and it could be seen that some of the PEEK material was squeezing out of the sides of the composite at the edges. When the samples were allowed to cool, "streaks" appeared on the aluminum. The "streaks" were examined in greater detail.

A sample of the PEEK/carbon fiber composite, to which aluminum foil was laminated, was sectioned to study the "streak" phenomenon and to determine if the visible lines on the aluminum were print-through from the carbon fibers. The orientation of the lines was in the same direction as the carbon fibers, but the section did not reveal that the lines were actually caused by print-through. This appears to suggest that the lines may be related to the stress condition to which the aluminum is subjected on cooling from the bonding temperature. The foil used in this experiment was an ordinary household 3000 series aluminum foil. Figures 11 through 14 show the carbon fiber density and the lines in question. The sections also revealed a surprisingly large number of voids between the plies and on the surface of the composite material. A high-quality reflective surface would require that these voids be bridged or filled on the surface to prevent the intrusion of atomic oxygen behind the reflective coating.

An attempt was made to polish the surface of the aluminum to see if a smooth surface could be obtained to which a coating could be applied. Although the surface could be improved substantially, cracks appeared on the surface that suggest the aluminum was failing in tension. This has apparently been observed previously on tubes for space structures developed by the Langley Research Center, whose approach was to use high-strength aluminum such as 7075-T6. This would suggest that foil utilizing 7075-T6 would not exhibit this behavior. The polished sample was also cycled between ice water and boiling water to observe any further degradation. None was observed. The availability of 7075-T6 foil is poor and no tests were planned.

An additional experiment was conducted with a polished sample. The aluminum foil was sandwiched to the composite under pressure in an oven and allowed to cool. The aluminum on one side of the sandwich was lightly polished and the sandwich reheated in the oven to observe the effect. New "streak" marks appeared on the aluminum foil upon cooling. This indicated that the aluminum slipped during the heating process and was subjected to the same stresses as before.

The conclusion reached from this experiment was that any surface layer that is attached to the composite at elevated temperature will show stress marks if the layer is thin and weak. It also showed that the surface of the composite moves substantially upon cooling from the matrix liquid state.

Although this method of attachment of an aluminum foil to the backside of the concentrator panels could be used, it is not suitable to serve as a leveling surface for the reflector. Peel strength of the bond to the aluminum was extremely strong.

\section{Steel and Glass Pressing}

The next experiment performed was the heating of a thermoplastic PEEK/carbon fiber sample between smooth steel sheets to determine if matrix material could be forced to the surface providing a smooth surface.

The following experiments were conducted.

Samples of the PEEK composite were heated to $730^{\circ} \mathrm{F}$ in an oven sandwiched between two glass plates. The glass touched the sample providing for a very smooth surface to which the matrix material could flow. Two steel plates supported the glass on the outside. This assembly was then pressed under temperature to smooth the surface. The surface of the composite did not become smooth, whereas PEEK matrix material bulged out of the center of the material indicating good liquefaction of the matrix. The matrix material did stick to the glass or steel making removal extremely difficult. It is unclear why the matrix material resisted flowing to the surface of the composite wetting the glass forming a smooth surface. In any case, the experiment showed that a release agent is required to prevent the matrix from sticking to the forming plattens. Release agents often contain small particulate matter which may be detrimental to produce a smooth surface, but this could not be confirmed by experiment. 


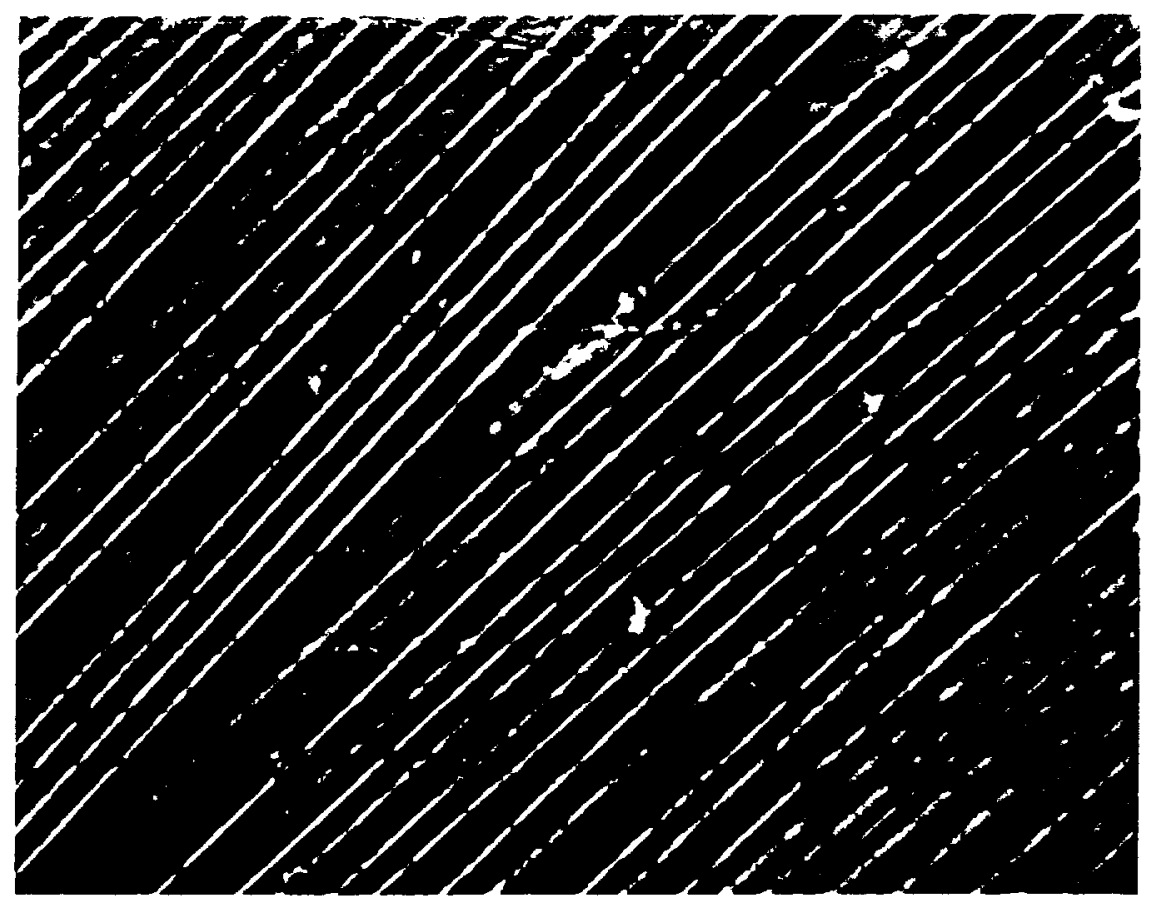

Figure 11. Surface of PEEK/carbon fiber composite showing the orientation and density of carbon fibers (400X)

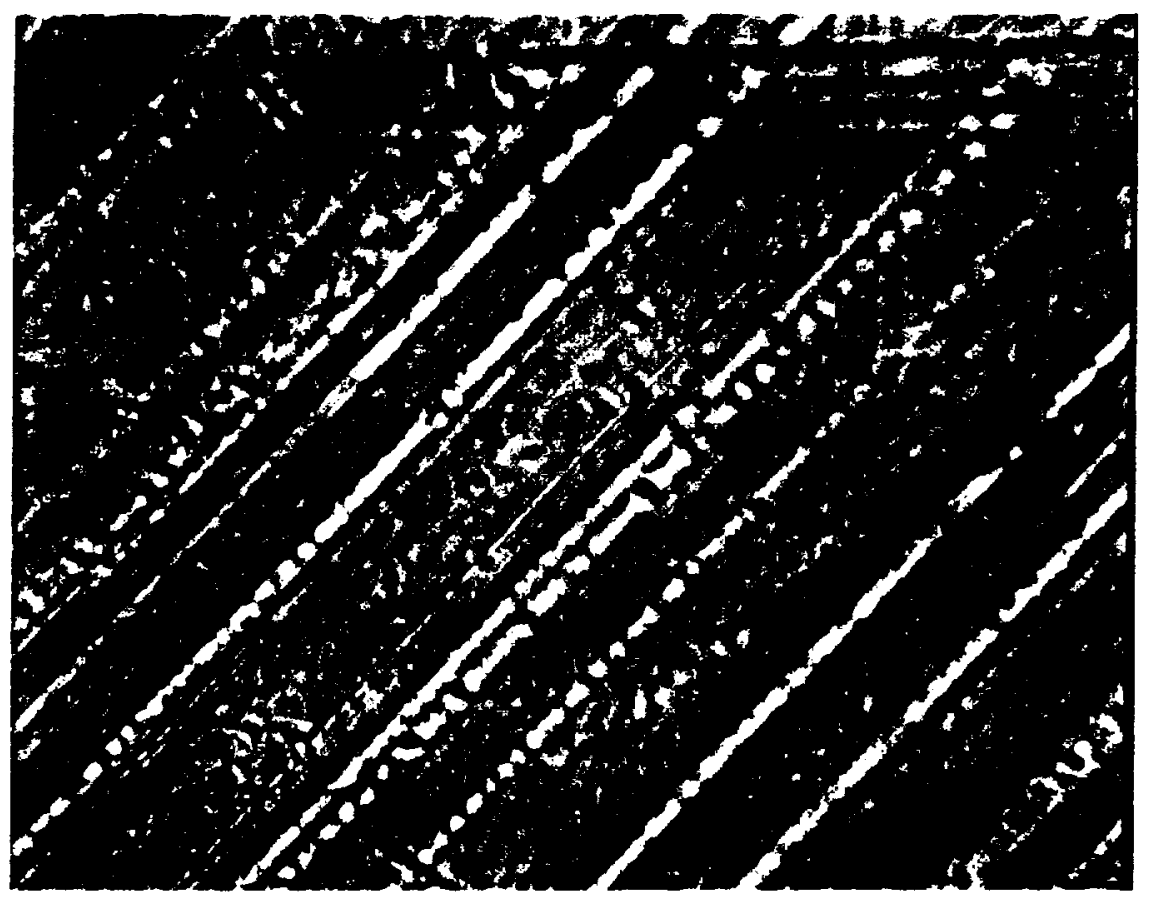

Figure 12. Aluminum surface after lamination to a PEEK/carbon fiber sample (400X) 
- - 


\section{ORIGINAL PMGE}

BLACK AND WHITE PHOTOGRAPH
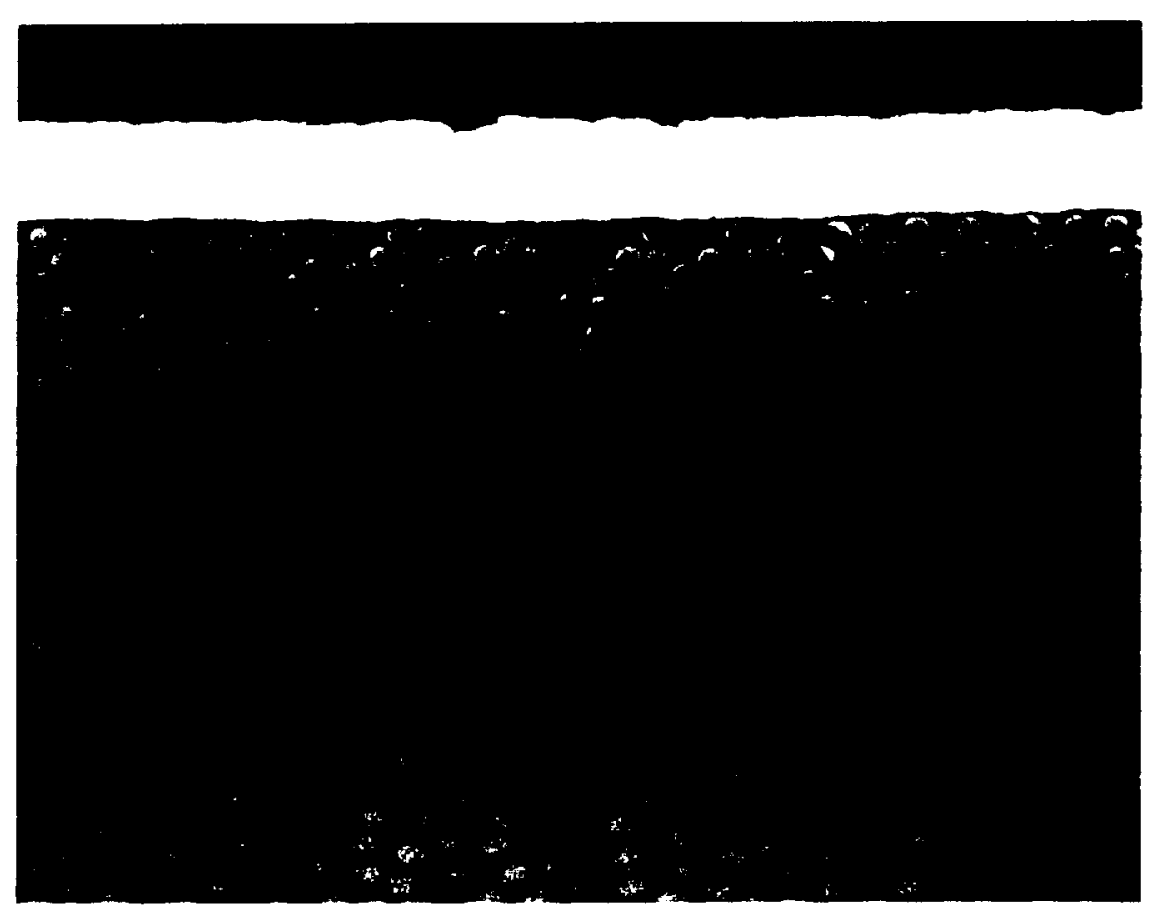

Figure 13. Section of a composite sample showing the aluminum layer, carbon fibers, PEEK, and second layer of carbon nibers $(400 \mathrm{X})$

ORIGINAL PAGE IS OF POOR QUALITY
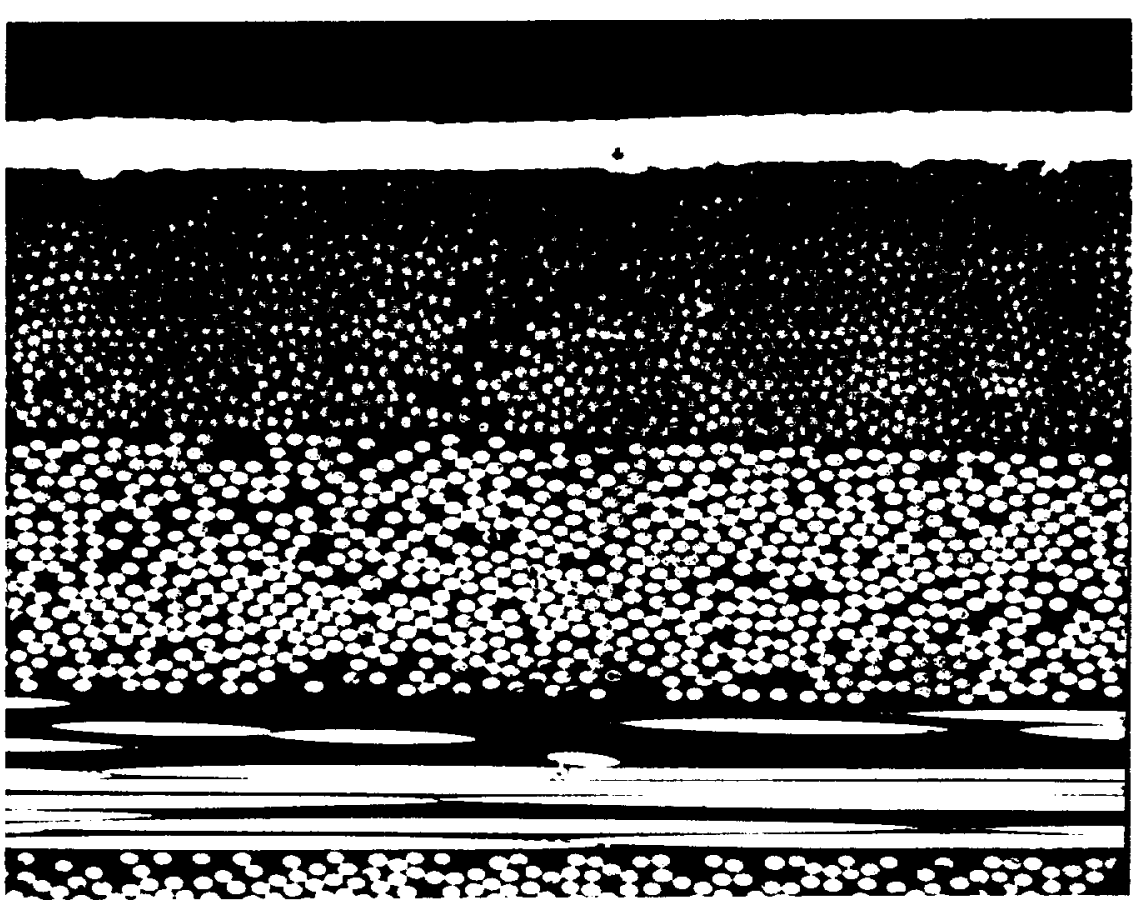

Figure 14. Cross-section of sample showing voids near the surface. Other samples showed similar voids between plies. This appears not be unusual $(200 \mathrm{X})$. 
The experiments carried out so far were relatively simple and inexpensive. To conclude, whether this method of smoothing could work, a four-cavity die was designed and fabricated that would allow accurate control of pressure and temperature.

Flat samples of composite were heated and pressed between smooth Inconel 725 sheets that were coated with Freekote FRP (a release agent recommended by ICl Fiberite). The samples were heated to $730^{\circ} \mathrm{F}$ under pressure of up to 300 psi. The results were essentially the same as before, the surface did not "wet" the Inconel sheets. It was concluded that insufficient PEEK matrix material was on hand in the matrix and that additions of PEEK may be the answer. The release agent appeared to do its job and permitted the removal of the samples from the Inconel sheet material, if properly applied uniformly over the entire surface.

A disadvantage of this manufacturing procedure would be the high compression forces required for smoothing at elevated temperature when large parts are produced.

\section{Steel and Glass Pressing with Film Addition}

It was concluded that the hot pressing of thermoplastic composite samples did not yield the desired results. The reason for the failure was believed to be the lack of sufficient PEEK matrix material on the surface of the composite base material. A 2-mil PEEK film was procured to add to the composite on one side for smoothing. This film was to fill the gaps between fibers. The same four-cavity tool was used as before to conduct these experiments. The surface produced was not smoother than the earlier samples as had been expected. Again the same phenomenon as with the aluminum sheet was observed. "Streaks" or lines formed on the surface of the composite. In some areas on the sample the process appeared successful whereas on others it was not. The surface topology of the samples produced were carefully examined to reach definitive conclusions.

The samples were sheared into smaller pieces, mounted on a scanning electron microscope (SEM) holder, and coated with approximately $500 \AA$ of gold by sputtering at $10^{-3}$ torr. The samples were analyzed in the SEM up to 10,000 $\mathbf{x}$ magnification from the top, at an angle, and from the cross section. The cross sectional view provided information about the composite bulk matrix and also the contour of the surface.

To obtain qualitative measurements of the surface, macroscopic $(200 \mu \mathrm{m})$ and microscopic $(100 \mu \mathrm{m})$ traces were taken using a contact surface profilometer. The macroscopic data indicated the surface roughness and also the level of warpage of the sample. The microscopic data indicated only the topology of the samples. Several traces of data were recorded of each sample and a best fit of the analyzed data was plotted. The delta height difference between the highest and lowest point was recorded. This is called the TIR value. The trace indicated the greatest unevenness of the surface for the area surveyed.

The following observation were made:

- The topology of the as-supplied (control) PEEK sample is uniform and contains the fewest irregularities. The hot-pressed samples had the most irregularities and the hot-pressing did not appear to have planarized the sample. The PEEK was pressed between embedded fibers and hence the surface planarity was not improved. The film-coated samples appeared to be the smoothest in the SEMs but the film had stability problems as it was reacting to the E-beam and was delaminating during examination.

- The SEM cross section of the control samples indicated uniform distribution of the carbon fibers in the PEEK matrix. But the hot-pressed samples were severely delaminated and the carbon fibers were no longer uniformly distributed. The film-coated sample, was also delaminated at several places, even though the surface was very smooth.

- The macroscopic profile test indicate that the control sample was the least warped and had a TIR value between 3 and $4 \mu \mathrm{m}$. Both sides of the PEEK sample had similar TIR values. The hot-pressed samples had equivalent results both in horizontal and vertical directions, but the overall surface unevenness was large - between 4 and $6 \mu \mathrm{m}$. The film-coated and hot-pressed 
samples were warped and it was difficult to obtain reasonable readings on the macroscopic level. The unevenness was on the order of $7 \mu \mathrm{m}$ for the film-coated samples.

- The microscopic study of the samples revealed the degree of surface roughness, without the effect of warpage. The control sample had a roughness TIR value of $1.2 \mu \mathrm{m}$, while the hotpressed samples had a roughness of about $1.5 \mu \mathrm{m}$. The hot-pressed samples were not improved by this method of planarization. The film-coated samples were smooth and had the lowest TIR value, about $0.5 \mu \mathrm{m}$. The stability and the delamination problems of the PEEK film needed to be solved. This method did not produce the desired results. It appeared that an adequately smooth surface could not be produced for a space reflector by this method.

\section{Flash Melting}

A process that had been considered was "flash melting." This process was not tried because it appeared that the basic problem of thermal distortion during thermal cycling would be present even if the surface would be perfectly smooth at a set temperature. Flash melting leaves the main structure of the composite cold and only melts the surface. This process has been used in the semiconductor industry and is commonly referred to as Rapid Thermal Anneal or Flash Anneal process. Tungsten halogen lamps are used to provide the radiation heat source to local areas of interest to be heated. In the flash melting process, the 2 -mil film would have been melted onto the surface. Various temperature time combinations would have to be tested to develop the combination yielding the best results.

\subsubsection{Vapor Deposition}

Another approach tested to level the surface was by E-Beam deposition of $\mathrm{SiO}_{2}$. The results of this work showed that leveling by this method does not necessarily improve with deposition thickness. A certain leveling is achieved beyond which no further improvement is obtained. The coating is very brittle, however, as thickness is increased. It should be expected that cracking will occur in a thermo-cyclic environment.

The objective of the tests performed were to determine if $\mathrm{SiO}_{2}$ of varying thicknesses applied to PEEK/carbon fiber composite samples could level the surface and this coating would have proper adhesion. Fifteen samples of the basic 60/0/60 layup 6-ply material were prepared.

Earlier SEM and surface profile work performed on the as-received PEEK samples indicated that the surface roughness of the samples was approximately in the range of 5 to $7 \mu \mathrm{m}$. Of the several methods available to deposit $\mathrm{SiO}_{2}$ E-Beam evaporation was chosen, since it provides for the lowest deposition thickness possible. E-Beam evaporation of $\mathrm{SiO}_{2}$ was chosen, since this process produces $\mathrm{SiO}_{2}$ with a very low thermal expansion coefficient that is chemically and mechanically stable. The liquid spin-on approach was not investigated for this experiment. Chemical vapor deposition deposits film easily but does not usually achieve the desired planarization desired. E-Beam deposition was also chosen because it can achieve high deposition rates. When compared to sputtered films E-Beam deposition is less conformal and has greater ability to fill up voids for the same film thickness. The theoretical analysis done with the E-Beam deposition conditions indicated that $10 \mu \mathrm{m}$ of $\mathrm{SiO}_{2}$ film would be necessary to planarize the PEEK samples with an average surface roughness of approximately $5 \mu \mathrm{m}$.

The substrates were first degreased in a vapor of trichloroethylene followed with a rinse in an ultrasonic bath in isopropyl alcohol and deionized water. This was followed by an in-situ plasma clean prior to deposition.

To ensure the adhesion of $\mathrm{SiO}_{2}$ on the PEEK sample would be adequate a quick trial deposition of approximately $2 \mu \mathrm{m}$ thickness was carried out. The film appeared to adhere well, but when subjected to a Scotch tape adhesion test failed. The film peeled off in certain areas. Research revealed that on plastic based substrates, the adhesion of $\mathrm{SiO}_{2}$ is often enhanced by a thin layer of Titanium (Ti) as an adhesion promoter. A $500 \AA \mathrm{Ti}$ adhesion promoter was therefore applied prior to the deposition of $\mathrm{SiO}_{2}$. The following process was used:

- Load the precleaned samples into the E-Beam system

- Load the Ti and silicon source

- Pump down to $4 \times 10^{-6}$ Torr with heat of $150^{\circ} \mathrm{C}$ 
- Plasma clean to burn the surface organics

- Evaporate and deposit $500 \AA$ of $\mathrm{Ti}$

- Bleed $\mathrm{O}_{2}$ into the chamber to $5 \times 10^{-5}$ Torr

- Deposit $\mathrm{SiO}_{2}$ at $1000 \AA / \mathrm{min}$ deposition rate

- Monitor the thickness with an Inficon quartz crystal monitor

The E-Beam system was a Varian Planetary system. The samples were mounted on a concave platform and were rotated approximately at $15 \mathrm{rpm}$ during deposition. The pumpdown time to base pressure of $4 \times 10^{-6}$ was approximately $4 \mathrm{hrs}$ and the ambient temperature was maintained at $150^{\circ} \mathrm{C}$ to ensure proper outgassing and low stress in the film. The two trial samples for adhesion were not reused. The fifteen fresh clean samples were deposited with $500 \AA$ of Ti followed by $8 \mu \mathrm{m}$ of $\mathrm{SiO}_{2}$. The $\mathrm{SiO}_{2}$ was formed by evaporating $\mathrm{Si}$ and reacting it with $\mathrm{O}_{2}$ in the evaporation chamber. The stoichiometry may not have been exactly correct. This technique of deposition provides a high deposition rate and poor conformality (better planarization). The deposition rate was between 900 and $1000 \AA / \mathrm{min}$ and thus required 80 minutes.

The samples were unloaded, inspected, and five samples reloaded for an additional coating of $3.5 \mu \mathrm{m}$ of $\mathrm{SiO}_{2}$. This provided a total thickness of $\mathrm{SiO}_{2}$ on five samples of 11 to $12 \mu \mathrm{m}$. The thickness was added to evaluate the improvement in planarity with increasing thickness.

The samples were subsequently annealed at $200^{\circ} \mathrm{C}$ for 3 to $4 \mathrm{hrs}$ in an oven to relieve film stresses that build up during deposition. Thick films $(8$ to $11 \mu \mathrm{m})$ often have high internal stresses that are best relieved immediately after processing. Even if the adhesion is quite good these stresses can be larger causing adhesion failure. High stresses can also arise from the mismatch of thermal expansion coefficients with the substrate. In this case, no such symptoms were observed.

The film was evaluated for adhesion by the Sebastian adhesion test system. An aluminum stub is attached to the surface of the film with an epoxy. The stub is then pulled until the epoxy or the film interface fail. The epoxy started to fail in this case near $10^{6}$ psi. No film lifting was observed by Scotch tape peeling.

To obtain qualitative measurements of the surface macroscopic and microscopic surface profilometer traces were taken. Results of these measurements were as follows:

- Control Peek samples

- $8 \mu \mathrm{m} \mathrm{SiO}{ }_{2}$ on PEEK

- $8 \mu \mathrm{m} \mathrm{SiO} \mathrm{S}_{2}$ on PEEK

- $11 \mu \mathrm{m} \mathrm{SiO}{ }_{2}$ on PEEK
$1000 \mu \mathrm{m}$ trace horizontally and vertically. This sample had no $\mathrm{SiO}_{2}$ deposition.

$1000 \mu \mathrm{m}$ trace horizontally and vertically, on two samples $100 \mu \mathrm{m}$ horizontally and vertically, on two samples $1000 \mu \mathrm{m}$ trace horizontally and vertically, on two samples.

The control sample with no $\mathrm{SiO}_{2}$ had an average surface roughness of approximately $4.8 \mu \mathrm{m}$. This was consistent with the measurements made earlier. The samples with $8 \mu \mathrm{m} \mathrm{SiO}$ deposition indicated a significant improvement in surface roughness. Macroscopically (including warpage) the TIR value improved to an average value of $1.9 \mu \mathrm{m}$ and as low as $1.4 \mu \mathrm{m}$. On the microscale, which measures the peaks and valleys over a very small area the indicated average surface roughness was $0.65 \mu \mathrm{m}$. The samples with $11 \mu \mathrm{m}$ of $\mathrm{SiO}_{2}$ did not indicate any further improvement over the $8 \mu \mathrm{m}$ samples. The average surface roughness was approximately $1.7 \mu \mathrm{m}$ on a $1000 \mu \mathrm{m} \mathrm{scan}$. Figure 15 shows the results of these measurements.

The goal to develop a coating for the PEEK composite which is optically flat and has good thermal and mechanical properties appears not achievable by this type of E-Beam coating. Good adhesion was achieved and some leveling. The surface roughness of the substrate was greatly improved to $1 \mu \mathrm{m}$ from the 3 to $5 \mu \mathrm{m}$ range. This improvement in the surface quality is not sufficient to achieve a specular reflectance of 90 to 95 percent, however. It was therefore concluded that smoothing by E-Beam evaporation would not meet the goals of this project. 


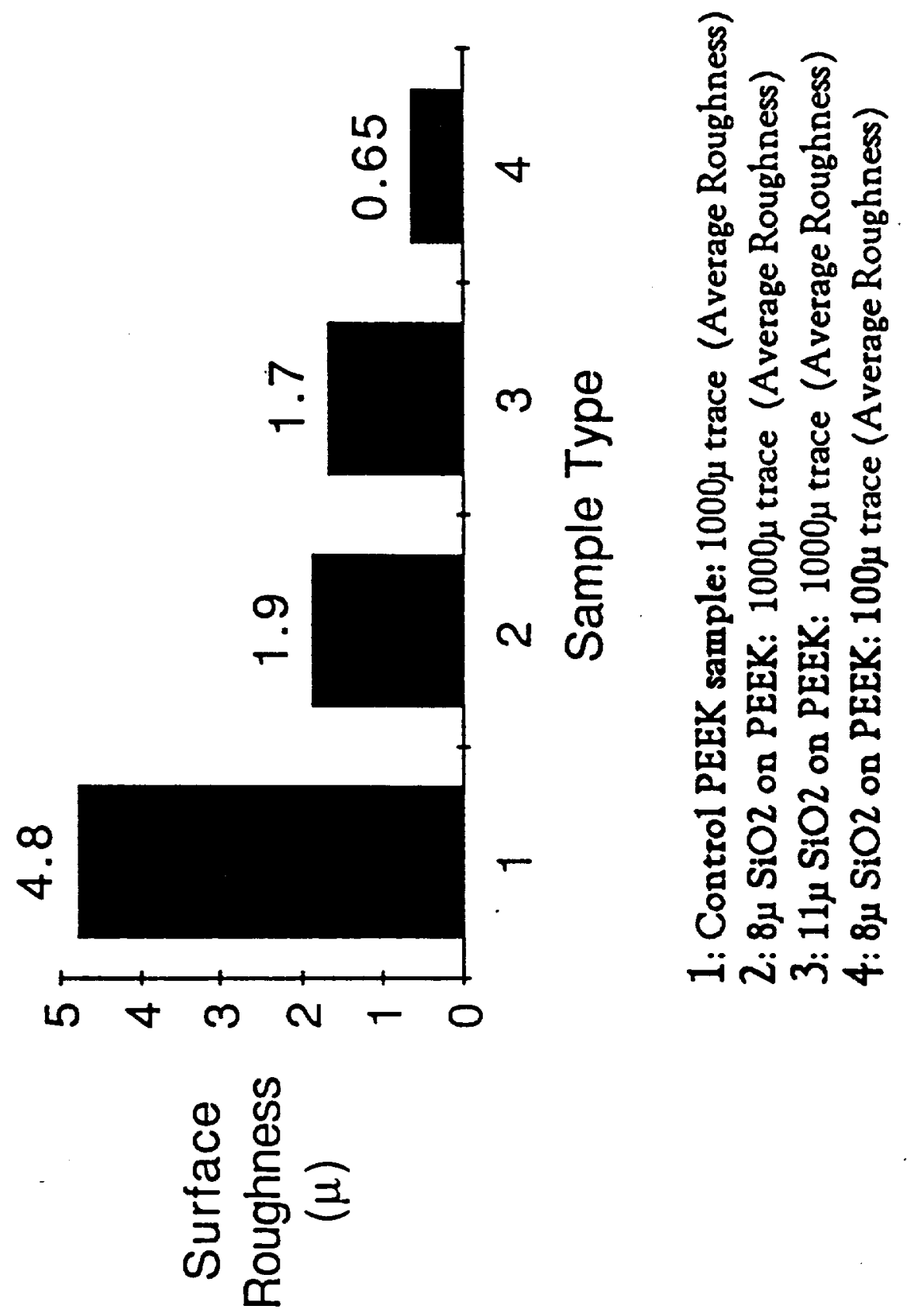




\subsubsection{Mechanical Machining and Polishing}

Several fairly simple attempts were made to machine or polish the composite. The results of these attempts were poor. When the carbon fibers are exposed they tend to fray, achieving exactly the opposite of the desired effect.

Machining of an aluminum surface, on the other hand, may have merit. Acurex obtained a diamond machined aluminum sample from Bryant Symons \& Co., Ltd. of Hodesdon, England. The sample was approximately $5 \mathrm{~cm}(2 \mathrm{in})$ $\times 5 \mathrm{~cm}(2 \mathrm{in}) \times 1.57 \mathrm{~mm}(.062 \mathrm{in})$ and had a surface roughness of 0.4 micron. The specular surface reflectivity was measured at Acurex and showed that this sample had a 92 percent reflectivity through a $15 \mathrm{mr}$ aperture. The instrument used for these measurements was a Portable Specular Relectometer, Model 15R manufactured by Devices \& Services Co. of Dallas, Texas. No protective layer had been applied to this sample.

An attempt was made to protect the aluminum sample by anodizing. Anodizing revealed some unexpected results. The surface apparently contained a significant amount of "smear" metal that was pushed into the machining grooves. This "smear" metal was removed during the short cleaning process showing the machining marks rendering the surface diffuse after coating.

This type of technology to produce a reflector could potentially serve the space program well, provided the base material is sufficiently light in weight. The thrust of this program was to investigate carbon composite materials and no further attempts were made to pursue this manufacturing technology. It appears that reflectors that are machined will require relatively thick substrates which may result in unacceptably high weight reflector panels.

\subsubsection{Plating}

It was learned during the course of the investigation that nickel undercoatings commonly used on chrome-plated parts serve as a leveling undercoat. Attempts were made to duplicate such a coating on the thermoplastic as an undercoat for a reflective surface.

The technique being investigated was the application of a bright nickel plate directly onto the substrate. This method failed to achieve a satisfactorily smooth coating. The coating was of variable thickness, resulting in a rough surface with many pin holes in locations where the conductivity of the substrate was poor. It is believed that this was caused by variable surface electrical conductance from point to point due to alternating surface areas of fiber and matrix material. The carbon fibers are highly conductive, while the PEEK is essentially non-conductive.

A second set of samples was prepared for nickel plating by the deposition of a flash copper coat by sputtering. The samples were first cleaned by a plasma etch and a copper flash coat of 1000 Angstrom was applied. The adhesion of the copper flash coating was not sufficient during the nickel plating process to permit adhesion. Initial samples cleaned by the standard cleaning techniques lost their entire flash copper coat. Subsequent samples were only rinsed and plated. The nickel coating was porous. This suggested that a thicker copper flash coating may be required. The coating did not adhere strongly and this method was therefore dismissed.

\subsubsection{Flow Coatings}

Two flow coatings were investigated for application on the thermoplastic composite. They were Silvue $\otimes_{200}$ and Polyim $^{\mathrm{TM}}$. Silvue 200 is a hard abrasion resistant coating often applied to plastic lenses on glasses. Since this coating is relatively thin at 3 to 5 micron, it was dismissed since the minimum coating thickness expected for this application was 10 to 15 micron.

Polyimides are manufactured by a number of manufacturers for a variety of purposes. For this experiment desired properties were:

- Good leveling capability

- Stability

- Low thermal expansion 
- Good adhesion

- Ease of use and low cost

An experiment was designed to determine if this material may be suitable for this application. The objective was specifically to:

Spin and coat Polyim ${ }^{\mathrm{TM}}$ of varying thickness on the samples of PEEK/Carbon fiber composite and identify the process to attain proper adhesion and leveling. Properties of Polyim ${ }^{\mathrm{TM}}$ are shown in Appendix B.

The samples selected were $60 / 0 / 60$ layup of PEEK/Carbon fiber composites, 6-ply with $0.127 \mathrm{~mm} / \mathrm{ply}$ $(.005 \mathrm{in} / \mathrm{ply}), 7.62 \mathrm{~cm} \times 7.62 \mathrm{~cm}(3 \mathrm{in} \times 3 \mathrm{in})$ square samples, 15 each.

The procedure that was followed in the experiment was to determine the correct speed of spin and proper amount of Polyim dispensed on the sample by varying the process conditions.

The substrates were first degreased in a vapor of trichloroethelyne followed with a rinse in an ultrasonic bath of isopropyl alcohol and deionized water to obtain a clean surface prior to deposition. The polyimide products have superior adhesion to metal, plastic, and inorganic substrates provided the interface is free of dust and other commonly absorbed contaminants. An adhesion promoter was not used in this experiment. Common adhesion promoters are HMDS (Hexamethyl disulphide) or APX-K1. HMDS is not compatible with Polyimides, however.

From previous measurements it was determined that a minimum thickness of the film should be at least $15 \mu \mathrm{m}$. The thickness range might be as high as $40 \mu \mathrm{m}$. The ability to cure the film without inducing severe tensile stress (due to loss of solvent) was a major concern. The proper viscosity of the solution also had to be prepared so that it could be dispensed and coated uniformly by spinning using commercially available spin tracks. The viscosity of the selected Polyimide $\mathrm{P}-18 / 19$ was approximately 70 poise at $37.8^{\circ} \mathrm{C}$.

The coating was applied in a Clean Room (Class 10) using a commercially available coating machine, manufactured by SVG Corporation. The pre-cleaned PEEK samples were mounted on the vacuum chuck and $3.5-4 \mathrm{~mL}$ of P-18 was dispensed while the sample was spun at a low rpm. After dispensing the rpm was increased to the specified speed (1000 to 1350) and held there for $60 \mathrm{sec}$. This ensured adequate solvent removal from the film which also prevents flowing during the curing process.

Several dispensing and speed variations had to be tested to attain the correct combination of speed and dispense rate. For these samples the following values resulted in the indicated film thicknesses.

$1000 \mathrm{rpm}$ resulted in $16 \mu \mathrm{m}$ film thickness

$1350 \mathrm{rpm}$ resulted in $13 \mu \mathrm{m}$ film thickness

To attain greater film thicknesses it was necessary to spin and apply Polyim several times. The samples were first soft cured after the first and intermediate spins and were completely cured after the last spin.

The most critical step in the process is the cure process. The purpose of the cure is to completely cure and imidize the film to limit outgassing and to stabilize the film mechanically and chemically. At the same time it is important to minimize the induced stresses to prevent the development of microcracks or voids due to rapid evaporation of the solvents. The cure was performed in three stages.

The first stage of the cure was performed on the track with substrate heating from below the sample. Substrate heating insures that the surface of the film does not harden before all the solvents are driven out. This prevents void formation. This step was performed at $100^{\circ} \mathrm{C}$ for $5 \mathrm{~min}$.

The second stage was also performed on the track. The temperature was increased to $160^{\circ} \mathrm{C}$ for 5 min.

The third and final stage was curing the samples in a Blue-M oven at $275^{\circ} \mathrm{C}$ for $40 \mathrm{~min}$. The purpose of this bake was the imidization of the film by chemically eliminating the water molecules and altering the chemical structure. This 
is also called the beta-stage bake. The enclosed data sheets in Appendix B show the effects of bake conditions. At the process conditions the selected film is expected to be imidized more than 97 percent.

A Sebastian adhesion test was performed to determine the mechanical integrity of the film. An aluminum stub was attached to the surface of the film with an epoxy. The stub was then pulled until the epoxy or the film failed at the interface. The epoxy in this case started to fail near $70,307 \mathrm{~kg} / \mathrm{cm}^{2}\left(10^{6} \mathrm{psi}\right)$. The adhesion test showed that the strength is at least $70,307 \mathrm{~kg} / \mathrm{cm}^{2}\left(10^{6} \mathrm{psi}\right)$. No film lifting was observed by Scotch tape peeling.

The following samples were prepared:

- Number 1 to 2

- Number 3 to 5

- Number 6 to 10

- Number 11 to 15
Used for characterization and process optimization

$16 \mu \mathrm{m}(1$ coat at $1,000 \mathrm{rpm})$

$26 \mu \mathrm{m}$ ( 2 coats at $1350 \mathrm{rpm}, 2$ soft bakes and 1 beta-bake)

$32 \mu \mathrm{m}$ ( 2 coats at $1000 \mathrm{rpm}, 2$ soft bakes and 1 beta-bake)

The following results were observed:

The samples were very slightly warped, but this appeared not to be a problem. The actual panels would have some curvature and would counteract the compressive forces of the film. The surface appeared shiny and smooth, however, it was difficult to assess the quality of the top surface since the film is transparent. It was conjected that a high specular reflectance surface would result if a reflective coating was applied to this surface. It was decided to coat these samples with a reflective coating to determine the actual quality of the reflective surface with this type of undercoating.

\subsection{REFLECTOR COATING}

Acurex performed a great deal of research in the development of front surface mirrors in prior programs. The most successful reflective coating including surface protection was a sputtered silicon dioxide or aluminum trioxide coating applied below and above the silver reflective coating. These coatings served as passivating films on top of the silver. Whether one of these coatings would be acceptable for service in space would have to be determined in future environmental tests. An aluminum oxide coating system was applied on top of the Polyim leveled samples. The following procedure was used and results achieved.

The basic material was a $60 / 0 / 60$ layup PEEK/carbon fiber composite, 6 ply with 0.0005 -in/ply, 3-in by 3 -in square sample. Ten composite samples with the sample numbers scribed on the back, as $4,5,7,8,9,10,11,12,13$, and 14 , were previously coated with various thicknesses of Polyimide P-18 and baked. The samples were preprocessed as follows:

- Numbers 4, 5: $16 \mu \mathrm{m}$ (1 coat at $1000 \mathrm{rpm}$ )

- Numbers 7-10: $26 \mu \mathrm{m}$ (2 coats at $1350 \mathrm{rpm}, 2$ soft bakes and $1 \beta$ bake)

- Numbers 11-14: $32 \mu \mathrm{m}$ ( 2 coats at $1000 \mathrm{rpm}, 2$ soft bakes and $1 \beta$ bake)

The ten composite samples were then processed as follows:

- Degrease and clean samples

- E-Beam $\mathrm{Al}_{2} \mathrm{O}_{3}+\mathrm{Ag}+\mathrm{Al}_{2} \mathrm{O}_{3}$ films of thickness $500 \AA+1200 \AA+500 \AA$-all samples

- E-Beam $\mathrm{SiO}_{2}$ film thickness $9000 \AA-10,000 \AA$ on samples-Sample Nos. 5, 9, 10, 13, and 14

- Perform analytical tests to determine:

- Adhesion

- Thickness

Precleaning was done to ensure proper adhesion of the subsequent films on the substrate. The cleaning sequence prior to evaporation of silver was as follows: 
- Rinse in DI water

- Wash with mild detergent

- Rinse with iso-propyl-alcohol

- Dry with nitrogen gun

- Spray with IPA and gradually pull from vapor

The deposition process used was Electron Beam evaporation because the process can use high-purity elements and can be performed under high vacuum, free of contamination to ensure maximum reflectivity. The sources for evaporation were pure $\mathrm{Ag}$ (99.999 percent pure) and grown sapphire crushed in liquid nitrogen for $\mathrm{Al}_{2} \mathrm{O}_{3}$. The deposition was performed sequentially without unloading the sample. The source was flash-evaporated by electron beam while the samples were mounted and rotated in a planetary system to ensure uniform thickness. The deposition was done at a temperature of $60^{\circ} \mathrm{C}$ and under a vacuum of $1-5 \times 10-5$ torr. Total cycle time was 150 minutes.

The thickness of the three layers was precisely calculated to provide maximum reflectance at the middle of the visible radiation spectrum, which is the yellow-green portion of the spectrum at Lambda $=5500 \AA$. Assuming that the refractive index of $\mathrm{Al}_{2} \mathrm{O}_{3}$ is 1.7 and that of $\mathrm{Ag}$ is 2.0, based on the relation of quarter wavelength:

$$
T=A / 4 \times N 1 / N 2=1563 A \text { of } A L_{2} O_{3}
$$

The thickness of $\mathrm{Al}_{2} \mathrm{O}_{3}$ was maintained around $1550 \pm 100 \AA$ in thickness of both the top and bottom layers to ensure destructive interference for maximum reflectivity. The bottom layer was kept the same for consistency purposes. The thickness of the Ag fill is more critical from a metallurgical standpoint than an optical one. Thick film can give rise to intrinsic stress and eventual cracking.

The thickness of the Ag layer was maintained at about $1100 \pm 100 \AA$. The thickness measurements were done in situ by optical interference measurement through a window. This measurement was periodically calibrated using a piezoelectric quartz crystal.

The deposition of $\mathrm{SiO}_{2}$ film on the samples as described above on top of the silver was provided to protect the $\mathrm{Ag}$ film from environmental degradation. The $\mathrm{SiO}_{2}$ film was also deposited by electron beam evaporation in a similar chamber. The source used was ultra-pure Silicon in an environment of oxygen with high partial pressure. The refractive index of the $\mathrm{SiO}_{2}$ film was calibrated to be at 1.46. The thickness of the film was $9500 \mathrm{~A}$.

Since the mechanical integrity of the films is of utmost importance, the films were evaluated for adhesion. No film lifting was observed by Scotch tape peeling.

The ultimate objective of this experiment was to obtain a high specular reflectance on the sample in the range of 95 percent or better. At the same time the reflector had to withstand environmental attack especially from atomic oxygen.

The specular reflectivity of the samples appeared high and all samples were shiny. The underlying PEEK carbon fiber was still visible, however. This meant that the surface was close to being flat, but was not optically flat. Samples 10 , 11 , and 12 were measured for their reflectivity with a portable specular reflectometer. Results of these measurements are shown in Table 2. Measured Specular Reflectance Values. The samples were compared to stainless steel and a low iron glass $3 \mathrm{~mm}$ thick glass solar mirror produced by Flabeck of Germany. The data shows that the reflectivity through a 25 $\mathrm{mR}$ orifice is near $\mathbf{8 0}$ percent, but that it falls off dramatically as the orifice is decreased in size. This can be attributed to the "waviness" that could be seen on the samples that appeared to be due to the carbon fibers. Although these samples represent the best that were produced they are not suitable for application directly. The process developed so far is promising, but better results must be achieved. The mechanical integrity of the film appeared very good. No failure due to adhesion or stress-cracking has been observed. The process would have to be optimized as far as the deposition of Polyimide is concerned. The viscosity and the thickness of Polyimide P-18 will have to be tailored in subsequent experiments to achieve higher planarity. It might be required to use Polyimide of two viscosities. A film with high viscosity should be used first to achieve some level of planarity and fill out the gaps between the carbon fibers. A film of low viscosity should then be applied to attain optical flatness. This would require a one-time process optimization and would not increase the manufacturing cost in production on a larger scale. 
No process problem was observed with the silver and aluminum oxide samples, but the $\mathrm{SiO}_{2}$ film deposition was not very successful. Minor crazing was observed in the $\mathrm{SiO}_{2}$ films. This happened probably due to high tensile stresses in the film. The film stress can be lowered by altering the deposition conditions. Alternate methods of application of this film such as sputtering or chemical vapor deposition may be the answer. Environmental tests would have to indicate whether such a film is required to protect the silver from degradation or whether a silver coating is applicable at all.

Sample nine was overheated in the deposition chamber during $\mathrm{SiO}_{2}$ deposition due to a loading problem and a rainbow effect was observed on the sample.

Environmental tests should be performed on these samples to determine the reliability and durability of this coating method prior to further work to achieve an optically flat surface. At this point, this coating offers the greatest promise of achieving an optically flat and reliable surface on a PEEK/carbon fiber composite base material.

Table 2. Measured specular reflectance values

\begin{tabular}{|l|c|c|c|}
\hline \multirow{2}{*}{ Sample Number } & \multicolumn{3}{|c|}{ Reflectance Through Orifice } \\
\cline { 2 - 4 } & $\mathbf{8 ~} \mathbf{~ R}$ & $\mathbf{1 4} \mathbf{~ m R}$ & $\mathbf{2 5} \mathbf{~ m R}$ \\
\hline 10 & 20.6 & 43.8 & 78.4 \\
11 & 19.5 & 40.4 & 77.1 \\
12 & 17.0 & 37.4 & 75.4 \\
Stainless Steel & 39.9 & 40.6 & 41.6 \\
Flabeck low iron glass reflector 3 mm thick & 95.9 & 96.4 & 96.4 \\
\hline
\end{tabular}

Instrument used: Portable specular reflectometer; Devices and Services Company; Model 15R, Serial \#021 



\section{SECTION 5 \\ CONCLUSION}

A concept for a self-deployable, high-performance parabolic concentrator for advanced solar-dynamic power systems was developed. The system allows for power ranges of 25 to $75 \mathrm{~kW}$. As the power systems become larger, it becomes more and more difficult to maintain the peak performance requirements set. Very high contour accuracies are required to achieve and maintain the specification efficiencies. The accuracy requirements impose ever increasing cost penalties on the system. Although cost was not a specific part of this study it is difficult to ignore the cost questions that arise when manufacturing feasibility is considered. The concentrator was therefore configured to take maximum advantage of existing manufacturing capabilities in this country. A system trade-off will eventually have to be performed to determine the optimum cost $/ \mathrm{kWh}$ delivered in space.

Recent experience with photovoltaic solar collectors have shown that vibrations, can be set up in systems due to thermal movements of components when the collectors move from the sun to shade location. A dish concentrating collector may not be able to tolerate such vibrations and provide the necessary concentrating accuracies necessary to function safely.

Parabolic dish concentrators must be dealt with very carefully. The "sunspot" and heat fluxes in the focal point area can be very dangerous and proper operation strategies must be adopted for safe operation in space. Of particular concern is the "acquisition" and "de-acquisition" sequence of the sun. "Acquisition and deacquisition" in this context means the placement of the sun spot or "fire ball" into the receiver cavity from a defocussed position. Terrestrial concentrators require high "slew" speeds to pass the "fire ball" over the receiver face plate and bring the concentrator to a rapid stop to prevent face plate damage. This concentrator was designed to allow the "de-acquisition" along the axis of the collector without incurring substantial moments on the dish. The sun-spot is also defocussed as the receiver moves out of position a feature not included in any terrestrial collector.

Development of the reflective surface was the most challenging problem on this project. It could not be shown, unfortunately, that the final reflector sample produced will be sufficient to satisfy the needs of a space concentrator and there is some question whether a composite material as the base material can ever serve in this role. Composite materials present some very special problems to the reflector designer due to their nonhomogeous nature.

An unexpected result of the work performed is the conclusion that it may not be possible to produce a highly specular surface on a non-homogeneous surface such as a composite material that is to be utilized in a thermo-cyclic environment, because of micro movements of the matrix material and fibers. The matrix material has a coefficient of thermal expansion (CTE) that is opposite of that for the carbon fibers. The matrix may expand while the fibers shrink. This relative movement sets up internal material stresses that result in stress patterns on the surface that change with temperature even though the macroscopic dimensions of the part (with a near-zero CTE) do not. These micro movements preclude an optically flat surface if the temperature varies. At one temperature the matrix material will be bulging and at another it will be thinning giving rise to the appearance of "lines" on the surface. This phenomena was partly observed when parts were removed from a hot oven and appeared smooth only to show "lines" when they had cooled. It is possible that the non-specularity that was observed on the last samples produced was enhanced by the annealing process which provides for stress relieve. This stress relieve was achieved at elevated temperature and may have introduced some nonspecularity. A curing process at the use temperature is clearly favored.

Silver was used as the primary reflective coating, however, aluminum was always considered as a backup reflective coating if environmental requirements could not be met with a silver coating. 
The specular reflectivity of the samples produced was near 80 percent through a $25 \mathrm{mR}$ orifice. The specularity fell rapidly for smaller orifice sizes showing that the goal had not been achieved. The underlying PEEK carbon fibers were still visible through the reflective coating. This means that the surface was close to being flat, but was not optically flat. The process developed shows promise and has yielded the best results. The reflectivity of the samples is good but must be improved significantly to satisfy the needs of a concentrator. The mechanical integrity of the films was very good. No failure due to adhesion has been seen. Some stress cracking was observed in the $\mathrm{SiO}_{2}$ layer, but this problem had been observed on other front surface mirrors produced for terrestrial applications and this problem can be overcome much more easily than the leveling guestion. If this coating were pursued further it would be necessary to optimize the deposition of Polyimide. The viscosity and the thickness of Polyimide P-18 will have to be tailored in subsequent experiments to achieve higher planarity. It might be required to use Polyimides of two viscosities. A film with high viscosity to achieve some level of planarity and fill out the gaps between the carbon fibers may have to be deposited first. Secondly, a film of Polyimide with low viscosity may have to be used to attain optical flatness. This will require a one-time process optimization.

No process problems were observed with the silver and aluminum oxide sample. The $\mathrm{SiO}_{2}$ film deposition was not very successful. Minor crazing was observed in the $\mathrm{SiO}_{2}$ films. This has been observed previously and is probably due to high tensile stresses in the film. The film stress can be lowered by altering the deposition conditions. It is possible that a sputtered film or a chemically vapor deposited film must be applied in place of an evaporated film. Environmental tests will indicate if such a film is required to protect the silver from degradation.

It is recommended that environmental tests be performed on these samples to determine the reliability and durability of this polyimide + silver + aluminum oxide + silicon dioxide film. At this point this is the best solution utilizing a PEEK/carbon fiber base material for a space concentrator reflector although much work remains to be done. 
APPENDIX A

PRELIMINARY DEVELOPMENT SPECIFICATION FOR A DEPLOYABLE, HIGH-PERFORMANCE, LONG-LIFE DISH CONCENTRATOR FOR ADVANCED SOLAR DYNAMIC POWER SYSTEMS FOR LEO, GEO, AND POLAR ORBIT APPLICATIONS

Acurex Project 8087 

TABLE OF CONTENTS

Section

Page

1

SCOPE

1

2 GENERAL REQUIREMENTS

1

2.1 Environmental Requirements .................... 2

2.1.1 Launch Requirements ......................... 2

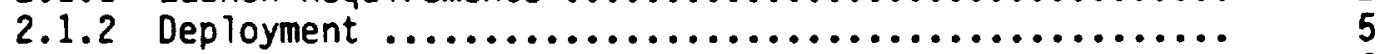

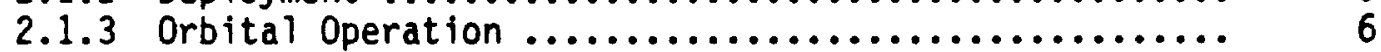

2.1.4 Atomospheric Environmental Requirements ............. 9

2.1 .5 Solar Constant ............................... 11

3 POWER SYSTEM REQUIREMENTS (DPSC) $\ldots \ldots \ldots \ldots \ldots \ldots \ldots \ldots \ldots \ldots \ldots$

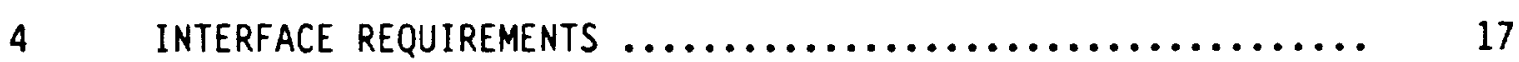

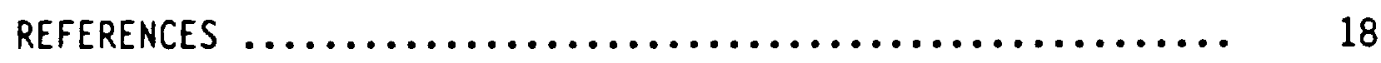



1. SCOPE

This specification establishes the design requirements, goals and definition of terms for the conceptual design of a deployable, high performance, long-life dish concentrator for advanced solar dynamic power systems for LOE, GEO and polar orbit applications.

The goal of the program is to develop a conceptual design for a concentrator that has wide applications, can be scaled for various sizes without major basic design modifications, has a high solar to electric conversion efficiency and offers a long operational life.

To insure that available resources are effectively deployed, high risk areas such as the materials from which the concentrator will be built shall be researched first to permit definition of appropriate design and methodologies.

NASA Lewis will provide the various receiver/engine parameters, such as weight, geometrical dimensions, aperture size and configuration as well as space station or satellite attachment configurations and load limits.

The conceptual design to be generated shall consist of drawings, sketches and narrative descriptions for the concentrator package/dispenser, concentrator, receiver/engine support system, reflective panels and the deployment methodology.

2. GENERAL REQUIREMENTS

The requirements for the advanced solar dynamic power systems concentrator (DPSC) can be categorized into:

- Environmental and

- Power system requirements

Environmental requirements deal with the terrestrial, launch and orbital conditions the DPSC will be exposed to that are imposed on the design. 
The power system requirements are those design goals that have been found to be beneficial for the program and in general have the effect of greater economy for the overall program. In this category are requirements for method of deployment, reliability, and performance. Additionaliy, interface characteristics for "other" system components will be defined.

\subsection{Environmental Requirements}

The DPSC shall survive and be fully serviceable after having been exposed to the respective terrestrial, launch and orbital environment during fabrication, ground check out, assembly, transportation and handling of pressure, temperature, acoustical, vibrational and cyclic loads and the atomospheric environment. Many of these criteria have been developed previously for other power system designs and these criteria have been adopted here as preliminary requirements.

\subsubsection{Launch Requirements}

\subsubsection{Configuration (Reference 1)}

The DPSC shall fit within the Shuttle bay dynamic envelope and allow required air movement in and out of the bay. Additionally, it must be possible to install required ground equipment handling mechanisms.

The module must stay within the Shuttle cargo bay longitudinal center of gravity envelope (Reference 2). Module attachments to the Shuttle orbiter should be compatible with the location and load capability of the orbiter attachments and/or cradle installation. The attachments should provide access for removal of the DPSC by means of the remote maneuvering system (RMS) in orbit. 


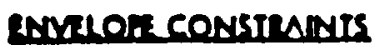

- 4.58 m DL OTNAMK ENVLLOR

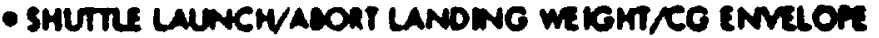

- 14. a max pariono car lenoth

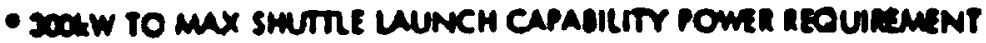

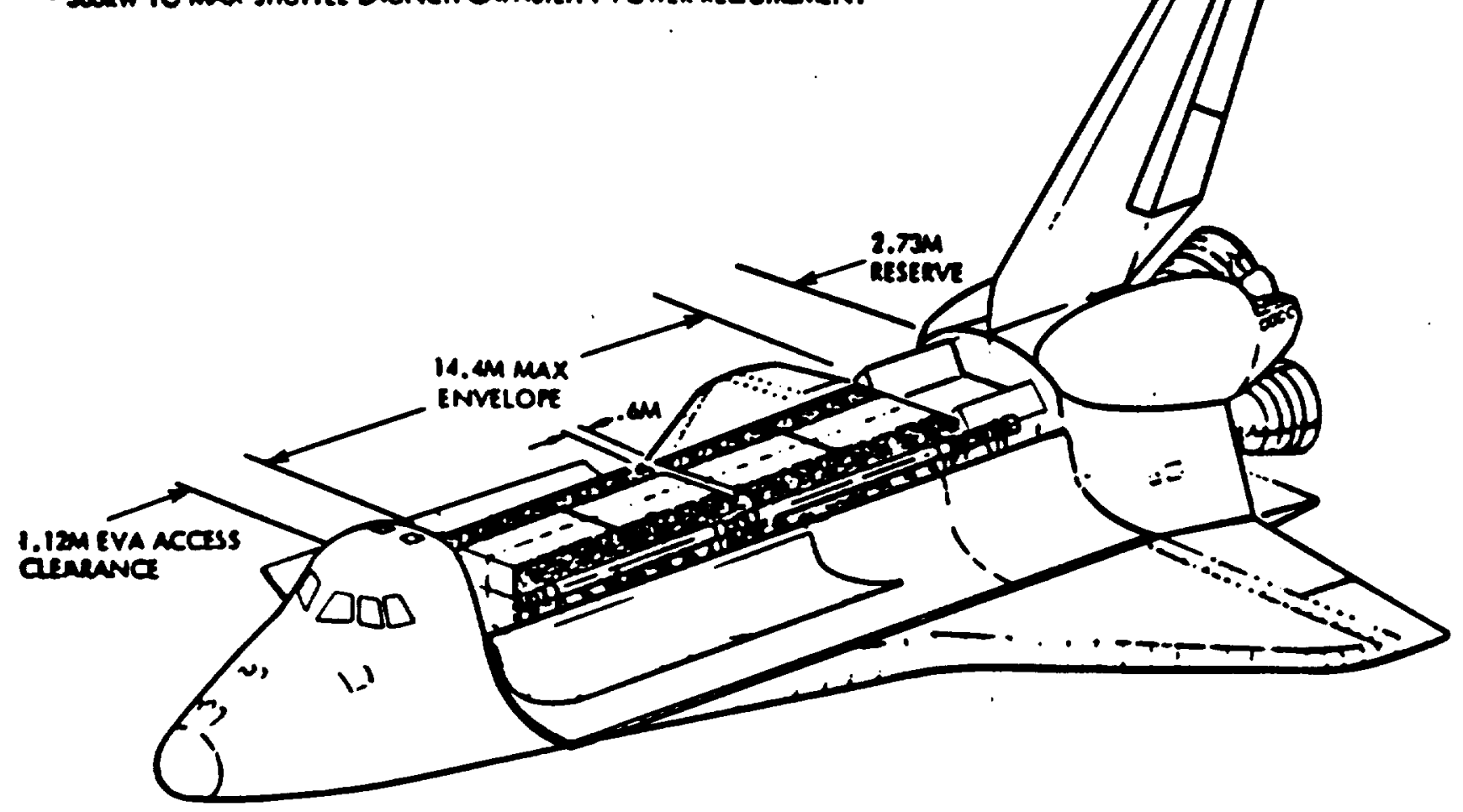

Figure 1. Modularity for Shuttle Compatibility

\subsubsection{Static Loads}

The critical load factors listed in Table 1 will be used to determine the Shuttle launch-induced loads. The landing load factors are included to provide for the possibility of mission abort-induced return and landing. The structure shall withstand a differential pressure of $3450 \mathrm{Nm}^{-2}$ (0.50 psi). 
Table 1. Systems Requirements for Structural Design (Launch Phase)

- STS (Orbiter) compatibility

- Orbiter cargo bay dynamic envelope

- Quasi-steady state flight loads -- acceleration in g's

- Boost environment $+2 \quad \pm 3 \quad \pm 5$

$N_{X} \star$ (axial) $N_{Y} \star$ (yaw) $N_{Z} \star$ (pitch)

$-5$

$+1.8$

$\pm 1.5$

$+4.2$

- Landing

$-2.0$

$-1.0$

*Load Factors in Orbiter coordinates. 


\subsubsection{Dynamic Loads}

The solar concentrator module must survive the Shuttle cargo bay acoustic environment (decibels versus frequency) given by the dotted line of Figure 2 (taken from Reference 2) This curve represents the recommended environment based on STS-1 through STS-4 flight data. The stowed solar concentrator module shall have a minimum modal frequency of $9.0 \mathrm{~Hz}$.

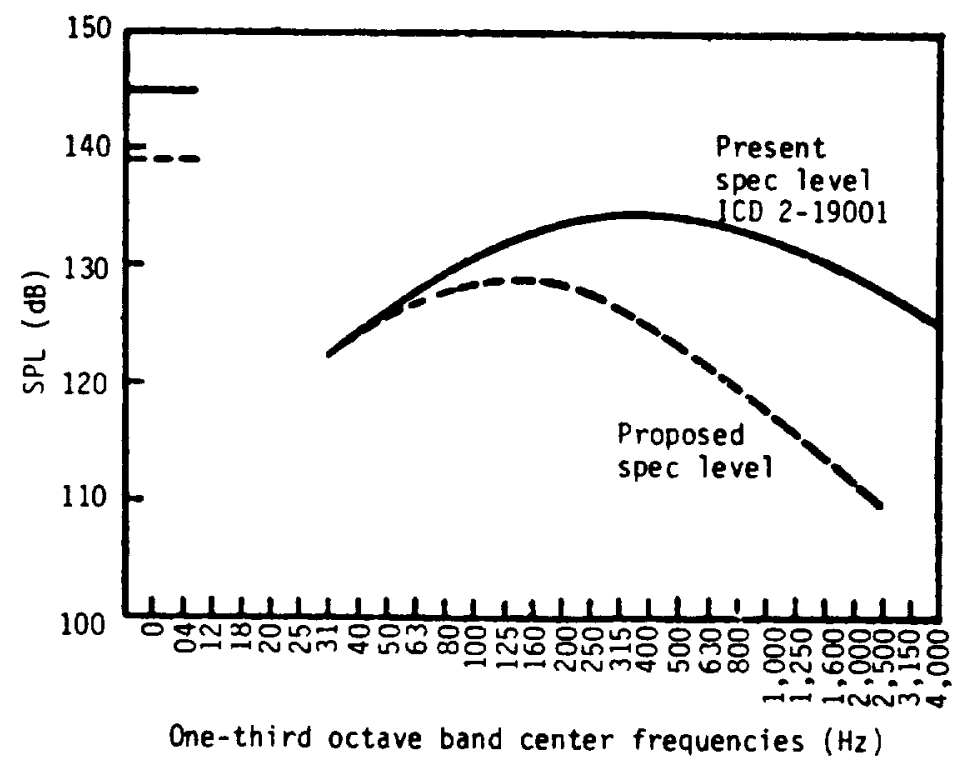

Figure 2. Revised Empty Payload Bay Acoustic Criteria for Lift-off

\subsubsection{Thermal Environment}

The thermal behavior is determined by the closed-door environment, the Shuttle bay, as modelled by the simplified Payload/Orbiter Thermal Simulator (SPORTS model) (Reference 3).

\subsubsection{Electrical Environment}

It is assumed that the module will be electrically inert during launch.

\subsubsection{Deployment}

This phase includes:

1. The detachment and removal of the DPSC from the orbiter's cargo bay and attachement to the satellite, or space station. 
2. Articulation and deployment of the module containers, and

3. Extension of individual concentrator elements and the power module.

The attachement interface will have provisions for soft docking of the concentrator. The attachment interface will also have provisions for structural attachment, transmission of power to the spacecraft, and two axis articulation of the concentrator to maintain pointing toward the sun to within \pm 0.3 degrees. Electrical power for deployment and extension of the solar concentrator module will be provided by either Shuttle or user spacecraft.

\subsubsection{Static Loads}

Static loads during this phase are assumed to be no greater than static loads during orbital operation.

\subsubsection{Dynamic Loads}

The structural attachments to the payload bay must provide for controlled release and removal of the DPSC. The rate of extension of the components and release rates for concentrator structural components shall not impose loads in excess of the launch and orbital operations capability.

\subsubsection{Thermal Environment}

The open-door environment of the Shuttle bay will be simulated by the SPORTS model during the early portion of the deployment phase.

\subsubsection{Electrical Environment}

The concentrator will be protected from electrical transients.

\subsubsection{Orbital Operation}

The concentrator module shall be designed to keep life-cycle energy costs low for satellites and the space station. Modularity is a major consideration in developing an acceptable design concept that can be used for a wide range of power needs of future satellites. General system requirements are tabulated in Table 2 and discussed below. 
Table 2. System Requirements for Orbital Operations

- Orbit of 500-600 km (introduces launch site and inclination restrictions)

- Attitude control

-- Stationkeeping acceleration ranges from $0.001 \mathrm{~g}$ to $0.01 \mathrm{~g}$

-- Control system frequency separation of at least one decade

- Thermal loading (not to exceed $\pm 1^{\circ}$ average in pointing error)

- Concentrator orientation (not to exceed $\pm 0.3^{\circ}$ in pointing error)

- Atmospheric drag $\left(4.3 \times 10^{-4} \mathrm{~N} / \mathrm{m}^{2}\right)$

- Solar pressure $\left(4.5 \times 10^{-6} \mathrm{~N} / \mathrm{m}^{2}\right.$ in GEO)

- Gravity gradient $\left(7.3 \times 10^{-5} \mathrm{~N} / \mathrm{m}^{2}\right)$ 


\subsubsection{Static Load}

The DPSC, housing and concentrator element subsystems shall sustain the loads associated with atmospheric drag, gravity gradient and solar pressure within acceptable deformation tolerances. The primary altitude range for orbital operation is assumed to be 500 to $600 \mathrm{~km}$. Acceptable deformation is defined as that which maintains concentrator performance under the combined influence of mechanical loads, thermal stresses and pointing errors for the concentrator as a whole.

\subsubsection{Dynamic Loads}

The attachment of the concentrator to the user spacecraft will result in the transfer of dynamic perturbations of two types, namely spacecraft pointing and station keeping and Shuttle docking maneuvers. To provide adequate frequency separation between the concentrator and the spacecraft control system, a minimum modal frequency (cantilevered from the user spacecraft interface) of $0.037 \mathrm{~Hz}$ is required.

\subsubsection{Thermal Environment}

In addition to direct solar load, the concentrator will be exposed to Earth emission and albedo. Global annual average values of 237 watts $\mathrm{m}^{-2}$ and 0.3 , respectively, shall be used to evaluate Earth radiation effects on the design. Orbit inclination values between 28.5 and 57 degrees shall be assumed to evaluate eclipse duration, irradiation fluence levels. Thermal interaction between concentrator and spacecraft is assumed to be second order and will be ignored due to lack of specific knowlege about spacecraft geometry and thermal characteristics. 


\subsubsection{Electrical Environment}

It is assumed that the solar concentrator delivers power to a spacecraft bus at a voltage between 150 and 300 volts.

\subsubsection{Atmospheric Environmental Requirements}

The atmospheric environment of low earth orbit (LEO) places the most severe hazards to the long term survivability of large mirrors in space compared to geosynchronous (GEO) or polar orbit requirements. Atomic oxygen is the dominant chemical constituent between 200 and $650 \mathrm{~km}$ altitude. Both aluminum and silver are very susceptible to oxidation and must be protected from attack (Reference 4).

The goal of the program is to design a DPSC with an operational life of 15 years in LEO, GEO, or polar orbit with a maximum efficiency degradation at the end of the life of 10 percent.

In addition to atomic oxygen attack, the effects of ultraviolet radiation, thermal cycling due to earth shading, electron and proton radiation, micrometeorites and space debris shall be accounted for in the design. Materials used shall be tested in simulated space environments to verify suitability if performance characteristics are not known.

\subsubsection{Atomic Oxygen (LEO)}

Figure 3 (Reference 5) shows the concentration of atomic oxygen as the primary chemical constituent at the primary altitude of interest. The kinetic energy of the impacting species is approximately $5 \mathrm{eV}$ for oxygen and approximately $100 \mathrm{eV}$ for nitrogen. Organic films showed significant recession rates in the range of 2 to $3 \times 10^{-24} \mathrm{~cm}^{3}$ /atom (Reference 5). $\mathrm{SiO}_{2}$ films show promise in reducing the attack. Pinholes cause significant degradation in the surrounding area under tested coatings. Pinholes must be controlled during manufacture and effects due to micrometeorites determined. 


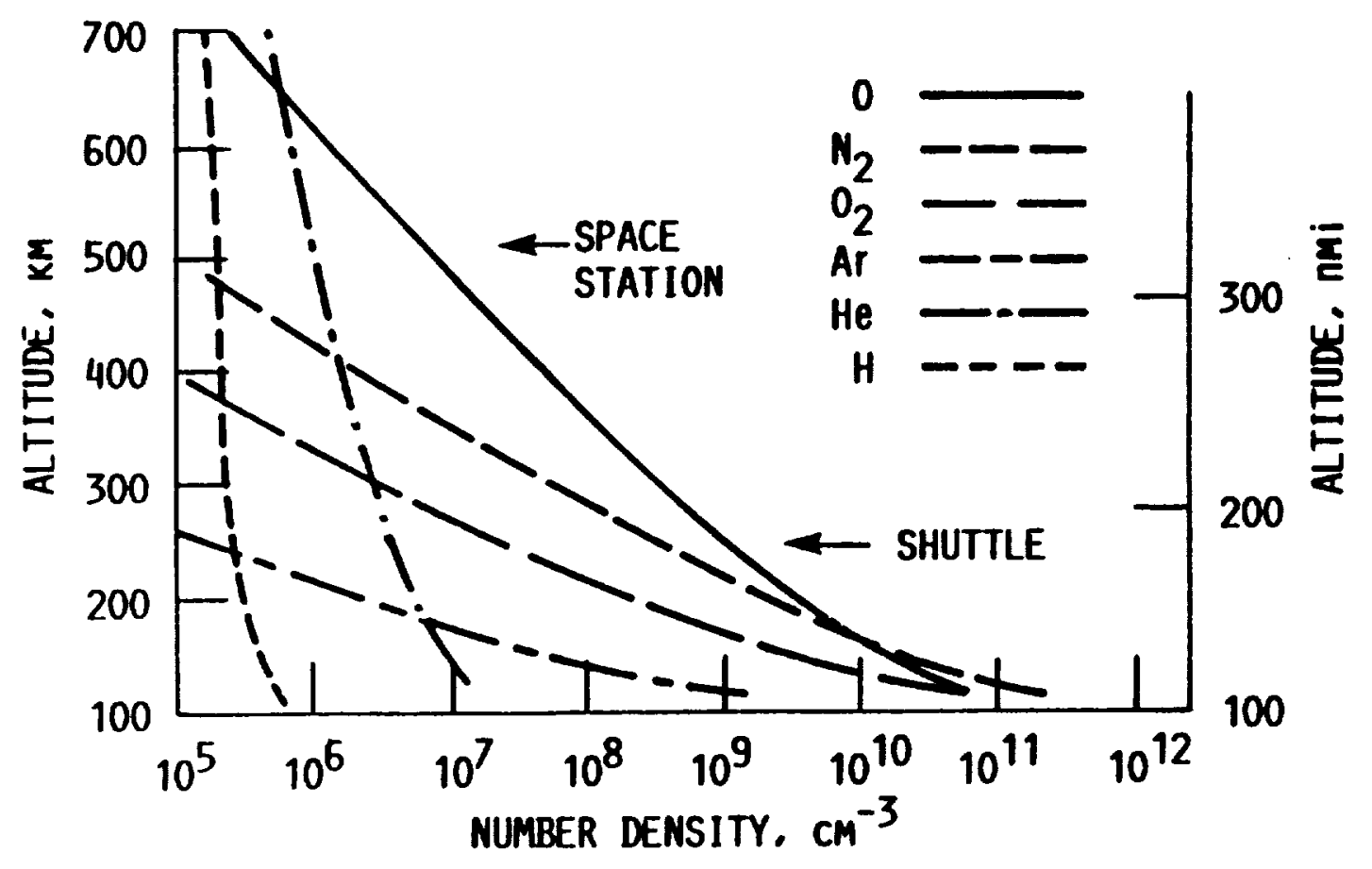

Figure 3. Atmospheric Composition 


\subsubsection{Utraviolet Radiation}

Radiation in the ultraviolet region is shown in Figure 4 (Reference 6) $(\lambda<.38 \mu \mathrm{m})$ a long with data for the visible range $(.38 \mu \mathrm{M}<\lambda<.78 \mu \mathrm{m})$ and the infrared $(\lambda<.78 \mu \mathrm{m})$ portions of the spectrum. Table 4 shows the numerical values for $.115 \mu \mathrm{m}<\lambda<50 \mu \mathrm{m}$.

\subsubsection{Thermal Cycling}

The DPSC components will be subjected to significant thermal cycling due to earth shading.

A temperature range of $\pm 200^{\circ} \mathrm{F}$ should be expected (Reference 4).

\subsubsection{Electron and Proton Radiation}

TBS

\subsubsection{Micrometeorites and Space Debris}

Flight data from the Pegasus $A$ and $B$ and Solar Max Missions provide some information as to the frequency of micrometeorite impacts at 300 to 465 nautical mile and 280 to 300 nautical mile altitudes respectively (see Figures 5 and 6 ). From this information predicted reflector damage can be derived (see Figure 7) (Reference 4).

\subsubsection{Solar Constant}

For purposes of solar performance calculations the solar constant shall be assumed fixed in intensity per unit time and unit area of surface perpendicular to the radiation. The new standard value proposed by Thekaekara and Drummond (1971) of $1,353 \mathrm{~W} / \mathrm{m}^{2}$ shall be used (Reference 8 ). 3. POWER SYSTEM REQUIREMENTS (DPSC)

The deployable, high performance, long life dish concentrator for advanced solar dynamic power systems shall be designed to satisfy all requirements for the manufacture, assembly, packaging, deployment and service 


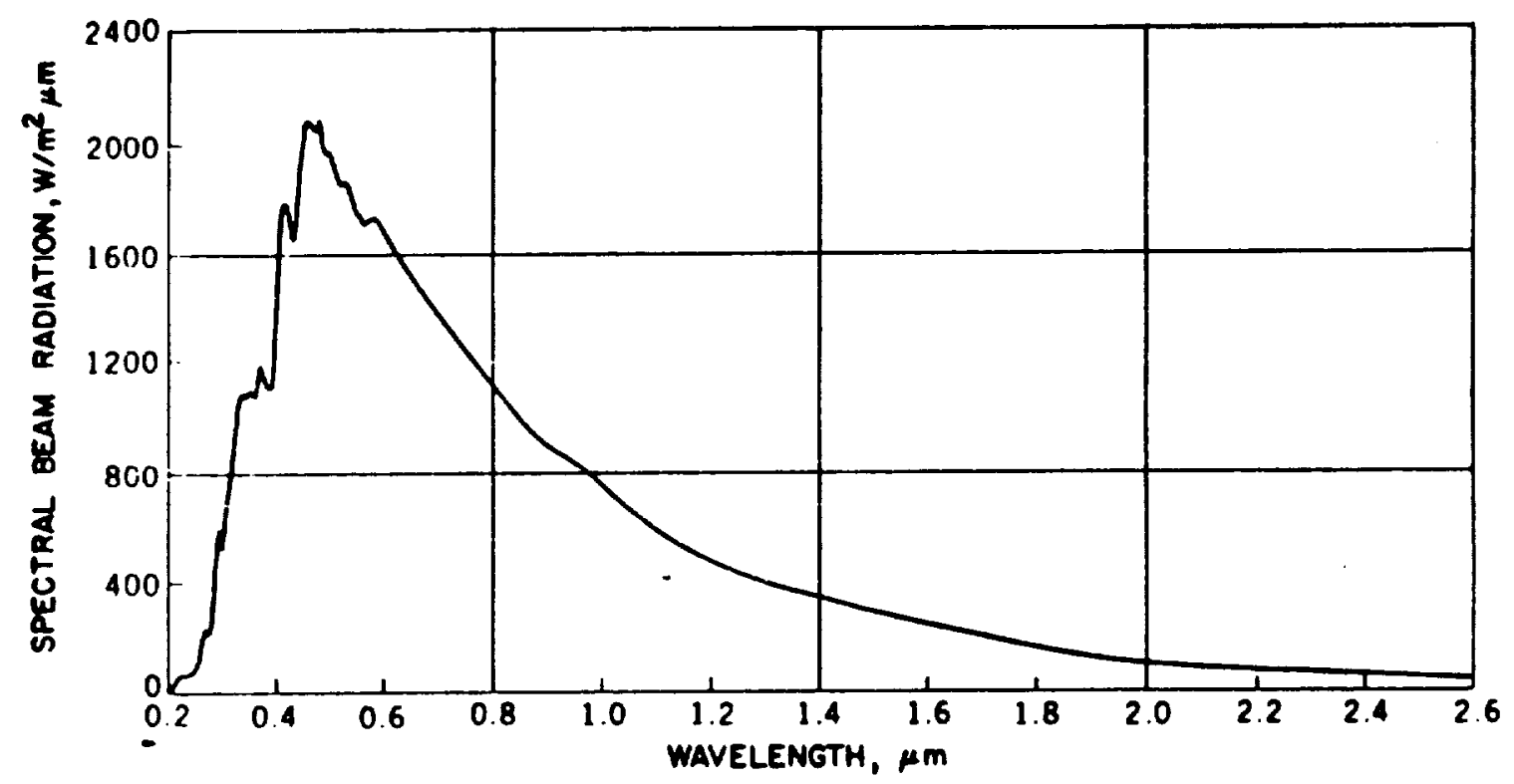

Figure 4. The NASA (1971) Standard spectral irradiance at the mean sunearth distance and a solar constant of $1353 \mathrm{~W} / \mathrm{m}^{2}$ 
Table 4. Extraterrestrial Solar Irradiance (Solar Constant $=1353$ $\left.w / m^{2}\right)(\text { Reference } 7)^{a}$

\begin{tabular}{|c|c|c|c|c|c|c|c|c|}
\hline$\lambda$ & $E_{\lambda}$ & $D_{\lambda}$ & $\lambda$ & $E_{\lambda}$ & $D_{\lambda}$ & $\lambda$ & $E_{\lambda}$ & $D_{\lambda}$ \\
\hline $\begin{array}{l}0.115 \\
0.14 \\
0.16 \\
0.18 \\
0.20 \\
0.22 \\
0.23 \\
0.24 \\
0.25 \\
0.26 \\
0.27 \\
0.28 \\
0.29 \\
0.30 \\
0.31 \\
0.32 \\
0.33 \\
0.34 \\
0.35 \\
0.36 \\
0.37 \\
0.38 \\
0.39 \\
0.40 \\
0.41 \\
0.42\end{array}$ & $\begin{array}{c}.007 \\
.03 \\
.23 \\
1.25 \\
10.7 \\
57.5 \\
66.7 \\
63.0 \\
70.9 \\
130 \\
232 \\
222 \\
482 \\
514 \\
689 \\
830 \\
1059 \\
1074 \\
1093 \\
1068 \\
1181 \\
1120 \\
1098 \\
1429 \\
1751 \\
1747\end{array}$ & \begin{tabular}{|c}
$1 \times 10^{-4}$ \\
$5 \times 10^{-4}$ \\
$6 \times 10^{-4}$ \\
$1.6 \times 10^{-3}$ \\
$8.1 \times 10^{-3}$ \\
0.05 \\
0.10 \\
0.14 \\
0.19 \\
0.27 \\
0.41 \\
0.56 \\
0.81 \\
1.21 \\
1.66 \\
2.22 \\
2.93 \\
3.72 \\
4.52 \\
5.32 \\
6.15 \\
7.00 \\
7.82 \\
8.73 \\
9.92 \\
11.22
\end{tabular} & $\begin{array}{l}0.43 \\
0.44 \\
0.45 \\
0.46 \\
0.47 \\
0.48 \\
0.49 \\
0.50 \\
0.57 \\
0.52 \\
0.53 \\
0.54 \\
0.55 \\
0.56 \\
0.57 \\
0.58 \\
0.59 \\
0.60 \\
0.62 \\
0.64 \\
0.66 \\
0.68 \\
0.70 \\
0.72 \\
0.75 \\
0.80\end{array}$ & $\begin{array}{l}1639 \\
1810 \\
2006 \\
2066 \\
2033 \\
2074 \\
1950 \\
1942 \\
1882 \\
1833 \\
1842 \\
1783 \\
1725 \\
1695 \\
1712 \\
1715 \\
1700 \\
1666 \\
1602 \\
1544 \\
1486 \\
1427 \\
1369 \\
1314 \\
1235 \\
1109\end{array} \mid$ & $\begin{array}{l}12.47 \\
13.73 \\
15.14 \\
16.65 \\
18.17 \\
19.68 \\
21.15 \\
22.60 \\
24.01 \\
25.38 \\
26.74 \\
28.08 \\
29.38 \\
30.65 \\
31.91 \\
33.18 \\
34.44 \\
35.68 \\
38.10 \\
40.42 \\
42.66 \\
44.81 \\
46.88 \\
48.86 \\
51.69 \\
56.02\end{array}$ & $\begin{array}{l}0.90 \\
1.00 \\
1.2 \\
1.4 \\
1.6 \\
1.8 \\
2.0 \\
2.2 \\
2.4 \\
2.6 \\
2.8 \\
3.0 \\
3.2 \\
3.4 \\
3.6 \\
3.8 \\
4.0 \\
4.5 \\
5.0 \\
6.0 \\
7.0 \\
8.0 \\
10.0 \\
15.0 \\
20.0 \\
50.0\end{array}$ & \begin{tabular}{|c|}
891 \\
748 \\
485 \\
337 \\
245 \\
159 \\
103 \\
79 \\
62 \\
48 \\
39 \\
31 \\
22.6 \\
16.6 \\
13.5 \\
11.1 \\
9.5 \\
5.9 \\
3.8 \\
1.8 \\
1.0 \\
.59 \\
.24 \\
$4.8 \times 10^{-2}$ \\
$1.5 \times 10^{-2}$ \\
$3.9 \times 10^{-4}$
\end{tabular} & $\begin{array}{r}63.37 \\
69.49 \\
78.40 \\
84.33 \\
88.61 \\
91.59 \\
93.49 \\
94.83 \\
95.86 \\
96.67 \\
97.31 \\
97.83 \\
98.22 \\
98.50 \\
98.72 \\
98.91 \\
99.06 \\
99.34 \\
99.51 \\
99.72 \\
99.82 \\
99.88 \\
99.94 \\
99.98 \\
99.99 \\
100.00\end{array}$ \\
\hline
\end{tabular}


Penetration of Aluminum Foils One Year Mission, 300 to $465 \mathrm{~N}$ Mile Orbit

\begin{tabular}{|c|c|c|c|c|}
\hline \multirow[b]{2}{*}{ Moterial } & \multirow[b]{2}{*}{ Foil Thichness } & \multicolumn{2}{|c|}{ equency of Penctrations - Mo/mes Sec } & \multirow{2}{*}{$\begin{array}{l}\text { Caledioted } \\
10 \text { Dia. } \\
\text { Impects/Yr }\end{array}$} \\
\hline & & Pagnesus A & Pepasus B & \\
\hline Al 2024-T3 & $400 \mathrm{~mm}$ & $2.4 \times 10^{-8}$ & $4.0 \times 10^{-8}$ & $6 \cdot 9$ \\
\hline Al 2024-TO & $200 \mu \mathrm{m}$ & $4.2 \times 10^{-7}$ & $2.2 \times 10^{-7}$ & $99-52$ \\
\hline \multirow[t]{3}{*}{ Al 1100.0} & $40 \mu m$ & $1.4 \times 10^{-6}$ & $2.0 \times 10^{-6}$ & $330-472$ \\
\hline & \multicolumn{2}{|c|}{$\begin{array}{l}\text {-Meteor Shower - Peak Value } \\
\text { (6 Day) Background }\end{array}$} & $\begin{array}{l}5.3 \times 10^{-6} 6 \\
1.6 \times 10^{-6}\end{array}$ & $\begin{array}{l}1250 \\
378\end{array}$ \\
\hline & \multicolumn{3}{|c|}{$\begin{array}{l}\text { Figure 5. Pegasus A and B Flight Data } \\
\text { Micrometeorite Impact Data }\end{array}$} & \\
\hline
\end{tabular}

Penetration of 2 Mil Kapton Thermal Blankets, Four Year Mission 280 to 300 N Mile

Visual Examination: 1 to 3 Impacts on Kapton Blanket Outer Layer on Each Module Side (Area?)

Penetration Caused Holes $<.050$ Inch Dia.

Local Removal of VDA From Backside of Kapton Outer Layer

Figure 6. Solar Max Mission Flight Data Micrometeorite Impact Data 
Assume: $\quad 10 \mathrm{~m}$ Reflector Dia. (78.5 $\mathrm{m}^{2}$ Area)

Meteorite Impact Causes Damage

to Dia. 10X Meteorite Penetration

Use Highest Impact Rates From

Pegasus A and B

Total Damaged Area $=7.6 \times 10^{-6} \mathrm{~m}^{2} / \mathrm{m}^{2}$

Percent Damaged $\mathbf{0} \mathbf{0 . 0 0 0 8 \%}$

Figure 7. Predicted Reflector Damage by Meteorite Impact in 10 Years 
and meet key goals and requirements of size, efficiency weight and performance. Specifically:

- Concentration ratio -- Minimum - 2000, Goal - 5000

- Concentrator efficiency -- Minimum - 90 percent, Goal - 95 percent

- Maximum efficiency degradation at end of life -- 10 percent

- Specific weight -- Maximum - $1.5 \mathrm{Kg} / \mathrm{sq} \mathrm{m}$, Goal -- $<1.0 \mathrm{~kg} / \mathrm{sq} \mathrm{m}$

- Operational life -- 15 years in LEO, GEO, or polar orbit

- Launch vehicle: Space transportation system

- Automatic on-orbit deployment (without EVA)

- Size Range -- 10 to $100 \mathrm{KWe}$ at system efficiency of 30 percent

- Survivablitity

Terrestrial environment: During fabrication, ground checkout, assembly, transporation and handling.

Launch Environment: Pressure and temperature changes as we 11 as acoustical and vibrational loads.

Orbital Conditions: Post Deployment: Vacuum, thermal cycling.and vibrational load.

The baseline design shall be for a 25 KWe power system and be symmetric about its axis. Providing for a solar to electric system efficiency of 30 percent, the concentrator must be sized to allow for 60 minutes of sun exposure and 30 minutes of shading in a 90-minute orbit. The DPSC shall be designed to be placed in orbit by the space shuttle. Requirements have been detafled in Section 2. It is envisioned that the concentrator including all components, i.e., panels, structure, power module and power module support, will be packaged in a dispenser, cartridge, or other packaging device. During the conceptual design, no specific requirements will be imposed other than interface requirements to permit the exploration of several concepts including the "sunflower" concept developed by NASA-Lewis in the 1960s. 
4. INTERFACE REQUIREMENTS

There are 2 interface requirements of major significance that must be defined to permit the conceptual design to proceed smoothly. They are:

- Interfaces, dimensions, weights, performance characteristics and other criteria of the power module including heat rejection panel configurations and

- Space station or satellite attachment configurations and maximum force and moment transmission characteristics.

These interface characteristics will be supplied by NASA-Lewis at a later date.

67 


\section{REFERENCES}

1. Low Concentration Ratio Solar Array for Low Earth Orbit Multi-100 kW Application, Final Report, Rockwell International Corporation, SSD830075-1, Volume I. (July 1983).

2. Space Shuttle Program, Level II Program Definition and Requirements, Space Shuttle System Payload Accommodations, NASA, JSC 07700, Volume XIV, Revision G; September 26, 1980.

3. Simplified Payload Orbiter Thermal Simulator (Sports Mode1), Rockwell Report STS 81-0333, dated February 1981.

4. Orbital Environment and Contamination Considerations for the Solar Dynamic Power System Solar Concentrator, Dr. Louis A. Rosales, TRW E\&D, Redondo Beach, CA 90274, Proceedings of the Solar Dynamic Power Systems Workshop Part II -- Collection and Thermal Storage -- August 1 through 3, 1984, NASA Johnson Space Center, Propulsion and Power Division, Houston, TX 77058.

5. Atomic 0xygen Effects on Surfaces in Low Earth Orbit. James T. Visentine, Lubert J. Leger, Calvin Schomburg, and Wi 11 iam B. Jones, NASA Johnson Space Center, Proceedings of the Solar Dynamic Power Systems Workshop Part II -- Collection and Thermal Storage -- August 1 through 3, 1984, NASA Johnson Space Center, Propulsion and Power Division, Houston, TX 77058.

6. NASA SP-8005, National Aeronautics and Space Administration, May (1971). "Solar Electromagnetic Radiation."

7. Thekaekara, M. P., Supplement to Proc. 20th Annual Meeting of Inst. for Environmental Sci., 21 (1974). "Data on Incident Solar Radiation."

8. Thekaekara, M. P. and Drummond, A. J., Nat. Phys. Sci., 229, 6 (1971) "Standard Values for the Solar Constant and Its Spectral Components." 
APPENDIX B

POLYIM $^{\mathrm{TM}}$ PROPERTIES 


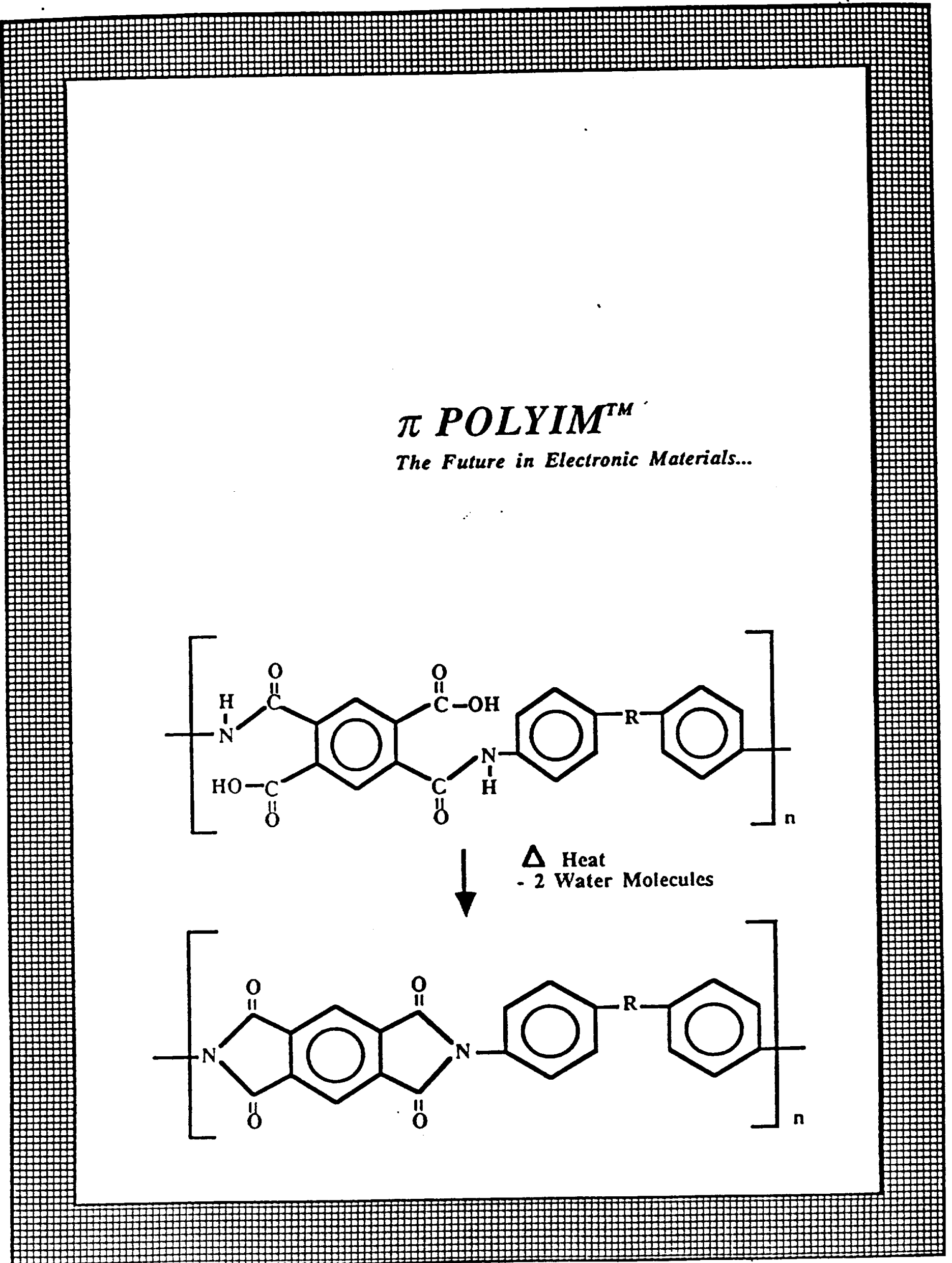

70 
III. $\pi$ POLYIM PROPERTIES

A) $P$ Series

Table of Liquid and Film Properties

\begin{tabular}{|c|c|c|c|c|}
\hline \multicolumn{4}{|c|}{$\begin{array}{r}\text { Product } \\
\end{array}$} & \multirow{2}{*}{$\pi \mathbf{P}$} \\
\hline \multirow{7}{*}{ 施 } & \multicolumn{2}{|r|}{ Property } & Units & \\
\hline & \multicolumn{2}{|c|}{ Solids Concentration } & $\%$ & 4-18 \\
\hline & \multicolumn{2}{|c|}{ Viscosity } & Poise & \\
\hline & \multicolumn{2}{|c|}{$\mathrm{Na}^{+}$Ions } & ppm & $<0.2$ \\
\hline & \multicolumn{2}{|c|}{$\mathrm{K}^{+}$Ions } & ppm & $<0.2$ \\
\hline & \multicolumn{2}{|c|}{$\mathrm{C}^{-}$Ions } & ppm & $<0.2$ \\
\hline & \multicolumn{2}{|c|}{ Filuracion } & $\mu \mathrm{m}$ & 0.2 Absolute \\
\hline \multirow{12}{*}{ (1) } & \multirow{5}{*}{$\frac{\bar{g}}{\frac{\bar{g}}{5}}$} & Tensile Strength & $\mathrm{kg} / \mathrm{mm}^{2}$ & 11 \\
\hline & & Young's Modulus Elascicity & $\mathrm{kg} / \mathrm{mm}^{2}$ & 246 \\
\hline & & Elongauion & $\%$ & 12.3 \\
\hline & & Adhesion $\left(3 M^{\oplus}\right.$ Tape \# 854) & \% loss & 0.0 \\
\hline & & Pinhole Density & $\mathrm{cm}^{2}$ & 0.23 \\
\hline & \multirow{3}{*}{$\begin{array}{c}\bar{\sigma} \\
\stackrel{E}{E} \\
\stackrel{E}{E} \\
F\end{array}$} & Thermal Conductivity & $\frac{\mathrm{cal}}{\mathrm{cmsec}} \mathrm{C}$ & -4.0 \\
\hline & & Decomposition Temperature & ${ }^{\circ} \mathrm{C}$ & $500-600^{\circ} \mathrm{C}$ \\
\hline & & Coeflieient of Thermal Expansion & ${ }^{\circ} C^{-1}$ & $-2.37 \times 10^{-5}$ \\
\hline & \multirow{4}{*}{ 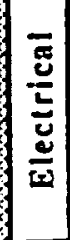 } & Dieloctric Strength & Vhem & $>320$ \\
\hline & & Dissipation Factor & @ 1 KHz & 0.0008 \\
\hline & & Volume Resistivity & ohm $\mathrm{cm}$ & $6 \times 10^{16}$ \\
\hline & & Diclectric Constant & @ 1 kHz & 3.2 \\
\hline
\end{tabular}

\begin{tabular}{|l|c|c|c|c|c|c|c|}
\hline \multicolumn{2}{|c|}{$\pi$ Product } & \multirow{2}{*}{ P18 } & P16 & P13 & P11 & P08 & P04 \\
\hline Property & Units & & & & & & \\
\hline \% Solids & $\%$ & 18.0 & 15.5 & 13.0 & 11.0 & 8.5 & 3.8 \\
\hline Viscosity & Poisc & 70.0 & 23.0 & 9.0 & 4.5 & 2.5 & 1.8 \\
\hline Thickness Range (Spin Application) & $\mu \mathrm{m}$ & $2.60-7.00$ & $1.85-4.15$ & $1.25-2.45$ & $0.82-1.60$ & $0.43-0.85$ & $0.09-0.20$ \\
\hline
\end{tabular}


B) Certificate of Analysis

\section{$\pi$ Polyim TM $^{\text {TM }}$ \\ Certificate of Analysis}

Product: $\pi$ Polvim P18

Lot \#:

Date of Q.C.:

Quantity Shipped:
P.O. \#:

Release \#:

Spoc:

Revision:
Paraneter

Viscosity Brookfield@ $37.8^{\circ} \mathrm{C}$

Sodium Ions Ion Selective Electrode

Potasium Ions Ion Selective Electrode

Filtration (Absolute)

Paricles@20X Magnification

Coating Thickness 5000 rpm Spin, Fully Cured Film

Solids Content

Residue on Ignition

Total Acidity

Flash Point

Specific Gravity

Homogeneity

Refractive Index@632nm

Type of Solution

Solvent Composition

NMP

Cyclohexanone

Appearance

Color

TLV-TWA for NMP

TLV-TWA for Cyclohexanone
Specification

$20 \pm 10$ Poise

$\leq 0.2 \mathrm{ppm}$

$\leq 0.2 \mathrm{ppm}$

$0.20 \mathrm{~mm}$

none visible

$1.90 \pm 0.19 \mu \mathrm{m}$

$18.0 \pm 1.8 \%$

$\leq 0.02 \%$

$\$ 45.0 \mathrm{mg} \mathrm{NaOH}$

$128^{\circ} \mathrm{C}$

$1.04 \pm 0.04$

$100 \%$

1.78

Solvent base

$61.5 \pm 5.0 \%$

$38.5 \pm 5.0 \%$

Clear liquid

Lgt. Brn Honey

$100 \mathrm{ppm}$

$50 \mathrm{ppm}$
Lot Value

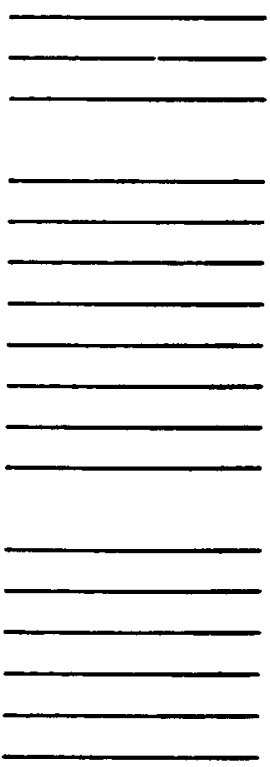




\section{C) Statistical Data}

\section{Thickness Control}

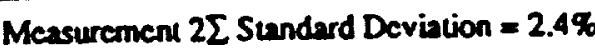

Lot w Lot $2 \Sigma$ Standard Deviation $=8.2 \%$

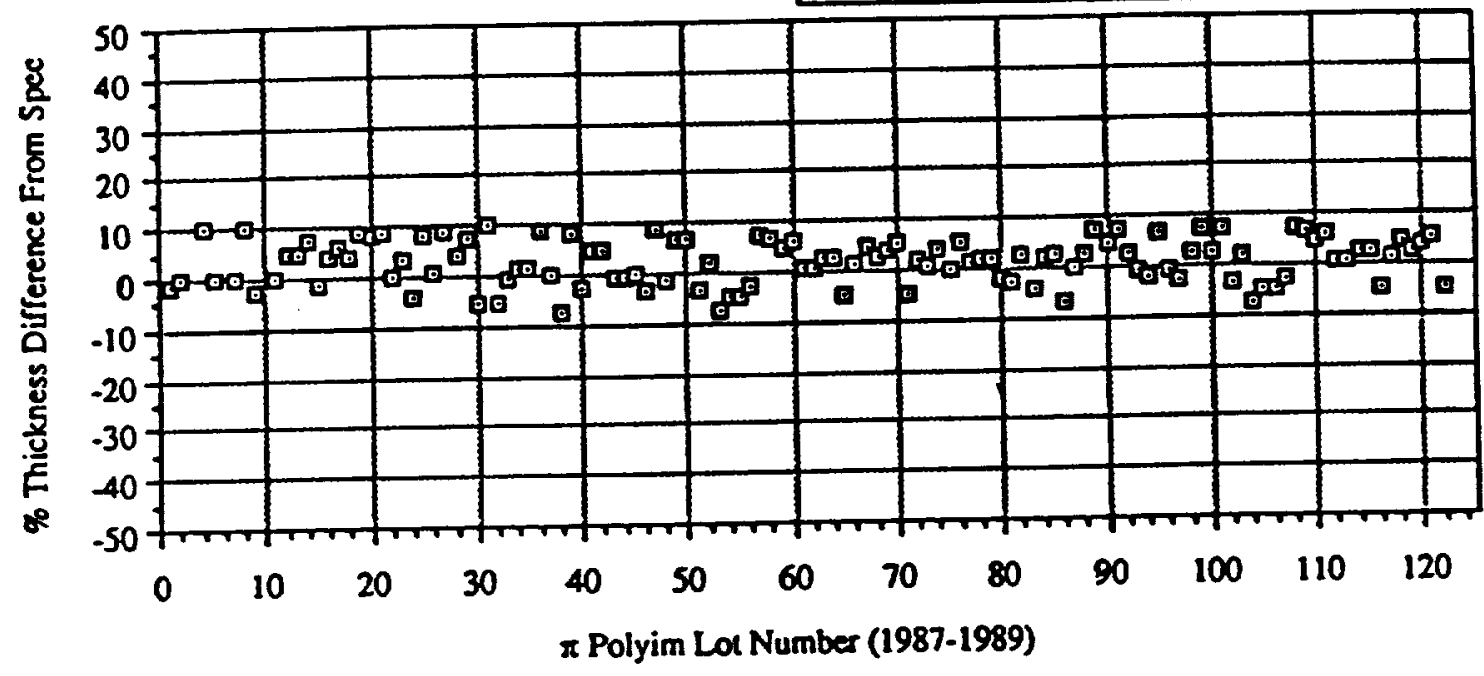

Viscosity Conttrol

Measurement 2 $\sum$ Standard Deviation $=3.6 \%$ Lot w Lot $2 \sum$ Standard Deviation $=11.4 \%$

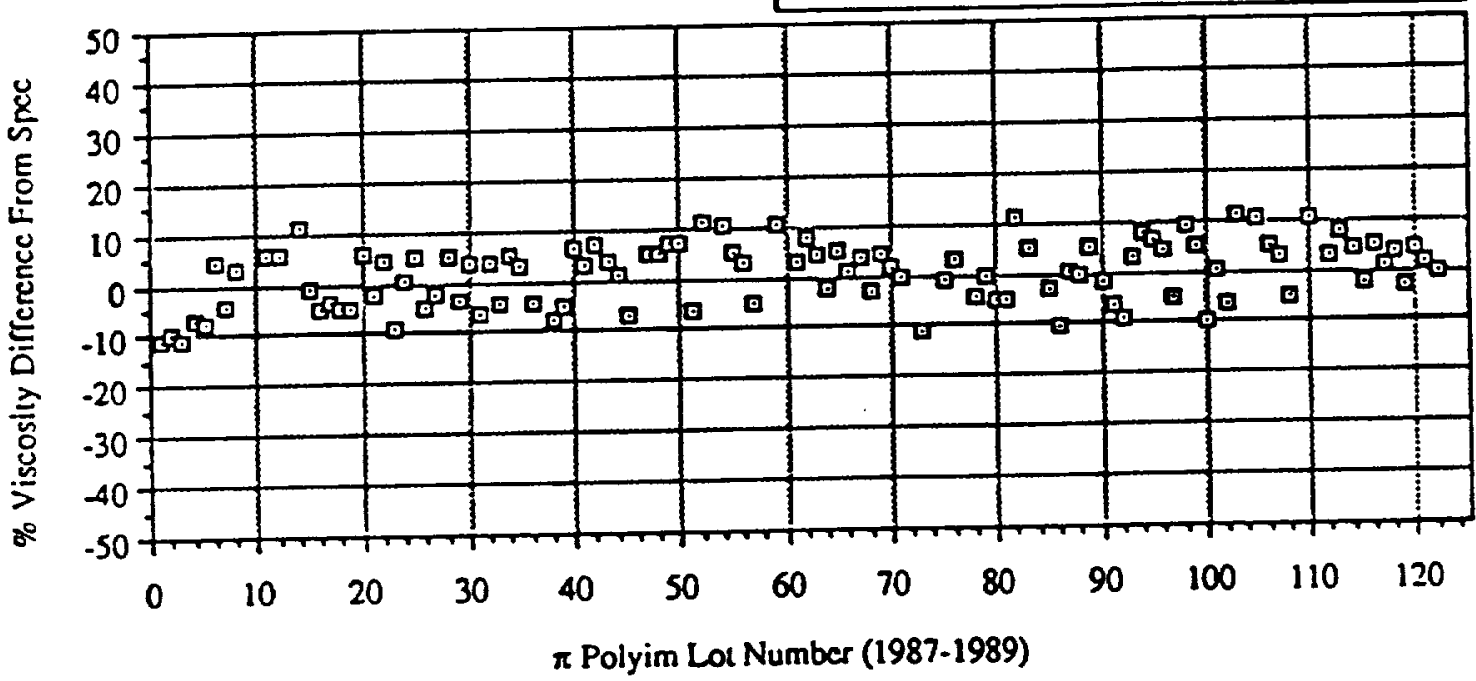

Trace Ion Control

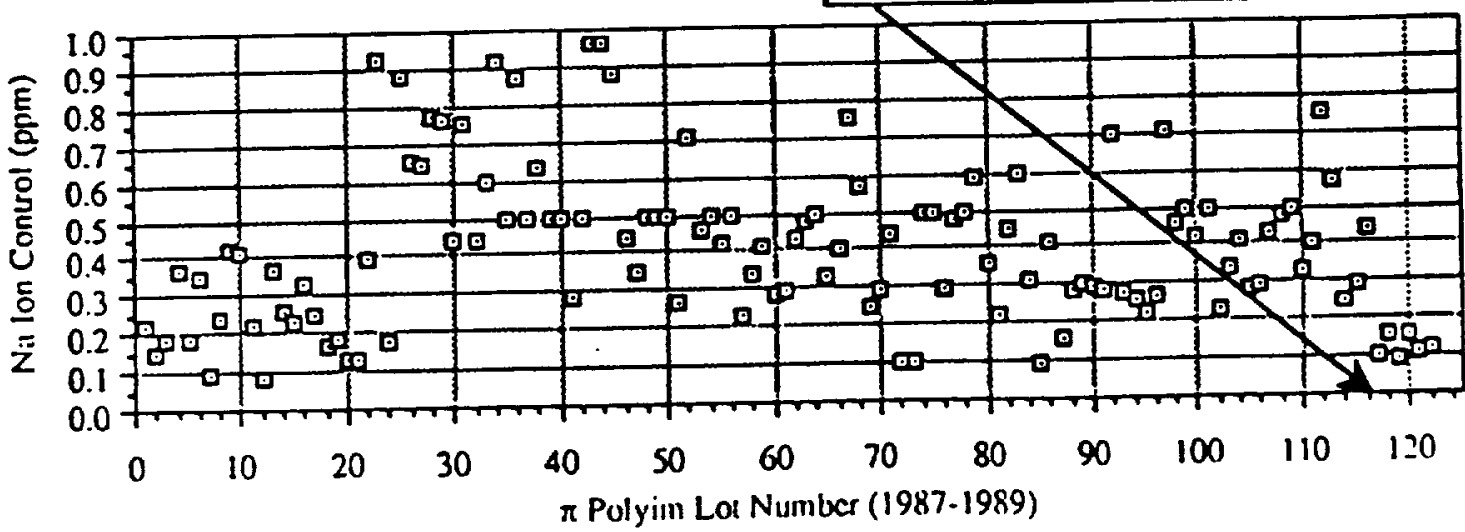


C) Product Spin Speed vs. Thickness Curves

$\pi$ Polyim P Product Thickness Curves
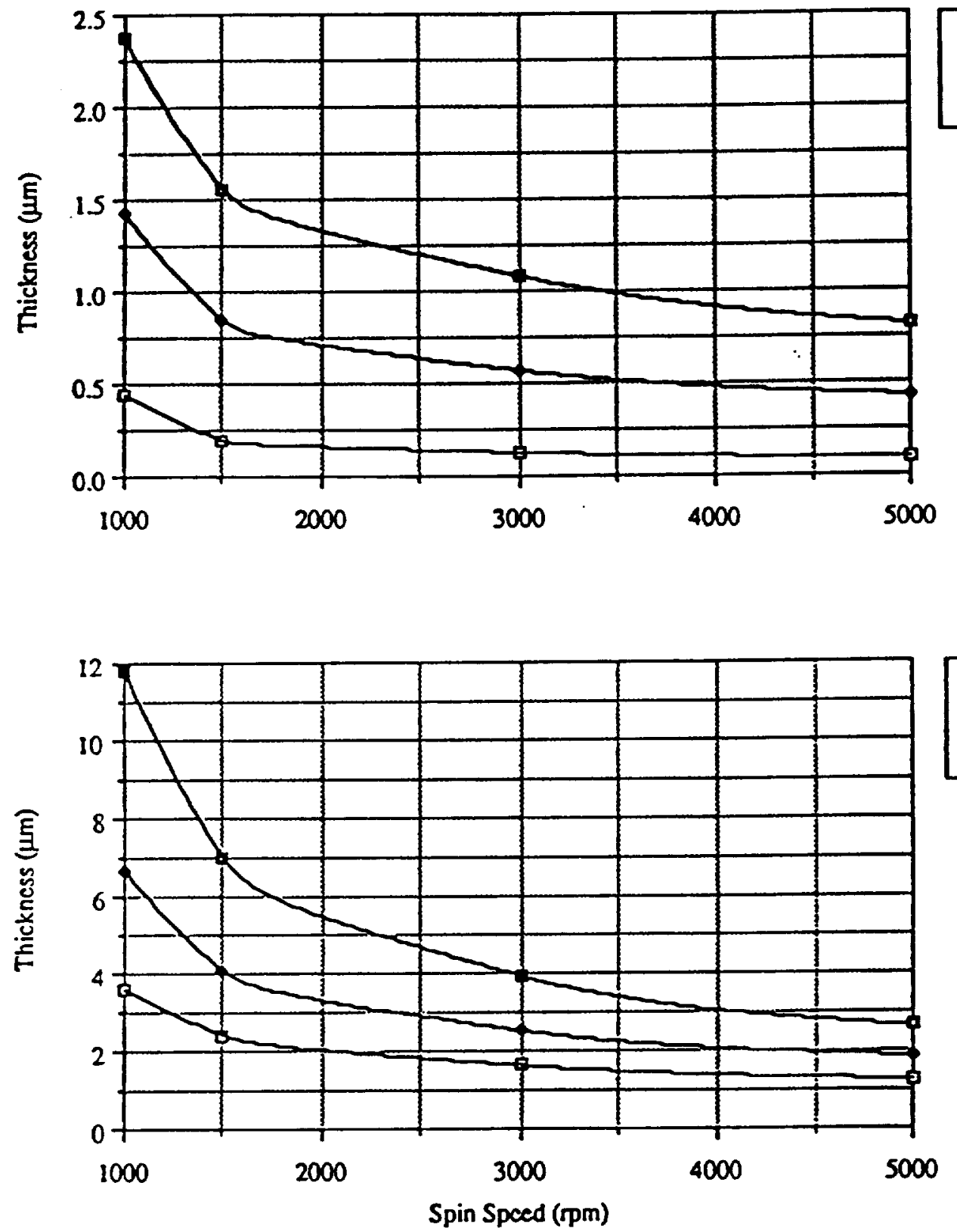

Note: The above data was generated using 90 second spin times with the following cure cycle:

- $120^{\circ} \mathrm{C}, 60$ second Hotplate bake.

- $400^{\circ} \mathrm{C}, 60$ minute Furnace bake in nirrogen atm. 


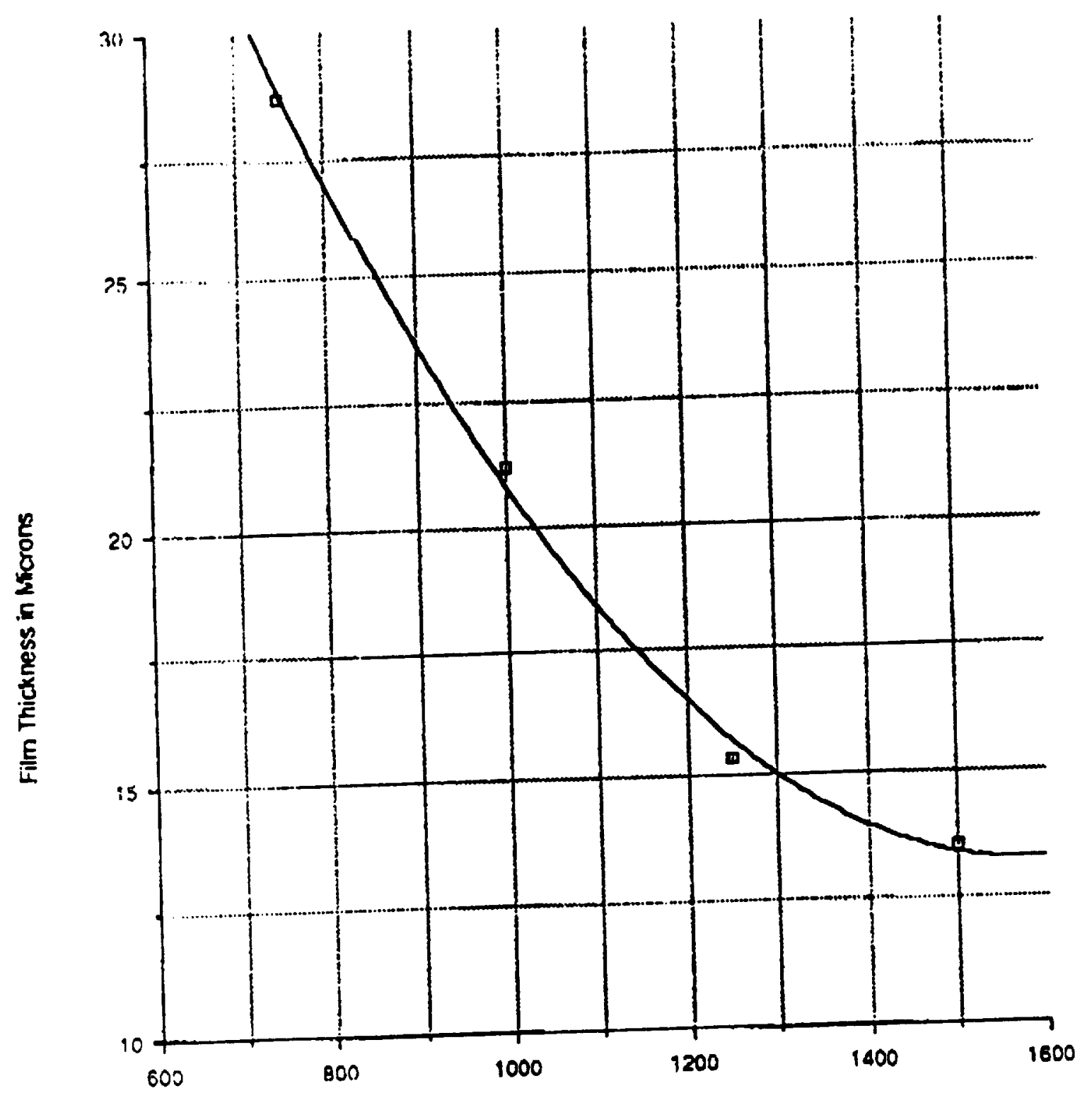

Spin Speed in APM

PPM $547 @ 18 \%$, Fllm Thickness 


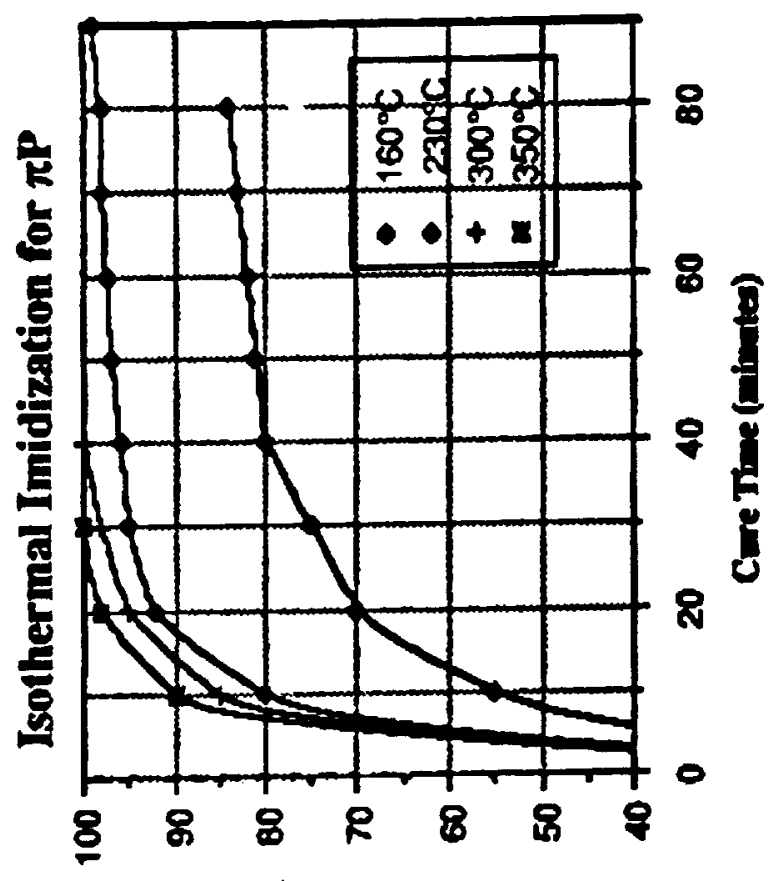

(ख) wop\&uppy

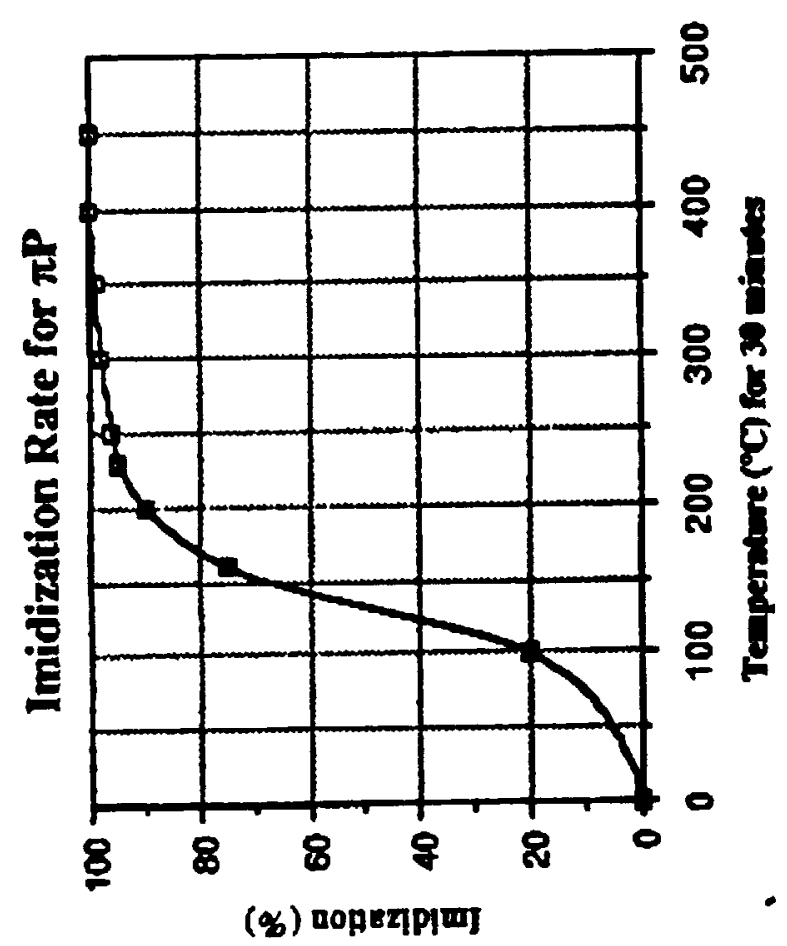

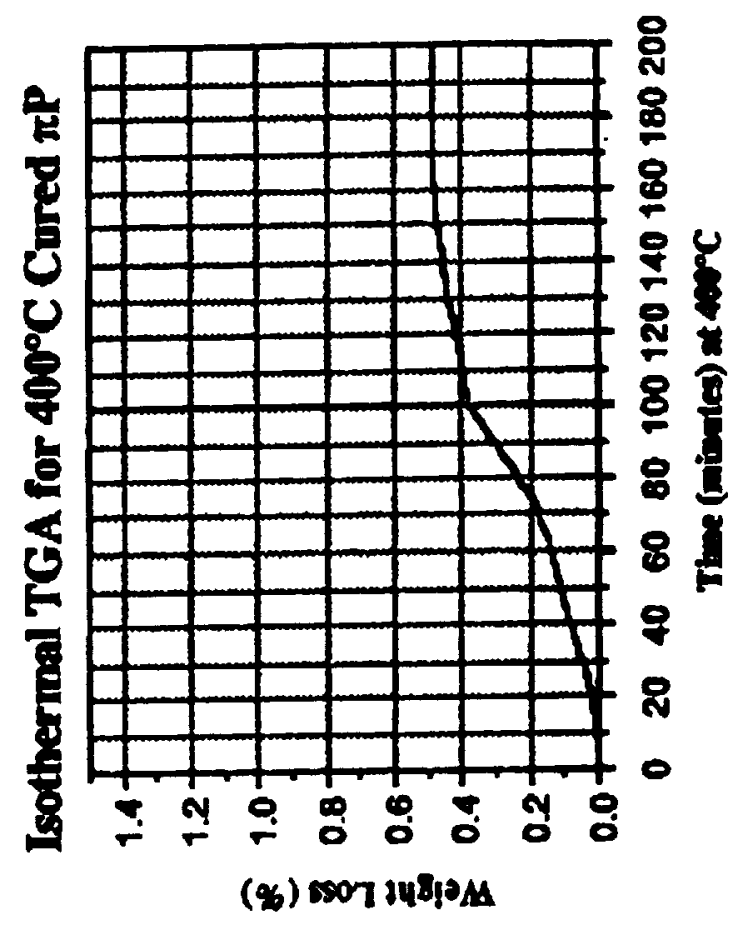

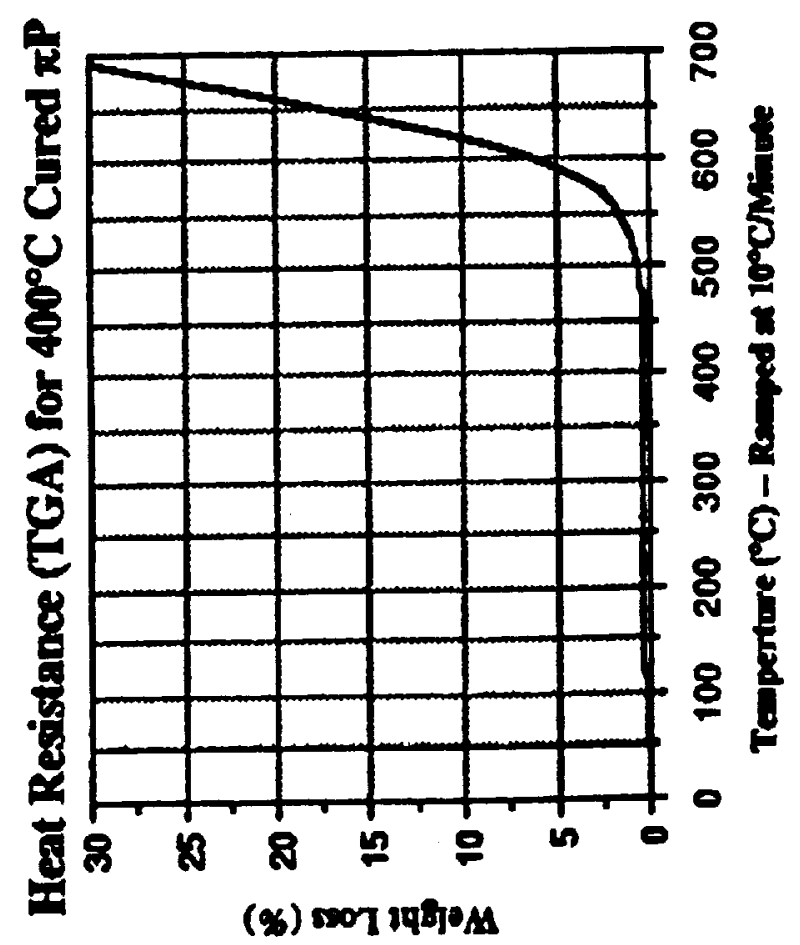




\section{Material Safety Data Sheet}

Dote lost revised November 29,1988

\section{General Information}

Chemical Nome 8 Symonyms

Resin solution

Chemicol Family

Organic

Proper DOT Shipping Nome

Resin_Solution UN1866

Monufocturer

Brewer science. INC.

Monufocturer's Address

2401 High Tech Drive Rolla, Mo 65401 USA
Trode Name $\&$ Synonyms

omni-Layer

Formulo

$\mathrm{N} / \mathrm{A}$

DOT Hazord Classification

Flammable_Ilquida Monufocturer's Phone Number

(314)364-0300

Chemtrec Phone Number

- $/ A$

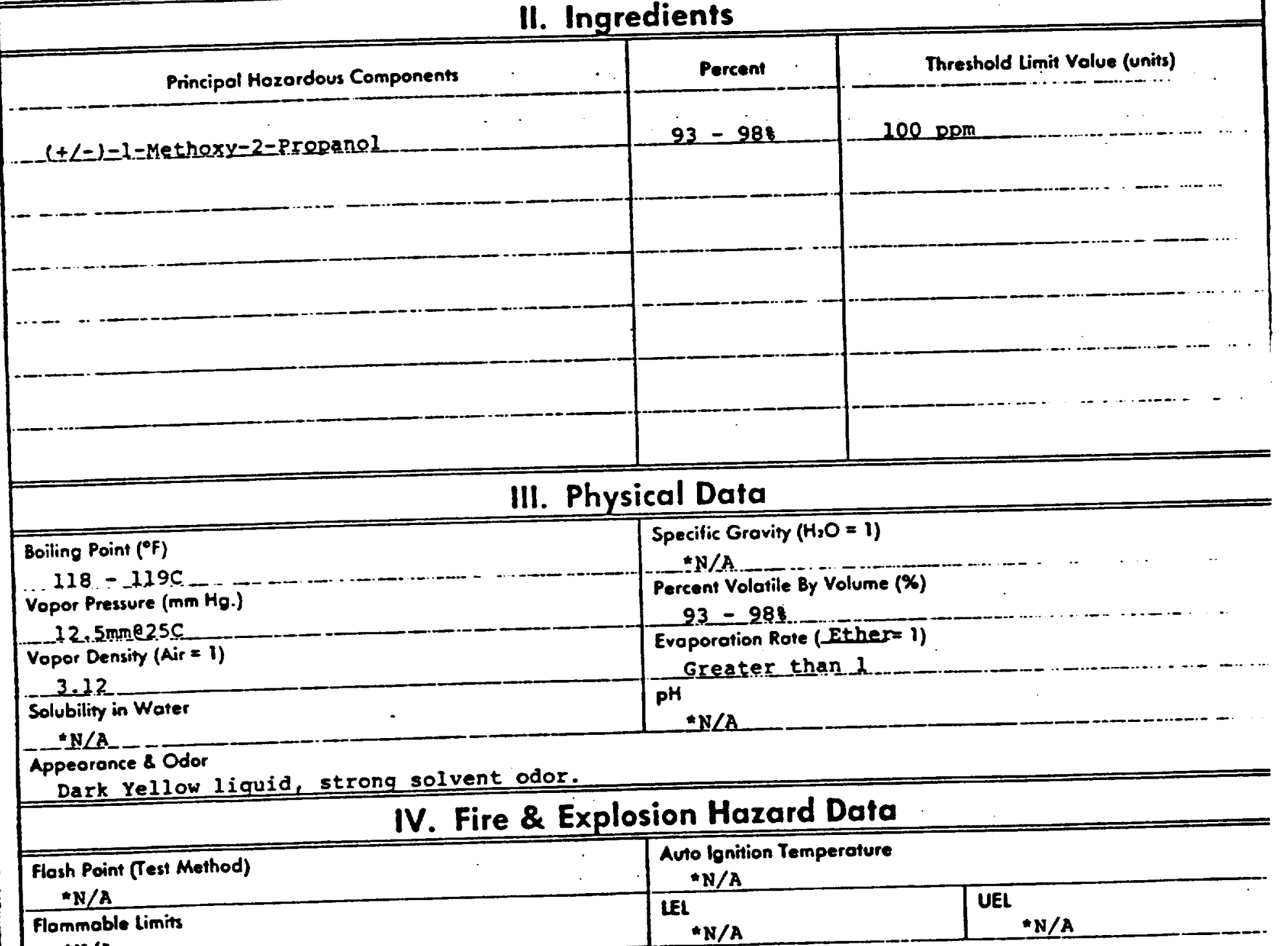

Extinguishing Medio

Carbon dioxide, Dry Chemical, AFFF Foam

Special fire Fighting Procedures

Use water to cool fire-exposed containers.

Unusual firs 8 Explosion Hazords

- Vapor may trayel_..considerable distance..to_source of ignition and..flash _back. Container. . explosion may occur under fire conditions. Forms explosive mixtures in air. 


\section{Health Hazard Data}

Threshold Limit Volve TwA 100 ppm

Corcinogen - NTP Program

- $\mathrm{N} / \mathrm{A}$

Symploms of Exposure

vausea or vomiting, headache, digziness. General Anesthetic. olfaction tumorst.
ACGIH Threshold timin Volue

TUA 100 ppm
OSHA Threshold Limit Volve

H/A

Corcinogen - LRC Program

$\mapsto \mathbf{H} / \mathbf{A}$

Medical Conditions Aggravated By Exposure

$\star \mathbf{N} / \mathbf{A}$

Primary Rowte(s) of Entry

. Inhalation ...jngestion and skin absorption.

Emergency First Aid

Eye and skin: Flush with water_for at least_15. minutes.__Inhalation:_Remove to fresh air.

Contact leaves a temporary yellow stain on skin.

\section{Reactivity Data}

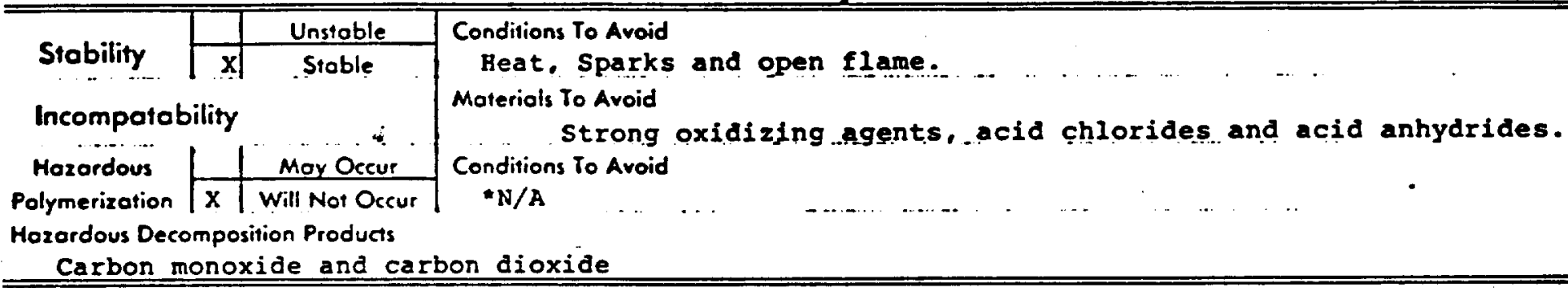

\section{Environmental Protection Procedures}

Spill Response

Remove sources of jgnition and heat. Avoid prolonged breathing or contact. Cover with an

activated absorbent, take up and place in closed container and transfer outdoors...

Waste Disposol Method

Same as for non-halogenated solvents or resins. Use methods which are in compliance with

Federal, State and Local regulations, or contact an approved and licensed disposal agency.

\section{Special Protection Information}

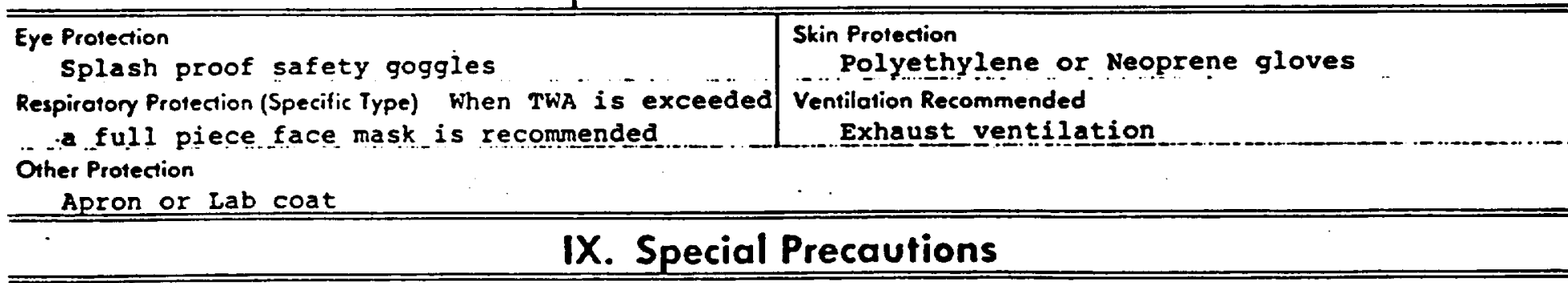

Hygienic Practices In Hondling \& Storage

Avoid contact. . Keep from ignition sources. Wash after handing.

Precautions for Repair \& Maintenonce Of Contominated Equipment

$\bullet N / A$

Other Precoutions

$-N / A$

"N/A: Not Available "From RTECS report 



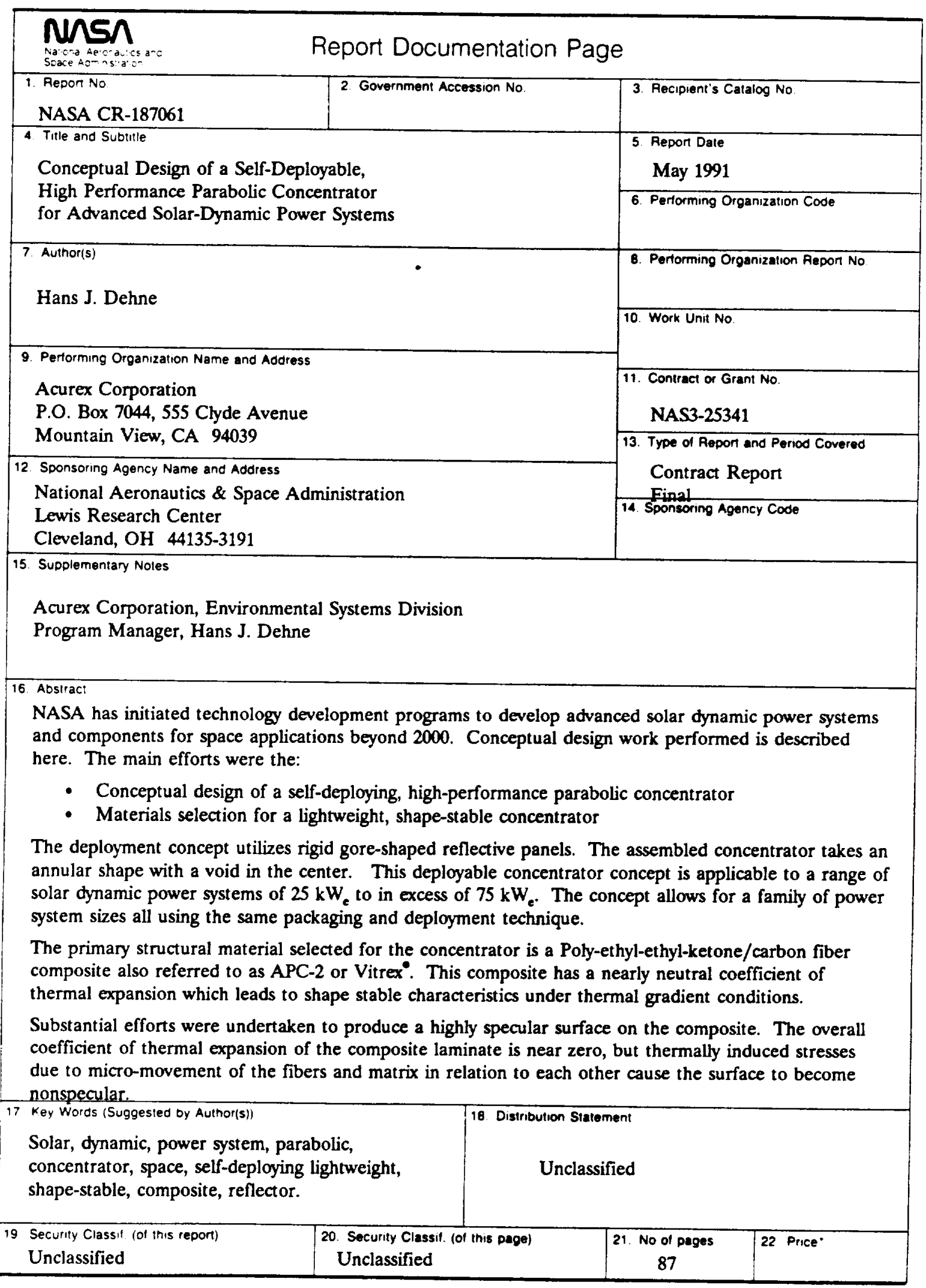





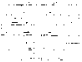


